\title{
MARISTELASCHAUFELBERGER SPANGHERO
}

\section{Avaliação longitudinal de pacientes portadores de}

esquizofrenia e transtorno esquizofreniforme utilizando

ressonância magnética de crânio

Tese apresentada à Faculdade de Medicina da Universidade de São Paulo para obtenção do título de Doutor em Ciências

Área de concentração: Psiquiatria

Orientador: Prof. Dr. Geraldo Busatto Filho

São Paulo

2008 
Dados Internacionais de Catalogação na Publicação (CIP)

Preparada pela Biblioteca da

Faculdade de Medicina da Universidade de São Paulo

Creprodução autorizada pelo autor

Spanghero, Maristela Schaufelberger

Avaliação longitudinal de pacientes portadores de esquizofrenia e transtorno esquizofreniforme utilizando ressonância magnética de crânio / Maristela Schaufelberger Spanghero. -- São Paulo, 2008.

Tese (doutorado) -- Faculdade de Medicina da Universidade de São Paulo. Departamento de Psiquiatria.

Área de concentração: Psiquiatria.

Orientador: Geraldo Busatto Filho.

Descritores: 1. Esquizofrenia 2. Imagem por ressonância magnética 3. Córtex cerebral 4. Estudos longitudinais

USP/FM/SBD-019/08 
DEDICATÓRIA

ÀAni, minha mãe, à Beatriz, minha irmã, e ao Rodrigo, meu amor. 


\section{Agradecimentos}

Ao professor e orientador Geraldo Busatto Filho, pelo incentivo e confiança constantes durante esses anos e por me supervisionar continuamente em cada etapa deste estudo.

Aos professores Márcia Scazufca e Paulo R. Menezes, pelo apoio e colaboração desde o início do estudo e pela acolhida em sua equipe de pesquisa.

À equipe do estudo epidemiológico “Estudo de Casos Incidentes de Psicoses Funcionais no Brasil”: Ana Cristina Schlithler, Bruno Coimbra, Daniel Cordeiro, Karine Vasconcellos, Karol Casagrande, Letícia Coutinho, Renata Nunes, Roberta Pompêo de Carvalho e Síntia Tasca pelo excelente trabalho de campo, dedicação, carinho e amizade.

Aos companheiros (funcionários, pós-graduandos, alunos) do Laboratório de Neuroimagem em Psiquiatria (LIM 21), por manterem a simplicidade, bom humor e espírito de equipe; em especial à amiga Sheila Cavalcante Caetano, pelo exemplo, incentivo e apoio desde o período de Residência Médica.

Aos professores Cláudio Campi de Castro e Claudia Costa Leite, chefes dos serviços de Ressonância Magnética do Instituto do Coração e do Instituto de Radiologia, respectivamente (HC-FMUSP), por viabilizarem e colaborarem com a realização dos exames de imagem deste estudo.

À equipe de funcionários dos serviços de Ressonância Magnética, que me acompanharam durante o longo período de coleta de exames; em especial à Graziela, Eduardo, Wanda, Ricardo, Daniel e Shirley, por tornarem esses momentos agradáveis, pela ajuda e pelo respeito e profissionalismo com que receberam os sujeitos voluntários da pesquisa. 
Ao professor Francesco Langone, do Instituto de Biologia da UNICAMP, pelo estímulo e por me indicar o melhor caminho.

E por último, mas não menos importante, agradeço aos voluntários desta pesquisa e a seus familiares, que se dispuseram a colaborar com nosso estudo durante um período difícil de suas vidas. 
“... pois desde o comeco preocupou-me um problema bem geral: de que estrato psíquico procedem as idéias tão impressionantes da esquizofrenia?..."

(C.G. Jung, carta a Manfred Bleuler, de 19.08.1950). 
Esta tese está de acordo com as seguintes normas, em vigor no momento desta publicação:

Referências: adaptado de International Committee of Medical Journals Editors (Vancouver).

Universidade de São Paulo. Faculdade de Medicina. Serviço de Biblioteca e Documentação. Guia de apresentação de dissertações, teses e monografias. Elaborado por Anneliese Carneiro da Cunha, Maria Julia de A. L. Freddi, Maria F. Crestana, Marinalva de Souza Aragão, Suely Campos Cardoso, Valéria Vilhena. $2^{a}$ ed. São Paulo: Serviço de Biblioteca e Documentação; 2005.

Abreviaturas dos títulos dos periódicos de acordo com List of Journals Indexed in Index Medicus. 


\section{SUMÁRIO}

\section{Lista de abreviaturas e siglas}

\section{Lista de figuras}

Lista de tabelas

\section{Resumo}

Summary

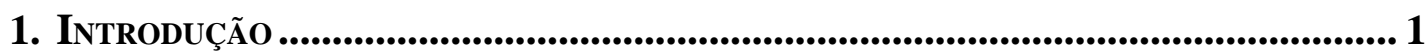

1.1 Aspectos gerais da esquizofrenia .................................................................................... 1

1.2 Neuroanatomia da esquizofrenia .................................................................................... 5

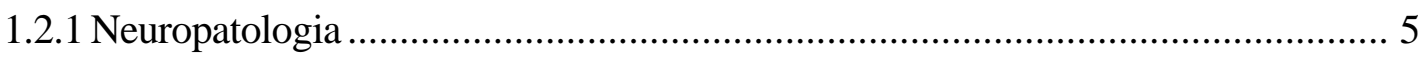

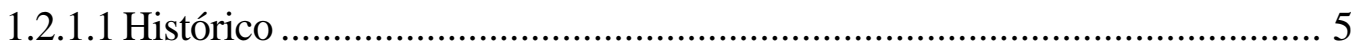

1.2.1.2 Estudos de neuropatologia contemporâneos ................................................ 6

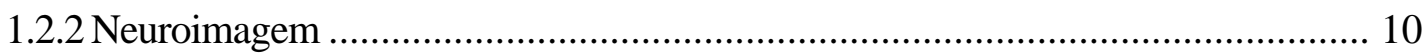

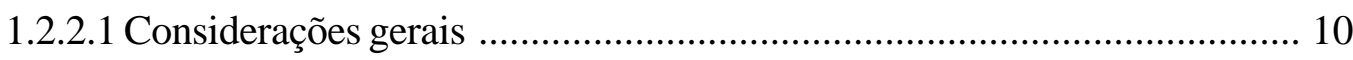

1.2.2.2 Volumetria por ressonância magnética ..................................................... 11

1.2.2.3 Volumetria por ressonância magnética em esquizofrenia - estudos

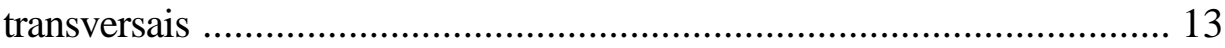

1.2.2.4 Volumetria por ressonância magnética em esquizofrenia - estudos longitudinais a partir do primeiro episódio psicótico ..................................................... 16

1.2.3 Implicações dos estudos neuroanatômicos para a investigação da etiopatogenia da

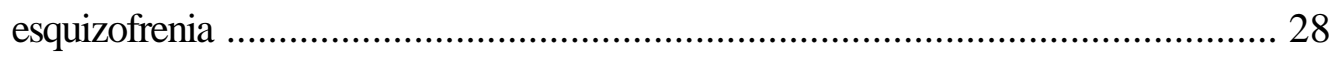

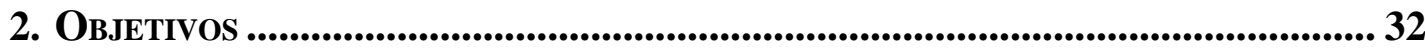

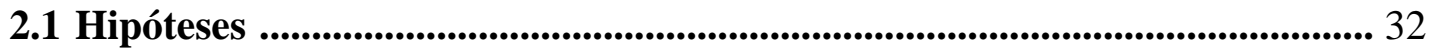

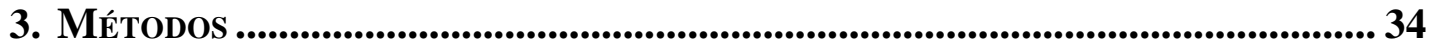

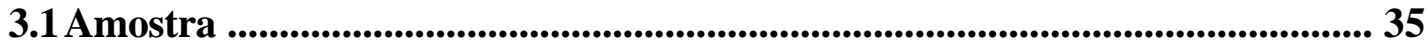




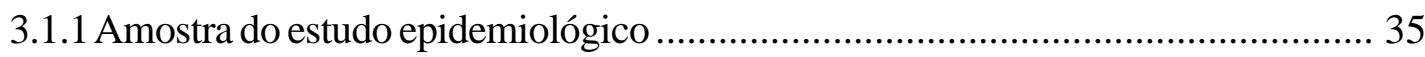

3.1.2 Amostra do estudo transversal de neuroimagem ................................................ 36

3.1.3 Amostra do estudo longitudinal de neuroimagem ............................................... 38

3.2 Procedimentos de avaliação clínica ............................................................... 39

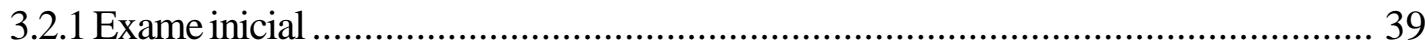

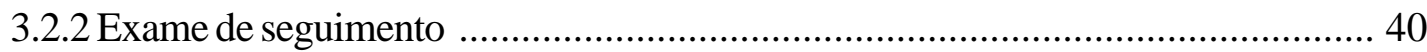

3.3 Exame de neuroimagem .............................................................................. 40

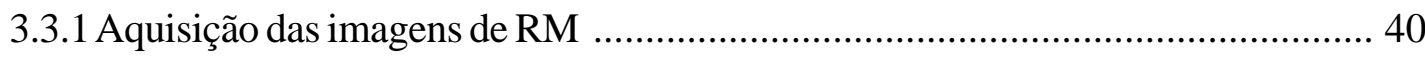

3.3.2 Processamento das imagens de RM ........................................................... 41

3.3.2.1 Etapa de pré-processamento das imagens e criação de template .............. 41

3.3.2.2 Etapa de processamento das imagens originais utilizando a template criada

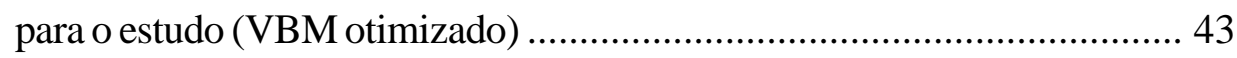

3.3.3 Confiabilidade entre as imagens adquiridas nos dois aparelhos de RM ............... 44

3.4 Análise dos dados ...................................................................................... 45

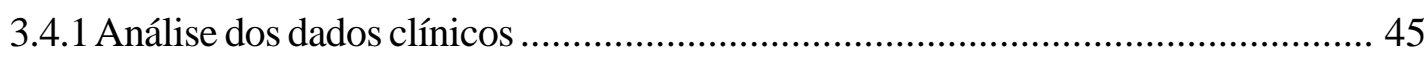

3.4.2 Análise das imagens de RM - morfometria voxel-a-voxel (VBM) ...................... 46

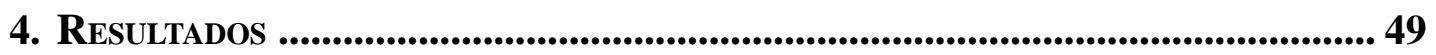

4.1 Estudo transversal ..................................................................................... 49

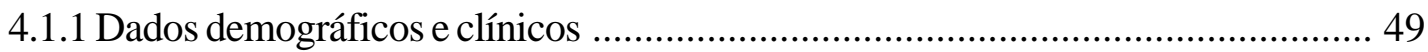

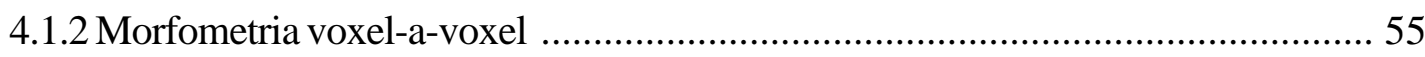

4.1.2.1 Comparação entre pacientes e controles ................................................ 55

4.1.2.2 Comparação entre pacientes e controles sem abuso ou dependência de

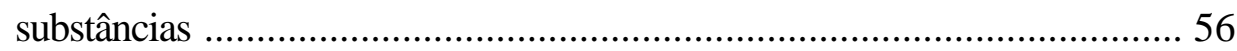

4.1.2.3 Correlações entre morfometria e variáveis clínicas no grupo de pacientes ... 57

4.1.2.3.1 Tempo de doença e duração da doença não tratada (DUP) ................... 57

4.1.2.3.2 Sintomas psicóticos ............................................................................ 58

4.1.2.4 Investigação dos efeitos do tratamento com antipsicóticos sobre o volume da

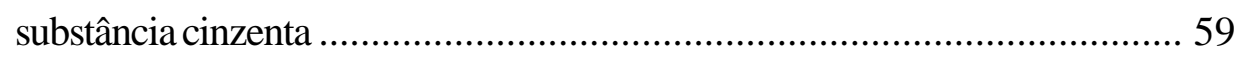

4.1.2.4.1 Comparação entre pacientes medicados e não medicados ....................... 59 
4.1.2.4.2 Correlação entre tempo de exposição a antipsicóticos e volume de

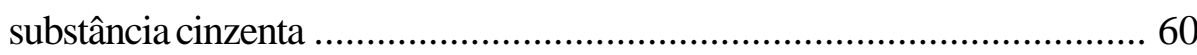

4.2 Estudo longitudinal ..............................................................................................61 61

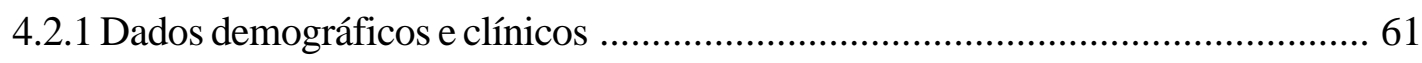

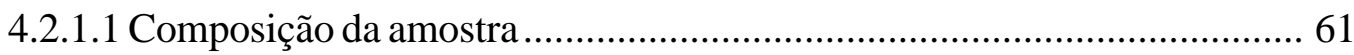

4.2.1.2 Comparação dos dados demográficos e clínicos entre sujeitos incluídos e não

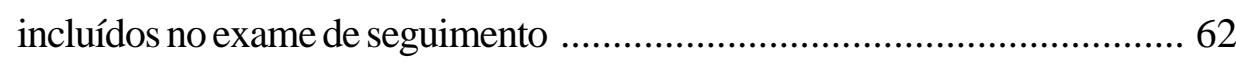

4.2.1.3 Comparação de dados demográficos entre pacientes e controles ao exame de

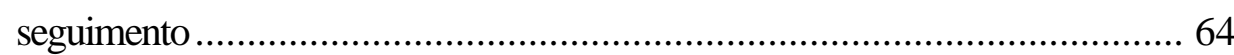

4.2.1.4 Características sócio-demográficas e clínicas dos pacientes (n=39) ao exame

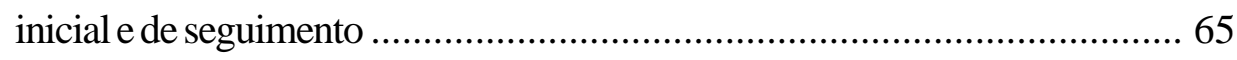

4.2.1.5 Tratamento medicamentoso durante o seguimento ................................... 66

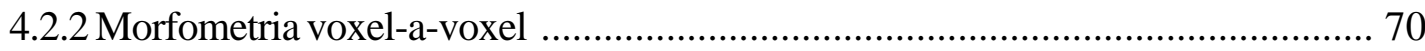

4.2.2.1 Comparação longitudinal entre pacientes e controles ................................ 70

4.2.2.2 Comparação longitudinal entre pacientes (teste t pareado) ........................ 71

4.2.2.3 Comparação longitudinal entre controles (teste t pareado) ........................ 71

4.2.2.4 Comparação longitudinal entre pacientes e controles sem diagnóstico de abuso ou dependência de substâncias ............................................................. 71

4.2.2.5 Comparação longitudinal entre pacientes com tempo de doença ao exame inicial menor que um ano e controles ..................................................... 72

4.2.2.6 Comparação longitudinal entre pacientes aderentes e não aderentes ao

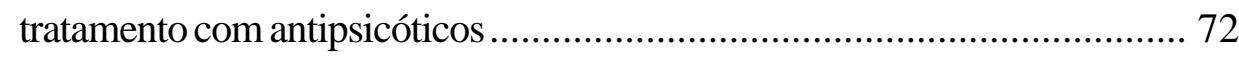

4.2.2.7 Comparação longitudinal entre pacientes aderentes expostos a antipsicóticos típicos e expostos a antipsicóticos atípicos ............................................. 73

5. DiscUSSÃo ......................................................................................................... 74

5.1 Interpretação dos resultados do estudo transversal à época do primeiro episódio

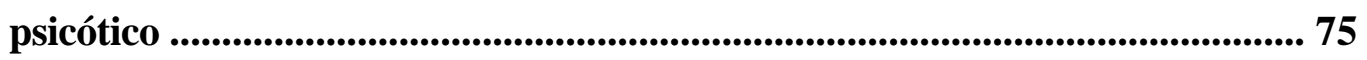

5.1.1 Características sócio-demográficas e clínicas da amostra ................................. 75

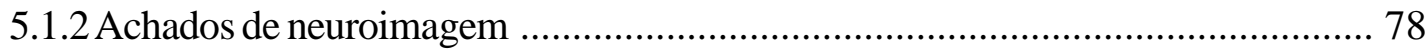


5.1.2.1 Redução do volume de substância cinzenta em pacientes comparados aos controles 78

5.1.2.2 Influência de possíveis fatores confundidores sobre o resultado da comparação entre pacientes e controles .................................................... 84

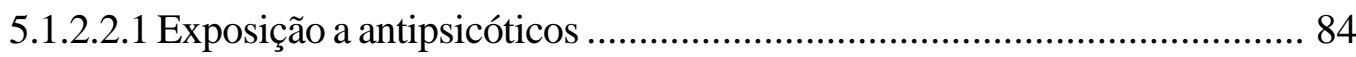

5.1.2.2.2 Uso de substâncias psicoativas ............................................................ 86

5.1.2.2.3 Variabilidade do tempo de história de psicose .................................... 87

5.2 Interpretação dos resultados do estudo longitudinal .................................... 87

5.2.1 Características sócio-demográficas e clínicas da amostra ................................. 87

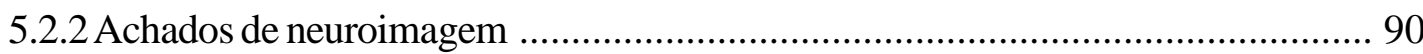

5.2.2.1 Alterações longitudinais de volume de substância cinzenta em pacientes e

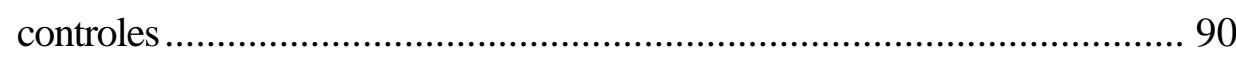

5.2.2.2 Influência de possíveis fatores confundidores sobre os resultados da comparação entre pacientes e controles .................................................. 93

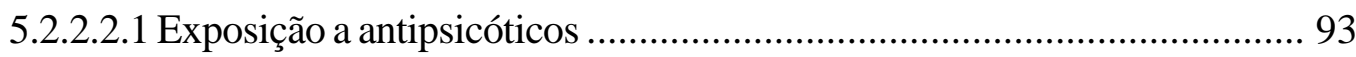

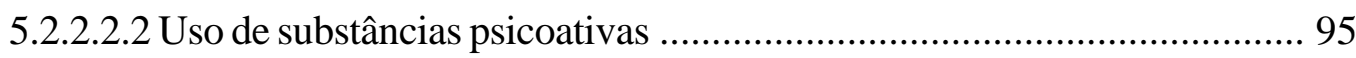

5.2.2.2.3 Variabilidade do tempo de psicose ....................................................... 96

5.2.2.3 Considerações a respeito do período de instalação e progressão de alterações

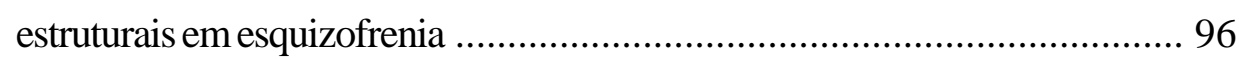

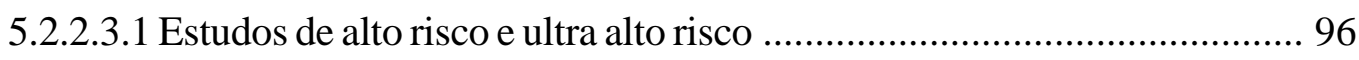

5.2.2.3.2 Integração entre resultados de neuroimagem ao primeiro episódio e ao

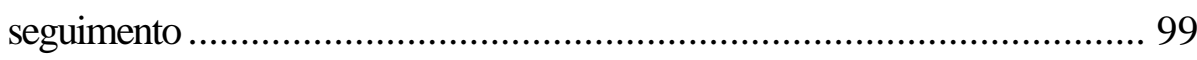

5.3 Considerações metodológicas ............................................................... 103

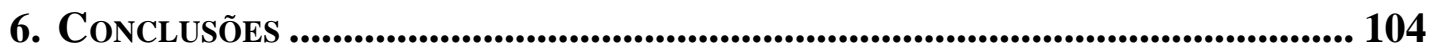

7. REFERÊNCIAS BIBLIOGRÁFICAS ..................................................................... 106 


\section{Lista de AbreViaturas e Siglas}

AAL-Automatic Anatomic Label

ANOVA-Análise de variância

ANCOVA-Análise de covariância

APs-Antipsicóticos

APA-American Psychiatry Association

BA - Área de Brodmann (Brodmann area)

CCI - Coeficiente de correlação intraclasse

CID 10 - Classificação Internacional das Doenças, 10ª edição

DICOM - Digital Imaging and Communications in Medicine

DP - Desvio-padrão

DUP - Duração da psicose não tratada (Duration of untreated psychosis)

DSM-IV-TR - Manual Diagnóstico e Estatístico de Transtornos Mentais - $4^{\mathrm{a}}$. edição-texto revisado (Diagnostic and Statistical Manual of Mental Disorders- 4th editionText Revision)

DTI-Diffusion tensor imaging

FWE-Family-wise error estimate

FWHM-Full-width at half maximum

GTS - Giro temporal superior

HR - Alto risco (High-risk)

InCor - Instituto do Coração

InRad - Instituto de Radiologia

LCR - Líquido cefalorraquidiano 
MATLAB - Matrix Laboratory

MNI - Montreal Neurological Institute

MTI-Magnetization transfer imaging

PANSS - Escala das síndromes positiva e negativa (Positive and negative syndrome scale)

PET - Tomografia por emissão de pósitrons (Positron emission tomography)

RM-Ressonância magnética

ROI - Região de interesse (Region of interest)

SCID - Entrevista clínica estruturada para o DSM-IV, transtornos do eixo I (Structured clinical interview for DSM-IV - axis I disorders)

SNC - Sistema nervoso central

SPECT - Tomografia por emissão de fóton único (Single-photon emission tomography)

SPGR - Spoiled gradient recalled acquisition

SPM-Statistical parametric mapping

SPM2 - Statistical parametric mapping, versão 2

SPSS - Statistical package for the social sciences

SVC - Small volume correction

T1 - Constante de tempo para relaxamento longitudinal

T2 - Constante de tempo para relaxamento transversal

TC-Tomografia computadorizada

TCE - Traumatismo crânio-encefálico

UHR - Ultra alto risco (Ultra high-risk)

VBM - Morfometria voxel-a-voxel (Voxel-based morphometry)

WHO - Organização Mundial de Saúde (World Health Organization) 


\section{LiSTA DE FigURAS}

Figura 1 - Seqüência de processamento das imagens por VBM 44

Figura 2 - Comparação entre pacientes e controles - análise transversal por VBM56

Figura 3 - Correlação negativa entre sintomas positivos (PANSS) e volume de substância cinzenta à RM inicial 58

Figura 4 - Correlação negativa entre exposição a antipsicóticos típicos e substância cinzenta à RM inicial 61

Figura 5 - Comparação entre pacientes e controles - análise longitudinal por VBM 70 


\section{LisTA DE TABELAS}

Tabela 1 -Critérios diagnósticos para Esquizofrenia e Transtorno Esquizofreniforme segundo os critérios do DSM-IV-TR

Tabela 2-Estudos volumétricos longitudinais por RM a partir do primeiro episódio psicótico em adultos

Tabela 3-Características sócio-demográficas da amostra à RM inicial 51

Tabela 4-Características clínicas dos pacientes à RM inicial 52

Tabela 5 - Características sócio-demográficas e clínicas dos pacientes medicados e não medicados à RM inicial 54

Tabela 6 - Áreas de redução de substância cinzenta em pacientes (n=62) comparados a controles ( $\mathrm{n}=94)$ 55

Tabela 7 - Áreas de correlação entre escores da PANSS e volume de substância cinzenta em pacientes $(\mathrm{n}=62)$ 59

Tabela 8 - Características sócio-demográficas e clínicas (ao exame inicial) dos pacientes com e sem exame de seguimento 63

Tabela 9-Características sócio-demográficas (ao exame inicial) dos controles com e sem exame de seguimento

Tabela 10 - Comparação de variáveis demográficas entre pacientes e controles submetidos ao exame de seguimento 65

Tabela 11 - Características relacionadas ao tratamento dos pacientes durante o seguimento 67

Tabela 12 -Comparação de variáveis sócio-demográficas e clínicas entre pacientes aderentes e não aderentes ao tratamento com antipsicóticos durante o seguimento .... 69 


\section{RESUMO}

Spanghero MS. Avaliação longitudinal de pacientes portadores de esquizofrenia e transtorno esquizofreniforme utilizando ressonância magnética de crânio [tese]. São Paulo: Faculdade de Medicina, Universidade de São Paulo; 2008. 120 páginas.

Alterações morfométricas cerebrais em pacientes com esquizofrenia têm sido descritas em muitos estudos utilizando ressonância magnética estrutural, sendo as mais consistentes o aumento ventricular e a redução do volume de substância cinzenta em neocórtex pré-frontal e temporal, ínsula, tálamo e no hipocampo/giro parahipocampal. No entanto, a natureza e o curso dessas alterações ainda não foram esclarecidos. Embora a principal hipótese a respeito da etiopatogenia da esquizofrenia sugira a presença de alterações anatômicas de início precoce e estáveis ao longo da doença, estudos longitudinais de ressonância magnética estrutural a partir do primeiro episódio psicótico têm indicado que, apesar de observáveis já no início da doença, ou mesmo antes do surgimento da mesma, algumas alterações podem ser progressivas, principalmente nos primeiros anos. Neste trabalho, foi comparado, transversal e longitudinalmente, o volume de substância cinzenta entre pacientes com esquizofrenia e transtorno esquizofreniforme após o primeiro contato com serviços de saúde e controles não psicóticos. As imagens de ressonância magnética estrutural de 62 pacientes e 94 controles procedentes da mesma área de captação, recrutados a partir de um estudo epidemiológico na cidade de São Paulo, foram adquiridas em um aparelho de 1,5 Tesla. Após um intervalo médio de 16 meses, 39 pacientes e 52 controles foram reexaminados. As imagens foram analisadas pelo método de morfometria voxel-a-voxel com o uso do programa Statistical Parametric Mapping e a significância estatística foi estabelecida em $\mathrm{p}<0,05$, corrigido para comparações múltiplas. A comparação inicial entre os grupos evidenciou áreas de redução de substância cinzenta nos pacientes em córtex pré-frontal direito e esquerdo, córtex temporal superior esquerdo, ínsula bilateral e hipocampo e giro parahipocampal direitos. A análise longitudinal evidenciou maior grau de preservação de substância cinzenta no grupo dos pacientes em córtex temporal superior esquerdo e em hipocampo/giro parahipocampal direitos. Não houve áreas de perda significativamente maior de substância cinzenta em pacientes comparados aos controles na análise longitudinal. Não foi encontrada diferença de volume de substância cinzenta entre pacientes com maior ou menor tempo de exposição aos antipsicóticos, tanto à análise inicial, quanto à análise longitudinal. Os resultados da análise transversal estão de acordo com a literatura sobre alterações cerebrais estruturais em primeiro episódio psicótico. Os achados da investigação longitudinal estão de acordo com alguns estudos de seguimento e apontam para a possibilidade de que essas alterações surgiriam antes do primeiro episódio psicótico. Além disso, tais resultados sugerem que, pelo menos durante o intervalo pesquisado, tais alterações não são progressivas. As diferenças volumétricas entre pacientes e controles não foram causadas pelo uso de antipsicóticos.

Descritores: esquizofrenia, imagem por ressonância magnética, córtex cerebral, estudos longitudinais. 


\section{SUMMARY:}

Spanghero MS. Longitudinal magnetic resonance imaging study of schizophrenia and schizophreniform disorder. [thesis]. São Paulo: Faculdade de Medicina, Universidade de São Paulo; 2008. 120 pages.

Morphometric brain abnormalities have been extensively described in subjects with schizophrenia in many structural magnetic resonance imaging studies, the most consistent findings being ventricular enlargement and gray matter reductions in frontal and temporal neocortices, insula, thalamus and hippocampus/parahippocampal gyri. However, the nature and course of these abnormalities have not yet been clarified. Although the main hypothesis regarding the etiopathology of schizophrenia implies the presence of early and stable anatomical brains abnormalities, longitudinal magnetic resonance imaging studies have suggested that, despite being present at the first episode of psychosis, or even before its onset, some brain abnormalities may be progressive, especially at the first few years of the disorder. In the present study, gray matter volumes were compared, at baseline and longitudinally, between first-episode patients with schizophrenia or schizophreniform disorder and non-psychotic controls. Structural magnetic resonance images from 62 patients and 94 controls, recruited from the same catchment area for an epidemiological study in the city of São Paulo, were acquired using a 1.5 Tesla scanner. After a mean period of 16 months, 39 patients and 52 controls were rescanned. Images were analyzed by voxel-based morphometry with the Statistical Parametric Mapping software and statistical significance was set at $\mathrm{p}<0.05$, corrected for multiple comparisons. Theinitial betweengroup comparison revealed gray matter reductions in patients, when compared to controls, in the right and left prefrontal cortices, left superior temporal cortex, bilateral insula and right hippocampus and parahipocampal gyrus. Longitudinally, patients exhibited significantly greater gray matter preservation in left superior temporal cortex and right hippocampus/ parahipocampal gyrus. There were no areas showing significantly greater gray matter loss in patients relative to controls in the longitudinal analysis. There were no gray matter differences between medicated and unmedicated patients, neither at baseline nor at follow-up. The findings of the baseline comparison are in accordance with previous studies that reported brain abnormalities in association with first episode psychosis. The longitudinal results are in accordance with some of the follow-up neuroimaging studies conducted to date and support the hypothesis that the described abnormalities could have been present before the onset of illness. Also, these findings suggest that, at least considering the follow-up interval of our study, such brain changes are not progressive. The volumetric differences between patients and controls observed in our study were not caused by antipsychotic medication effects.

Descriptors: schizophrenia, magnetic resonance imaging, cerebral cortex, longitudinal studies. 


\subsection{AsPeCtos gerais Da ESQUIZOFRENIA}

A esquizofrenia é o mais debilitante dos transtornos mentais e está entre as 10 principais causas mundiais de incapacitação, quando estas são ajustadas por faixa etária. Apresenta incidência anual de 0.2-0.4 por 1.000 habitantes, com uma prevalência ao longo da vida de cerca de 1\%. Sua incidência é a mesma entre os sexos, embora as mulheres apresentem uma idade de início mais tardia. Quando utilizados critérios diagnósticos mais estritos, a incidência e a prevalência da esquizofrenia costumam ser as mesmas em diferentes culturas (Mueser e McGurk, 2004).

Considerada como o principal tipo de transtorno psicótico, a esquizofrenia apresenta sinais e sintomas diversos, englobando quase todos os aspectos da cognição e do comportamento (percepção, pensamento, linguagem, motricidade, atenção, volição, emoção e funções executivas) (Andreasen e Carpenter, 1993). Os sintomas costumam ser agrupados 
em sintomas psicóticos positivos, sintomas negativos e déficits cognitivos. Os pacientes com esquizofrenia apresentam dificuldades no funcionamento social, além de comprometimento em muitas outras áreas, como aumento do risco para abuso de substâncias e doenças infecciosas, exposição à violência, disfunção familiar e sintomas depressivos e ansiosos. Como resultado da interação desses fatores, a esquizofrenia cursa com maiores taxas da mortalidade por suicídio, acidentes e patologias clínicas (Mueser e McGurk, 2004).

O início da doença ocorre, em geral, na segunda ou terceira década de vida (entre os 16 e 30 anos), sendo infreqüente seu início antes da puberdade ou após os 40 anos (Lewis e Lieberman, 2000; Mueser e McGurk, 2004).

O curso e o prognóstico da esquizofrenia são heterogêneos, com tendência a recaídas sintomáticas e alguns déficits geralmente presentes ao longo da vida (Mueser e McGurk, 2004). Uma parcela considerável dos pacientes apresenta evolução desfavorável (Hegarty et al., 1994) após um processo de repetidas exacerbações e remissões parciais (Lewis e Lieberman, 2000), passando a apresentar sintomas persistentes e deterioração clínica, com perda funcional significativa. Esse padrão de deterioração clínica costuma ocorrer nos primeiros 5-10 anos de doença, sendo mais evidente nos 3 primeiros anos de doença ativa (Lewis e Lieberman, 2000; McGlashan, 2006).

Embora quadros psicóticos tenham sido descritos desde a antiguidade, a caracterização nosológica moderna da esquizofrenia teve início com Kraepelin no final do século XIX. Este autor enfatizava o início e o curso do quadro, sendo a deterioração clínica progressiva em pacientes jovens considerada característica do transtorno (justamente denominado à época, “dementia praecox”) (Kraepelin, 1919). Paralelamente, em 1911, Bleuler (1950) descrevia um modelo mais transversal e procurava identificar sintomas característicos, principalmente as alterações de pensamento e afeto. Já a abordagem de Schneider (1959) também era transversal, com ênfase em grupo de sintomas psicóticos denominados por ele de “primeira ordem”. 
Nos dois sistemas de classificação psiquiátrica vigentes, a Classificação de Transtornos Mentais e de Comportamento da décima edição da Classificação Internacional das Doenças (CID-10, WHO, 1992), e a quarta edição revisada do Manual Diagnóstico e Estatístico dos Transtornos Mentais (Diagnostic and Statistical Manual of Mental Disorders, 4th edition, text revision - DSM-IV-TR), da Associação Psiquiátrica Americana (American Psychiatry Association, APA, 2000), os critérios para diagnóstico de esquizofrenia empregam uma síntese dos conceitos de Kraepelin, Bleuler e Schneider. Ambos os sistemas definem objetivamente sintomas e déficits da esquizofrenia de maneira similar. No entanto, o DSMIV inclui a necessidade de disfunção ocupacional em seus critérios e estabelece o período de 6 meses de sintomas para o diagnóstico, diferentemente da CID-10. Dessa maneira, o DSMIV fornece uma definição mais estrita da esquizofrenia, embora a confiabilidade do diagnóstico entre os dois sistemas seja alta (Andreasen e Carpenter, 1993; Mueser e McGurk, 2004).

O DSM-IV inclui entre os transtornos psicóticos o chamado transtorno esquizofreniforme, no qual estão presentes os critérios para esquizofrenia, mas com duração limitada a menos de 6 meses e sem a obrigatoriedade de declínio funcional, embora a maioria dos indivíduos com este transtorno experimente disfunção em várias áreas do funcionamento diário. Os critérios diagnósticos do DSM-IV-TR para esquizofrenia e transtorno esquizofreniforme encontram-se na Tabela 1. 
Tabela 1 -Critérios diagnósticos para Esquizofrenia e Transtorno Esquizofreniforme segundo o DSM-IV - TR

\section{Critérios diagnósticos para esquizofrenia}

A. Sintomas característicos: no mínimo dois dos seguintes quesitos, cada qual presente por uma porção significativa de tempo durante o período de 1 mês (ou menos, se tratados com sucesso):(1) delírios(2) alucinações(3) discurso desorganizado(4) comportamento amplamente desorganizado ou catatônico(5) sintomas negativos, isto é, embotamento afetivo, alogia ou abulia.Nota: apenas um sintoma é necessário quando os delírios são bizarros ou as alucinações consistem em vozes que comentam o comportamento ou os pensamentos da pessoa, ou duas ou mais vozes conversando entre si.

B. Disfunção social/ocupacional: por uma porção significativa de tempo desde o início da perturbação, uma ou mais áreas importantes do funcionamento estão acentuadamente abaixo do nível alcançado antes do início (ou quando o início se dá na infância ou adolescência, incapacidade de atingir o nível esperado de realização interpessoal, acadêmica ou profissional).

C. Duração: sinais contínuos da perturbação persistem pelo período mínimo de 6 meses. Esse período de 6 meses, deve incluir pelo menos 1 mês de sintomas que satisfazem o critério A e pode incluir períodos de sintomas prodrômicos ou residuais.

D. Exclusão de Transtorno Esquizoafetivo e Transtorno do Humor.

E. A perturbação não se deve aos efeitos fisiológicos diretos de uma substância ou a uma condição médica geral.

F. Se existe um histórico de Transtorno Autista ou de outro Transtorno Global do desenvolvimento, o diagnóstico adicional de Esquizofrenia é feito apenas se delírios ou alucinações proeminentes também estão presentes pelo período mínimo de 1 mês.

Critérios diagnósticos para transtorno esquizofreniforme

A. Satisfaz os critérios A, D e E para Esquizofrenia.

B. Um episódio do transtorno (incluindo as fases prodrômica, ativa e residual) dura no mínimo 1 mês, porém no máximo 6 meses. 


\subsection{NEUROANATOMIA DA ESQUIZOFRENIA}

Até hoje, o processo etiológico e a fisiopatologia da esquizofrenia e de outras psicoses funcionais não foram esclarecidos. As principais áreas de investigação em esquizofrenia são a neuroanatomia, a neuroquímica e a neurofisiologia em seres humanos e em modelos animais. As pesquisas nessas áreas originaram o modelo atual para a etiologia da esquizofrenia, o qual se baseia na interação entre múltiplos genes de suscetibilidade e fatores de risco ambientais (biológicos e psicossociais) (Mueser e McGurk, 2004), resultando em alterações de neurocircuitaria envolvendo, principalmente, a neurotransmissão dopaminérgica e glutamatérgica nas vias mesolímbicas e mesocorticais e os circuitos envolvendo o córtex préfrontal, o sistema límbico, os núcleos da base e o tálamo (Friston et al., 1992; Deakin e Simpson, 1997; Lewis e Lieberman, 2000; Molina et al., 2005a).

Em seguida, serão descritos os principais dados relativos às pesquisas em neuroanatomia da esquizofrenia, conduzidas com técnicas de neuropatologia e neuroimagem.

\subsubsection{Neuropatologia}

\subsubsection{Histórico}

Inicialmente, o exame de tecido cerebral “post mortem” foi a principal fonte de dados relevantes para o conhecimento sobre a neuroanatomia da esquizofrenia. Na primeira metade do século $\mathrm{XX}$, a pesquisa em psiquiatria estava intimamente ligada à neuroanatomia e à neuropatologia, e as bases cerebrais de doenças inicialmente consideradas funcionais, como coréia de Huntington, epilepsia, doença de Alzheimer e doença de Pick, estavam sendo evidenciadas. Do mesmo modo, Kraepelin (1919) acreditava que a “dementia praecox” possuía um substrato neuropatológico. O primeiro estudo neurohistológico em “dementia praecox” foi publicado por Alzheimer em 1897 (citado por Bogerts, 1999), em que foram 
descritas alterações neuronais corticais, claramente diferentes daquelas que mais tarde seriam observadas nas demências senis. Outros autores, em seguida, observaram alterações em estudos neuropatológicos em esquizofrenia, como atrofia cortical, alterações celulares em córtex, em tálamo e nos núcleos da base. Porém, esses estudos foram criticados e permaneceram controversos, sendo esse tema esquecido por mais de trinta anos (entre os anos de 1950 e 1980, aproximadamente), período em que a maioria dos neuropatologistas acreditava não haver alterações morfopatológicas na esquizofrenia (Bogerts, 1999).

A partir da década de 80 do século passado, graças às novas técnicas histoquímicas, um número considerável de estudos “post mortem” em esquizofrenia vêm sendo conduzidos, empregando um melhor desenho de estudo e métodos mais refinados de análise em relação aos predecessores. Entretanto, são necessários métodos estatísticos sofisticados para demonstrar uma diferença entre grupos de pacientes e controles, já que existe uma sobreposição considerável de achados entre os grupos e os parâmetros de muitos pacientes encontram-se na faixa normal.

\subsubsection{Estudos de neuropatologia contemporâneos}

Os estudos de neuropatologia mais recentes procuraram, inicialmente, investigar a presença de processos degenerativos, similares aos encontrados em doenças neurodegenerativas como as demências. Em seguida, o foco passou a ser o estudo da citoarquitetura cortical e, posteriormente, a investigação das sinapses.

Revisões dessas investigações neuropatológicas conduzidas com técnicas modernas foram elaboradas por Harrison (1999), Bogerts (1999), Kasai (2002), Harrison e Weinberger (2005), e suas principais conclusões no estudo da esquizofrenia são descritas a seguir:

-Macroscopia: tais estudos indicam redução do volume encefálico, alargamento ventricular, redução do volume de estruturas do lobo temporal, redução do volume talâmico e 
aumento dos núcleos da base. Outros achados são: ocorrência freqüente de “cavum septi pellucidi” e ausência da assimetria estrutural normal do córtex. Todavia, há estudos negativos para cada um desses parâmetros, e no caso dessas avaliações macroscópicas, medidas de volume por neuroimagem “in vivo” seriam mais vantajosas. Não foram descritas alterações neurodegenerativas capazes de explicar a redução de volume cerebral. Da mesma forma, os déficits cognitivos da esquizofrenia não são explicáveis em termos neuropatológicos convencionais de neurodegeneração.

-Ausência de gliose: a astrocitose reativa é considerada sinal de inflamação prévia, conseqüência de processos infecciosos, inflamatórios ou neurodegenerativos. Acredita-se que a gliose não seja um padrão presente na esquizofrenia, mas sua ausência não é uma medida definitiva para caracterizar a natureza do processo patológico.

- Citoarquitetura: o real valor dos estudos neuropatológicos estaria na elucidação dos padrões moleculares e microscópicos da esquizofrenia, que estão além do alcance da neuroimagem estrutural “in vivo”. São avaliados a densidade, número, tamanho, forma, orientação, localização e agrupamento das células do sistema nervoso central (SNC). Não há uma anormalidade única considerada totalmente estabelecida na neuropatologia da esquizofrenia. A mais notável alteração consiste em neurônios localizados ou agrupados de forma aberrante no córtex entorrinal e na substância branca do neocórtex. Essas alterações são fortemente indicativas de uma anomalia afetando migração, sobrevivência e conectividade neuronal. Porém, mesmo esses achados têm resultados negativos e limitações metodológicas.

Os achados mais convincentes são redução do volume de neurônios no hipocampo e no córtex pré-frontal dorsolateral (acompanhada por aumento da densidade neuronal).Além do córtex, alterações consistentes ocorrem no tálamo: número reduzido de neurônios no núcleo médio-dorsal, que possui projeções para o córtex pré-frontal, e também no núcleo anterior (novamente, neurônios tálamo-corticais). 
Achados recentes referem-se à redução do número e de função de oligodendrócitos. Devido a seu papel na mielinização e em outros aspectos da integridade sináptica e neuronal, seu envolvimento na esquizofrenia está provavelmente ligado às alterações neuronais e às conseqüências dessas alterações, mas não se sabe quais são as anormalidades primárias ou secundárias.

- Sinapses, dendritos e axônios: são avaliados ultra-estruturalmente ou indiretamente com marcadores imunológicos ou moleculares. O estudo indireto das sinapses é feitos através da expressão e abundância das proteínas concentradas nos terminais pré-sinápticos. Essa medida pode referir-se a densidade sináptica, tamanho da sinapse, número de vesículas por terminal ou alterações estruturais na região pré-sináptica.

São consistentes os achados de redução dos níveis de proteínas sinápticas na formação hipocampal (hipocampo e giro parahipocampal), principalmente afetando terminais excitatórios glutamatérgicos, assim como alterações em dendritos pós-sinápticos. A redução de proteínas sinápticas também é descrita em córtex pré-frontal dorsolateral (associadas à menor densidade de dendritos) e no tálamo.

Os achados de redução sináptica são compatíveis com os dados de redução do tamanho dos neurônios, uma vez que essas estruturas são proporcionais umas à outras. A redução sináptica também é compatível com o aumento da densidade neuronal, pois os dendritos, axônios e sinapses formam a maior parte da neurópila, e se esta estiver reduzida, os neurônios estarão agrupados de maneira mais próxima.

As revisões citadas acima convergem para as seguintes conclusões: a redução do volume e da espessura cortical em esquizofrenia ocorreria por redução da neurópila e do tamanho dos neurônios, e não por perda neuronal, sugerindo alterações na organização sináptica, dendrítica e axonal; a redução de volume cortical afetaria mais a substância cinzenta do que 
a substância branca; a patologia subcortical está menos estabelecida, com exceção do núcleo dorsal do tálamo, que estaria reduzido e teria menor número de neurônios.

Embora o tipo e extensão da patologia em áreas límbicas em esquizofrenia sejam variáveis entre os estudos e não haja um padrão homogêneo de achados, a vasta maioria dos autores concorda com a existência de alterações sutis em regiões límbicas numa porcentagem significativa de pacientes com esquizofrenia. Portanto, assume-se que a patologia do sistema límbico seja um componente essencial da fisiopatologia desse transtorno (Bogerts, 1999).

Mais do que fornecer um achado específico, as pesquisas neuropatológicas da esquizofrenia têm identificado alterações quantitativas em vários parâmetros normais da microcircuitaria neural, desde a árvore dendrítica, corpo celular e axônio até o terminal sináptico, incluindo elementos da glia. Nesse sentido, os achados neuropatológicos podem ser vistos como consistentes com as hipóteses de que ocorreria uma disconectividade funcional entre diferentes regiões cerebrais na esquizofrenia, hipótese esta proeminente nos modelos fisiopatológicos contemporâneos para este transtorno (Friston e Frith 1995; McGuire e Frith, 1996; Andreasen et al., 1996; Deakin e Simpson, 1997; Bullmore et al., 1998).

Teoricamente, os padrões neuropatológicos representam o substrato anatômico das anormalidades funcionais num circuito que envolve o mesencéfalo, o núcleo accumbens, o tálamo, o córtex têmporo-límbico e o córtex pré-frontal (Lewis e Lieberman, 2000).

Apesar das contribuições da neuropatologia ao estudo da esquizofrenia e dos avanços nas técnicas utilizadas, os grupos de pesquisa ainda usam diferentes métodos, analisam diferentes áreas e as amostras continuam a ser pequenas. Além disso, a sutileza da patologia e as limitações conceituais e práticas na pesquisa cerebral “post mortem” significam que essa abordagem não será capaz de fornecer, por si só, explicações completas sobre a causa da patologia deste transtorno psiquiátrico (Harrison, 1999). 


\subsubsection{Neuroimagem}

\subsubsection{Considerações gerais}

As técnicas de neuroimagem têm tornado possível a avaliação "in vivo” das anormalidades estruturais e funcionais do SNC nos transtornos psiquiátricos, sem os potenciais fatores de confusão da fixação e de outras fontes de artefatos que podem influenciar o exame do tecido cerebral “post mortem”. Permitem, ainda, a avaliação dos estágios iniciais da doença e podem ser longitudinais (Diwadkar e Keshavan, 2002). É importante salientar que os estudos de neuroimagem contribuíram como incentivo para novos estudos neuropatológicos e para a integração entre achados anatômicos e funcionais em esquizofrenia (Bogerts, 1999).

Inicialmente, os estudos de neuroimagem em psiquiatria utilizavam a tomografia computadorizada (TC). Sua aplicação ocorreu principalmente nas décadas de 70 e 80 do século passado (Diwadkar e Keshavan, 2002).

Progressivamente, a TC foi substituída nesses estudos pela técnica de ressonância magnética (RM), que pode fornecer informações morfométricas anatômicas (através da modalidade estrutural), neuroquímicas (com o uso da espectroscopia por RM), fisiológicas (com o uso da RM funcional) ou a respeito da conectividade e integridade de substância branca (com o uso de imagem por tensor de difusão, diffusion tensor imaging, DTI). Além da RM, outros métodos de neuroimagem funcional incluem a tomografia por emissão de pósitrons (positron emission tomography, PET), que permite medidas de metabolismo cerebral de glicose, fluxo sanguíneo e função de receptores, e a tomografia por emissão de fóton único (single-photon computed emission tomography, SPECT), também usada para medir a perfusão cerebral e a função de receptores (Gur et al., 2007).

Os métodos de neuroimagem são diversos e complementares e são utilizados para o estudo dos processos subjacentes aos transtornos psiquiátricos, dentre eles, os transtornos 
psicóticos (Gur et al., 2007). Neste trabalho, serão focalizados os estudos que investigam as alterações morfométricas em esquizofrenia.

Estudos de neuroimagem estrutural por TC e RM, investigando alterações anatômicas volumétricas, têm proporcionado algumas das mais consistentes evidências a favor da existência de anormalidades cerebrais na esquizofrenia. Nessa área, o estudo inicial foi o de Johnstone e colaboradores (1976), em que foram demonstrados, com o uso da TC, ventrículos laterais anormalmente alargados em pacientes com esquizofrenia crônica. Desde então, o alargamento ventricular têm sido um dos mais consistentes achados na literatura de neuroimagem em esquizofrenia (Elkis et al., 1995).

Muitos estudos com TC em esquizofrenia foram conduzidos desde então e, em resumo, demonstraram dilatação dos sulcos e ventrículos cerebrais (Lewis, 1990; Raz e Raz, 1990; Van Horn e McManus, 1992; Raz, 1993). Faz-se necessário enfatizar que essa técnica apresenta limitações, uma vez que não permite medidas tridimensionais ou delimitação precisa entre substância branca e cinzenta. O início do uso da RM, na década de 1980, permitiu a avaliação de medidas quantitativas tridimensionais dos diferentes compartimentos encefálicos (substâncias cinzenta, branca e líquor). Outro aspecto a ser observado é que a RM não emite radiação ionizante, sendo um procedimento seguro para os voluntários submetidos ao exame, além de possuir a vantagem de maior resolução espacial. Nesse contexto, os avanços na área de RM estrutural permitiram uma caracterização mais refinada das alterações cerebrais em esquizofrenia “in vivo” (Pearlson e Marsh, 1999).

\subsubsection{Volumetria por ressonância magnética}

A maioria dos estudos de RM em psiquiatria foi conduzida com o método de volumetria por regiões de interesse (regions of interest, ROI), que consiste no emprego de medidas volumétricas de regiões cerebrais definidas “a priori” e delineadas manualmente, a partir de 
bordas anatômicas relativamente arbitrárias, com variações nos critérios usados pelos diferentes estudos. Em geral, nos estudos iniciais com ROI, o volume de determinada região era calculado sem que houvesse a segmentação entre substância cinzenta e branca, o que dificultava inferências a respeito da natureza dos achados. Esse método é também sujeito a viés do observador e demanda tempo excessivo, dificultando sua aplicação em estudos com grandes amostras (Diwadkar e Keshavan, 2002).

Mais recentemente, métodos completamente automatizados vêm sendo utilizados em estudos de RM, permitindo comparações de substância cinzenta voxel-a-voxel entre diferentes grupos de sujeitos, tornando desnecessária a seleção de regiões “a priori” e possibilitando o exame de todo o encéfalo e o uso de amostras maiores. A técnica automatizada mais empregada é conhecida como morfometria voxel-a-voxel (voxel-based morphometry, VBM), comumente conduzida com o uso do programa Statistical Parametric Mapping (SPM) (Good et al., 2001). O emprego desta técnica possibilita tanto a validação dos achados descritos nos estudos anteriores com ROI, como novas descobertas em outras áreas cerebrais (Gur et al., 2007).

Neste método, as imagens de RM estrutural sofrem inicialmente transformações espaciais em um espaço estereotáxico padronizado, para que sejam removidas as variações interindividuais de formato e tamanho cerebrais. Posteriormente, são segmentadas em compartimentos de substância cinzenta, branca e líquor e suavizadas com um filtro gaussiano (full width at half maximum, FWHM), o qual espalha o sinal da imagem, tornando a distribuição dos voxels mais próxima da distribuição normal. O tamanho do filtro gaussiano a ser utilizado pode variar de acordo com a hipótese do estudo, geralmente entre 4 e 12 mm. Para a pesquisa de diferença de volume em regiões cerebrais pequenas, costuma-se suavizar a imagem com um filtro de diâmetro menor do que o utilizado para a investigação de áreas corticais extensas. Após essas etapas, os segmentos de substância cinzenta (ou branca) são, então, comparados estatisticamente entre os grupos (voxel-a-voxel), resultando na geração 
de mapas estatísticos que mostram a localização de agrupamentos de voxels onde foram detectadas diferenças significativas (Ashburner e Friston, 2000). Em resumo, em comparação com a técnica de ROI, a VBM apresenta como vantagens a independência do observador, a praticidade e a possibilidade de avaliação do encéfalo inteiro. Essa técnica, contudo, não é utilizada para avaliação volumétrica do sistema ventricular.

Em relação ao desenho, os estudos mais freqüentes têm empregado avaliações transversais, comparando-se a morfometria cerebral de um grupo de pacientes (em início de doença, em estágios crônicos ou em risco) com a de um grupo controle (sujeitos normais ou assintomáticos). Estudos transversais têm sido empregados também para a investigação de correlações entre características clínicas e volume de estruturas cerebrais. Outros estudos empregam um desenho longitudinal, em que as amostras são reavaliadas ao longo do tempo, permitindo a investigação do padrão temporal das alterações cerebrais.

\subsubsection{Volumetria por ressonância magnética em esquizofrenia - estudos transversais}

Os primeiros estudos de RM estrutural em esquizofrenia avaliaram amostras de pacientes crônicos comparados a controles saudáveis. Pode-se dizer que esses estudos corroboram os resultados dos estudos de TC e em parte, mas não inequivocamente, os achados de neuropatologia (Wright et al., 2000). A partir de 1991 (DeLisi et al., 1991), começaram a ser publicados estudos de RM avaliando pacientes em primeiro episódio psicótico, geralmente à época da primeira hospitalização. Essa nova abordagem apresenta vantagens em relação aos estudos com pacientes crônicos, uma vez que elimina fatores de confusão como cronicidade da doença e exposição prolongada a tratamento com antipsicóticos (APs), contribuindo para a investigação dos efeitos temporais das alterações cerebrais (Keshavan e Schooler, 1992). 
Os estudos de RM estrutural em esquizofrenia são numerosos e alguns dos achados são considerados como os mais consistentes na neuroanatomia da esquizofrenia. As alterações volumétricas, em geral, são encontradas tanto em pacientes com doença crônica quanto em pacientes em primeiro episódio psicótico em relação a controles saudáveis, e caracterizamse por diferenças volumétricas de estruturas como um todo ou especificamente de substância cinzenta. A substância branca é mais difícil de ser analisada em estudos com RM convencional, por parecer mais uniforme e homogênea (Shenton et al., 2001). Estudos que investigam alterações de substância branca vêm sendo conduzidos com técnicas de DTI e magnetization transfer imaging (MTI), e não são discutidos neste trabalho.

Apesar da existência de estudos individuais com resultados positivos e negativos para as medidas volumétricas de determinada região cerebral, os achados a seguir são os de maior consistência na literatura, sendo descritos em revisões sistemáticas e metanálises. Em síntese, os estudos de RM estrutural mostram que, em comparação com controles saudáveis, pacientes com esquizofrenia apresentam:

- diminuição de volume cerebral total (Lawrie e Abukmeil, 1998; Wright et al., 2000; Vita et al., 2006; Steen et al., 2006) e de substância cinzenta global (Lim et al., 1996; Gur et al., 1999, Cahn et al., 2002).

- aumento do volume ventricular total (Wright et al., 2000), especialmente dos ventrículos laterais (Suddath et al., 1990; Lawrie e Abukmeil, 1998; Wright et al., 2000; Vita et al., 2006; Steen et al., 2006) e terceiro ventrículo (Shenton et al., 2001; Vita et al., 2006; Steen et al., 2006).

- redução de volume do lobo frontal (Wright et al., 2000), redução de substância cinzenta pré-frontal e órbito-frontal (Shenton et al., 2001; Honea et al., 2005).

- reduções das seguintes estruturas: lobo temporal como um todo (Lawrie e Abukmeil, 1998), lobo temporal medial (Shenton et al., 2001; Honea et al., 2005), amígdala (Wright et al., 2000), hipocampo (Nelson et al., 1998; Shenton et al., 2001; Vita et al., 2006; Steen et 
al., 2006), complexo amígdala-hipocampo (Nelson et al., 1998; Lawrie e Abukmeil, 1998; Wright et al., 2000; Shenton et al., 2001), giro parahipocampal (Shenton et al., 2001; Honea et al., 2005) e giro temporal superior (Wright et al., 2000; Shenton et al., 2001; Honea et al., 2005).

- prevalência de “cavum septi pellucidi” aumentada (Degreef et al., 1992; Kasai et al., 2004).

- aumento do volume de núcleos da base (revisão de Shenton et al., 2001), considerado secundário à exposição aos neurolépticos, uma vez que os pacientes em primeiro episódio psicótico com pouca ou nenhuma exposição à medicação ou pacientes tratados com APs atípicos apresentaram redução volumétrica ou ausência de alteração quando comparados a controles normais (Chakos et al., 1994 e 1995; Keshavan et al., 1994a e 1998a; Corson et al., 1999. Lang et al., 2004).

- redução do volume do tálamo (Wright et al., 2000; Shenton et al., 2001, Honea et al., 2005).

- alterações em cerebelo, ainda que de forma menos consistente em comparação com os achados anteriores (Levitt et al., 1999; Shenton et al., 2001; Okugawa et al., 2003).

Embora a maioria dos estudos volumétricos tenha utilizado a metodologia de ROI, uma metanálise recente de estudos de esquizofrenia (englobando estudos de pacientes em primeiro episódio e estudos com pacientes crônicos) que empregaram a técnica de VBM descreve anormalidades em áreas cerebrais compatíveis com as principais áreas descritas nos estudos com ROI (Honea et al., 2005). Essa metanálise demonstrou que os déficits regionais mais robustos encontrados nos estudos com VBM estão presentes no giro temporal superior (GTS) esquerdo e no lobo temporal medial (hipocampo), além de reduções de volume em região pré-frontal (especificamente envolvendo o giro frontal inferior e giro frontal medial), córtex temporal superior direito, giro parahipocampal direito, cíngulo anterior, ínsula e tálamo. Deve-se destacar que a ínsula é uma das estruturas pouco estudadas com 
metodologia de ROI, mas que vem sendo identificada como área de redução de volume em esquizofrenia consistentemente em estudos de VBM (Honea et al., 2005).

Alguns grupos de pesquisa submeteram a mesma amostra à morfometria pelas duas técnicas. Os primeiros estudos com pacientes em primeiro episódio psicótico a usar a técnica de VBM foram conduzidos por Job et al. (2002) e Kubicki et al. (2002). Ambos confirmaram os achados de redução de regiões de lobo temporal obtidos pelo método de ROI em seus estudos prévios com as mesmas amostras (Lawrie et al., 2001 e Hirayasu et al., 1998, respectivamente). No estudo de Kubick com VBM, foi necessário o emprego da correção para volumes pequenos (small volume correction, SVC) do SPM para a investigação do hipocampo, assim como o uso de um filtro gaussiano menor. Adicionalmente, o uso do VBM permitiu a observação de novos achados nos estudos desses dois autores, que não haviam sido identificados inicialmente, em virtude das limitações do método manual de ROI.

\subsubsection{Volumetria por ressonância magnética em esquizofrenia - estudos longitudinais a partir do primeiro episódio psicótico}

Apesar do grande número de estudos transversais de volumetria em esquizofrenia e da consistência e replicação dos achados, a natureza das alterações anatômicas encontradas e seu papel na fisiopatologia do transtorno ainda não são completamente conhecidos. Sob essa perspectiva, torna-se fundamental estabelecer em que períodos essas anormalidades ocorrem e qual seu curso temporal. Para esse fim, os principais métodos de investigação são os estudos transversais (que avaliam as correlações entre medidas morfométricas cerebrais e a duração da doença) e os estudos longitudinais de medidas volumétricas cerebrais (envolvendo o acompanhamento da mesma amostra ao longo do tempo) (Vita et al., 2006).

Os estudos empregando análises transversais de correlação entre tempo de doença e volumes cerebrais (tanto no início da doença quanto em pacientes crônicos) mostraram 
resultados conflitantes. Enquanto a maioria desses estudos não mostrou correlação entre alterações volumétricas cerebrais e a duração da doença (ou a idade de início) (Vita et al., 1991; Marsh et al., 1994; Gur et al., 2000; Vita et al., 2006), outros sugerem que a existência de uma relação entre tempo de doença e redução de volume de lobo temporal esquerdo (Keshavan et al., 1998b; Hietala et al., 2003), córtex pré-frontal (Molina et al., 2004; Premkumar et al., 2006), hipocampo (Velakoulis et al., 2002) e giro parahipocampal (Razi et al., 1999). Outro estudo transversal avaliou o efeito da duração da doença em pacientes com doença recente (transtorno esquizofrenifrome ou esquizofrenia com início há 1 ano, em média) e com doença crônica (mais de 10 anos de história) (Chakos et al., 2005). Neste estudo, foi encontrada uma correlação positiva entre tempo de doença e volume hipocampal nos sujeitos com doença recente, mas não nos pacientes crônicos, sugerindo que as mudanças de volume não são lineares. Por outro lado, neste mesmo estudo (Chakos et al., 2005) evidenciou-se que, embora pacientes em primeiro episódio psicótico já apresentassem menor volume de hipocampo em relação aos controles, essa diferença era maior quando eram comparados pacientes com esquizofrenia crônica em relação a um grupo controle da mesma idade, sugerindo que uma alteração hipocampal já estaria presente no início da doença, mas teria ainda um caráter progressivo ao longo do tempo.

Além da inconclusão a respeito da progressão das alterações cerebrais gerada pelos estudos transversais, os estudos longitudinais são mais adequados para a investigação dessas alterações, uma vez que excluem a variação entre sujeitos e diminuem o risco de vieses (Pantelis et al., 2005).

A maioria dos estudos longitudinais conduzidos inicialmente com TC falhou em demonstrar progressão de aumento ventricular em esquizofrenia (Nasrallah et al., 1986; Illowsky et al., 1988; Vita et al., 1988 e 1994; Sponheim et al., 1991; Jaskiw et al., 1994), embora resultados positivos tenham sido relatados (Madsen et al., 1999). Todavia, estudos com TC apresentam limitações técnicas, já descritas anteriormente, e foram substituídos ao 
longo do tempo por estudos longitudinais conduzidos com RM. Inicialmente avaliando pacientes crônicos, os resultados desses estudos longitudinais com RM estrutural foram diversos, mas sugerem uma possível progressão de alterações em estágios crônicos da doença, geralmente associada a um pior prognóstico clínico (Nair et al., 1997; Mathalon et al., 2001; Pantelis et al., 2005; Hulshoff e Kahn, 2008).

Conforme já citado, estudos com pacientes crônicos apresentam mais fatores de confusão e são menos esclarecedores quanto à instalação e ao curso das anormalidades cerebrais, uma vez que se espera que a progressão das alterações cerebrais ocorra principalmente no período de maior deterioração funcional dos pacientes (primeiros anos após o surgimento do quadro clínico).

Um tipo particular de estudo longitudinal tem empregado amostras de pacientes com esquizofrenia de início precoce (na infância ou início da adolescência) com resultados apontando para progressão de alterações volumétricas em relação aos controles (Jacobsen et al., 1998; Sporn et al., 2003; Greenstein et al., 2006). Como estes estudos investigam um tipo raro de psicose e são pouco passíveis de comparação direta com os estudos em adultos, tais achados não serão discutidos neste trabalho.

A maioria dos estudos longitudinais mais recentes tem empregado amostras a partir do primeiro episódio psicótico em adultos jovens, foco deste trabalho. Os métodos e resultados destes estudos são sintetizados na Tabela 2.

O primeiro estudo deste tipo foi conduzido por DeLisi e colaboradores (1991), com uma amostra inicial de 87 pacientes e 52 controles. À avaliação inicial, os pacientes apresentavam aumento de volume ventricular em relação aos controles (DeLisi et al., 1991). Atualmente, esse estudo longitudinal já apresentou os resultados de um período de seguimento de 10 anos. Em resumo, os resultados demonstraram que nos primeiros 5 anos de seguimento, os pacientes ( $n=50)$ apresentaram aumento de ventrículo lateral esquerdo e redução de hemisférios cerebrais em relação aos controles ( $\mathrm{n}=20$ ), mas não houve diferença em medidas 
de núcleo caudado, lobo temporal, giro temporal superior e hipocampo (DeLisi et al., 1997a). Ao final de 10 anos, os pacientes ( $n=26$ ) apresentaram volumes ventriculares mais heterogêneos que os controles ( $\mathrm{n}=10$ ) e foi observada, inesperadamente, uma correlação positiva entre o tamanho dos ventrículos e melhor prognóstico (DeLisi et al., 2004). Novamente, não foram observadas reduções em medidas de lobos temporais ou de giro temporal superior (DeLisi et al., 2005). Uma das limitações dos estudos desse grupo de pesquisadores é o uso de um protocolo relativamente rudimentar de RM morfométrica, com cortes espessos e grande intervalo entre os mesmos.

Outros grupos de pesquisa conduziram investigações longitudinais por RM a partir do primeiro episódio psicótico, em comparação a um grupo controle, empregando intervalos entre os exames que variaram de 12 meses a 4-5 anos. Os principais resultados positivos foram:

- alterações globais: reduções progressivas do volume cerebral total (Cahn et al., 2002; Wood et al., 2001) e de substância cinzenta global (Cahn et al., 2002), aumento progressivo dos espaços liquóricos (Ho et al., 2003; Bachman et al., 2004; Nakamura et al., 2007) e dos ventrículos laterais (Lieberman et al., 2001; Cahn et al., 2002, Nakamura et al, 2007).

- alterações regionais: reduções progressivas de lobos frontal (Gur et al., 1998; Bachmann et al., 2004, Ho et al., 2003; Nakamura et al., 2007) e temporal (Bachmann et al., 2004; Nakamura et al., 2007), giro de Heschl e “planum temporale” esquerdos (Kasai et al., 2003a) e giro temporal superior esquerdo (Kasai et al., 2003b)

Apesar dos achados positivos descritos acima, em alguns casos o mesmo grupo de investigadores, seguindo a mesma amostra, relata resultados negativos para outras regiões do cérebro investigadas longitudinalmente, assim como foi descrito no caso do estudo do grupo de DeLisi et al. (1997a, 2004, 2005). Desta forma, na amostra estudada por Kasai e colaboradores (estudos citados acima), embora tenham sido evidenciadas alterações em 
regiões temporais após cerca de 1 ano e meio de seguimento (Kasai et al., 2003a), não foi encontrada progressão em complexo amígdala-hipocampo (Kasai et al., 2003b), nem redução de substância cinzenta de lobo frontal (Dickey et al., 2004). O estudo de seguimento com uma das maiores amostras recrutadas até hoje (Ho et al., 2003) avaliou 73 pacientes (41 em primeira hospitalização, com 2 anos de doença em média e 32 já hospitalizados anteriormente, com média de 3 anos de história) e 23 controles após intervalo de 3 anos. Apesar deste estudo ter evidenciado, ao seguimento, aumento de espaços liquóricos corticais e redução de volume frontal nos pacientes em relação aos controles, e uma associação de aumento de ventrículos laterais com mau prognóstico, não foi demonstrada redução de volume cerebral total, de substância cinzenta total, nem de lobos temporais e parietais.

Outro estudo a avaliar uma amostra grande de pacientes foi o de Lieberman e colaboradores (2001), com 53 pacientes e 13 controles avaliados em intervalos médios de 2 anos. Nesse estudo, foram observados aumento de volume ventricular e redução cortical global apenas nos sujeitos com mau prognóstico, mas não foram encontradas alterações em núcleo caudado, hipocampo e volume cortical na amostra como um todo.

Alguns estudos relataram redução volumétrica de regiões temporais mediais no grupo de pacientes em relação ao grupo controle à avaliação inicial, mas não observaram progressão desta redução (em hipocampo, por exemplo) durante o seguimento, contrariando suas hipóteses “a priori” (Lieberman et al., 2001, Wood et al., 2001 Kasai et al., 2003b; Withworth et al., 2005).

Em relação ao método utilizado, o primeiro estudo de seguimento em adultos a utilizar VBM foi o estudo de Price et al (2006), que seguiu 16 pacientes e 12 controles (a partir de uma amostra inicial de 30 pacientes e 30 controles) por 3,7 anos. Foi utilizado o VBM a partir de imagens de RM por MTI e não foi encontrada interação entre grupo diagnóstico e tempo para o volume de substância cinzenta. Os autores sugerem que a ausência de alterações de substância cinzenta descrita neste estudo pode ser conseqüência do emprego de uma 
amostra pequena. Já o estudo de Théberge et al. (2007) mostrou que pacientes (sem uso prévio de medicação), embora não diferissem dos controles em volume de substância cinzenta ao exame inicial, evoluíam, após 30 meses, com redução mais acentuada em giro temporal superior (área de Brodmann, BA - 22) e núcleo caudado à esquerda. A comparação intragrupo mostrou que os pacientes (medicados e estabilizados clinicamente) apresentaram redução em várias regiões (córtex frontal, temporal e parietal bilateralmente, cíngulo posterior, amígdala e hipocampo, caudado e tálamo direitos), enquanto os controles não apresentaram diferenças longitudinais.

Outro estudo longitudinal de VBM com resultados positivos foi o de van Haren et al. (2007), empregando pacientes com esquizofrenia com doença recente e crônica (tempo de doença variando entre 0,4 a 36 anos). Esse estudo mostrou reduções de substância cinzenta após 5 anos nos pacientes (em giros frontal e temporal superiores, núcleo caudado e tálamo direitos) comparados aos controles. Observou-se que a redução de substância cinzenta e o aumento de volume ventricular excessivos nos pacientes em relação aos controles ocorriam nos 20 anos iniciais de doença, e que, após esse período, o grau de alteração volumétrica cerebral seguia o mesmo padrão do envelhecimento normal (van Haren et al., 2008).

A maior parte dos pacientes avaliados nos estudos acima permaneceu em uso de APs (típicos e/ou atípicos) durante o intervalo de seguimento. Os estudos foram naturalísticos, não havendo controle dos pesquisadores sobre a exposição e tipo de medicação utilizada durante o intervalo entre os exames, o que dificulta a comparação entre os resultados. Enquanto alguns autores postulam um efeito protetor da medicação sobre o volume ventricular (DeLisi et al., 1997a; Lieberman et al., 2001; Cahn et al., 2002), outros correlacionaram uma redução progressiva de substância cinzenta cortical global (Cahn et al., 2002) ou de lobo frontal (Gur et al., 1998, Théberge et al., 2007) à exposição aos APs durante o intervalo de seguimento.

O único estudo longitudinal controlado para medicação, até o momento, foi publicado por Lieberman e colaboradores (2005), com resultados que sugerem que APs típicos (no 
caso, o haloperidol) podem ter efeito de redução de volume em córtex cerebral, enquanto um AP atípico (no caso, a olanzapina) não produziria esse efeito. Achado semelhante foi observado por van Haren et al. (2007 e 2008), em um estudo que sugere que a exposição à olanzapina ocasiona menor perda de substância cinzenta durante o seguimento.

Uma revisão recente sobre o efeito dos APs em estudos de RM sugere, em síntese, que o uso de APs típicos levaria a aumento do volume dos núcleos da base, redução de córtex frontal ou ausência de alteração cortical. Já a exposição a antipsicóticos atípicos não causaria aumento volumétrico de núcleos da base, mas teria esse efeito sobre o tálamo e o córtex cerebral (Scherk e Falkai, 2006).

Apesar das vantagens metodológicas em relação aos estudos transversais de RM e aos estudos longitudinais de TC, os resultados dos estudos longitudinais de RM até o momento são variáveis. Essa variabilidade pode ser causada pelos seguintes fatores: diferenças entre as amostras (o conceito de primeiro episódio não é definido estritamente, por exemplo, ou varia entre os estudos), diferenças na duração do período de seguimento, dificuldades para seguir amostras grandes e outras diferenças metodológicas (estudos investigando diferentes regiões do cérebro, por exemplo). 
Tabela 2 - Estudos volumétricos longitudinais por RM a partir do primeiro episódio psicótico em adultos

\begin{tabular}{|c|c|c|c|c|}
\hline Autores & $\begin{array}{l}\text { Amostra / } \\
\text { (intervalo) }\end{array}$ & $\begin{array}{l}\text { Método } \\
\text { (regiões) }\end{array}$ & $\begin{array}{c}\text { APs no } \\
\text { seguimento }\end{array}$ & Resultados longitudinais \\
\hline $\begin{array}{l}\text { DeLisi et } \\
\text { al.(1997a) }\end{array}$ & $\begin{array}{c}50 \text { pacientes } \\
20 \text { controles } \\
(4-5 \text { anos })\end{array}$ & $\begin{array}{c}\text { ROI } \\
\text { (hemisférios, } \\
\text { LT, GTS, } \\
\text { cerebelo, } \\
\text { CAH, CC, } \\
\text { VVLL) }\end{array}$ & $\begin{array}{c}\text { uso } \\
\text { contínuo=37 } \\
\text { sem uso=13 }\end{array}$ & $\begin{array}{l}\text { - pacientes: } \downarrow \text { hemisférios, } \\
\downarrow \text { istmo de corpo caloso, } \\
\downarrow \text { cerebelo direito e } \uparrow \text { VL esq. } \\
\text { - medicação contínua: menor } \\
\text { alteração em V V L L e } \\
\text { hipocampo dir. }\end{array}$ \\
\hline $\begin{array}{l}\text { DeLisi et } \\
\text { al.(2004) }\end{array}$ & $\begin{array}{l}26 \text { pacientes } \\
10 \text { controles } \\
(10 \text { anos })\end{array}$ & $\begin{array}{l}\text { ROI } \\
\text { (hemisférios } \\
\text { eVVLL) }\end{array}$ & $\begin{array}{l}\text { sem uso=6 } \\
\text { típicos }=7 \\
\text { atípicos }=13\end{array}$ & $\begin{array}{l}\text { - pacientes: mudança de } \\
\text { VVL L mais heterogênea } \\
\text { - melhor prognóstico nos } \\
\text { pacientes com } \uparrow V \text { V L L } \\
\text { - sem efeito de medicação }\end{array}$ \\
\hline $\begin{array}{l}\text { DeLisi et } \\
\text { al.(2005) }\end{array}$ & $\begin{array}{l}27 \text { pacientes } \\
10 \text { controles } \\
(10 \text { anos })\end{array}$ & $\begin{array}{c}\text { ROI } \\
\text { (LT, GTS) }\end{array}$ & $\begin{array}{c}\text { não } \\
\text { mencionado }\end{array}$ & $\begin{array}{l}\text { - sem diferença entre grupos } \\
\text { - sem correlações com } \\
\text { medidas de sintomas ou } \\
\text { prognóstico }\end{array}$ \\
\hline $\begin{array}{c}\text { Gur et } \\
\text { al.(1998) }\end{array}$ & $\begin{array}{l}20 \text { nunca } \\
\text { tratados } \\
20 \text { crônicos } \\
17 \text { controles } \\
\text { (30 meses) }\end{array}$ & $\begin{array}{c}\text { ROI } \\
\text { (VCT, LT, LF, } \\
\text { LCR) }\end{array}$ & $\begin{array}{l}\text { psicose inicial - } \\
\text { média de } 17 \\
\text { meses de uso } \\
\text { crônicos -média } \\
\text { de } 19 \text { meses de } \\
\text { uso }\end{array}$ & $\begin{array}{l}\text { - } \downarrow \text { LF esq. mais acentuada } \\
\text { nos pacientes } \\
\text { - } \downarrow \text { LT mais acentuada nos } \\
\text { controles; nunca tratados vs } \\
\text { crônicos: } \downarrow \text { LF e } \uparrow \text { LT } \\
\text { - dose de AP associada com } \downarrow \\
\text { LF e LT }\end{array}$ \\
\hline $\begin{array}{c}\text { Keshavan et } \\
\text { al. (1998) }\end{array}$ & $\begin{array}{c}15 \text { nunca } \\
\text { tratados } \\
12 \text { controles } \\
\text { (01 ano) }\end{array}$ & $\begin{array}{c}\text { ROI (GTS e } \\
\text { cerebelo) }\end{array}$ & sem uso=1 & $\begin{array}{l}\text { - } \uparrow \text { de GTS bilateral nos } \\
\text { pacientes (esquizofrenia), } \\
\text { mas não nos controles }\end{array}$ \\
\hline
\end{tabular}

continua 
Tabela 2 - Estudos volumétricos longitudinais por RM a partir do primeiro episódio psicótico em adultos (continuação)

\begin{tabular}{|c|c|c|c|c|}
\hline Autores & $\begin{array}{l}\text { Amostra / } \\
\text { (intervalo) }\end{array}$ & $\begin{array}{l}\text { Método } \\
\text { (regiões) }\end{array}$ & $\begin{array}{c}\text { APs no } \\
\text { seguimento }\end{array}$ & Resultados longitudinais \\
\hline $\begin{array}{l}\text { Lieber- } \\
\text { man et al. } \\
(2001)\end{array}$ & $\begin{array}{c}\text { córtex e } \\
\text { VVLL }=53 \\
\text { caudado }=37 \\
\text { hipocampo }=36 \\
13 \text { controles } \\
(6 \text { anos })\end{array}$ & $\begin{array}{l}\text { ROI(VcT, } \\
\text { caudado, } \\
\text { VV,VVLL, } \\
\text { hipocampo } \\
\text { anterior) }\end{array}$ & $\begin{array}{l}\text { exposição em } \\
75 \% \text { do tempo } \\
\text { (típicos) }\end{array}$ & $\begin{array}{l}\text { - } \uparrow \mathrm{VV} \text { e } \uparrow \text { hipocampo nos } \\
\text { pacientes de mau } \\
\text { prognóstico; } \downarrow \text { de hipocampo } \\
\text { nos controles } \\
\text { - } \uparrow \text { córtex em pacientes de } \\
\text { bom prognóstico; } \downarrow \text { nos } \\
\text { controles } \\
\text { - } \uparrow \text { caudado em ambos os } \\
\text { grupos de pacientes } \\
\text { - córtex, hipocampo e } \\
\text { caudado: sem associação com } \\
\text { duração de tratamento }\end{array}$ \\
\hline $\begin{array}{l}\text { Wood et al. } \\
\text { (2001) }\end{array}$ & $\begin{array}{l}30 \text { primeiro } \\
\text { episódio ( } 1.9 \\
\text { anos) } \\
12 \text { crônicos } \\
\text { (2.3 anos) } \\
26 \text { controles } \\
\text { (2.2 anos) }\end{array}$ & $\begin{array}{c}\text { ROI(LT, } \\
\text { VCT, VIC, } \\
\text { hipocam-po) }\end{array}$ & $\begin{array}{c}\text { primeiro } \\
\text { episódio: sem } \\
\text { uso= } 40 \% \\
\text { crônicos: } \\
\text { sem uso=17\% }\end{array}$ & $\begin{array}{l}\text { - hipocampo e LT } \downarrow \text { em } \\
\text { ambos os grupos de } \\
\text { pacientes em relação aos } \\
\text { controles transversalmente, } \\
\text { mas sem interação grupo x } \\
\text { tempo } \\
\text { - sem efeito de medicação }\end{array}$ \\
\hline $\begin{array}{l}\text { Puri et } \\
\text { al.(2001) }\end{array}$ & $\begin{array}{l}24 \text { pacientes } \\
12 \text { controles } \\
\text { (08 meses) }\end{array}$ & $\begin{array}{l}\text { ROI(VCT, } \\
\text { VVLL) }\end{array}$ & sem uso $=3$ & $\begin{array}{l}\text { - V V L L mais heterogêneos } \\
\text { nos pacientes, sem diferenças } \\
\text { nas médias }\end{array}$ \\
\hline $\begin{array}{l}\text { Cahn et al. } \\
\text { (2002) }\end{array}$ & $\begin{array}{l}34 \text { pacientes } \\
36 \text { controles } \\
\text { (01 ano) }\end{array}$ & $\begin{array}{c}\text { ROI (VCT / } \\
\text { SC / SB / } \\
\text { VVLL / } \\
\text { cerebelo) }\end{array}$ & em uso $=$ todos & $\begin{array}{l}\text { - pacientes: } \downarrow \text { VCT e } \downarrow \text { SC } \\
\text { global; }\end{array}$ \\
\hline
\end{tabular}

continua 
Tabela 2 - Estudos volumétricos longitudinais por RM a partir do primeiro episódio psicótico em adultos (continuação)

\begin{tabular}{|c|c|c|c|c|}
\hline Autores & $\begin{array}{l}\text { Amostra / } \\
\text { (intervalo) }\end{array}$ & $\begin{array}{l}\text { Método } \\
\text { (regiões) }\end{array}$ & $\begin{array}{c}\text { APs no } \\
\text { seguimento }\end{array}$ & Resultados longitudinais \\
\hline $\begin{array}{l}\text { Ho et al. } \\
\text { (2003) }\end{array}$ & $\begin{array}{c}73 \text { pacientes } \\
-1^{\circ} . \text { contato }= \\
41 \\
- \text { contato } \\
\text { prévio }=32 \\
23 \text { controles } \\
(3 \text { anos })\end{array}$ & $\begin{array}{c}\text { ROI(VCT, } \\
\text { VVLL,LF, } \\
\text { LTLP, } \\
\text { cerebelo, } \\
\text { volume } \\
\text { liquórico de } \\
\text { cada lobo) }\end{array}$ & $\begin{array}{c}\text { média de uso = } \\
83,5 \% \text { do } \\
\text { tempo } \\
\text { uso } \\
\text { contínuo=38 } \\
\text { clozapina=15 } \\
\text { a maioria } \\
\text { recebeu } \\
\text { atípicos } \\
\text { adesão } \\
\text { classificada } \\
\text { como boa. }\end{array}$ & $\begin{array}{l}\text { - pacientes: } \uparrow \text { volume de } \\
\text { líquor (no córtex e LF) e } \downarrow \text { LF } \\
\text { (SB) } \\
\text { - } \uparrow \text { V V L L nos pacientes de } \\
\text { mau vs bom prognóstico } \\
\text { - sintomas negativos } \\
\text { associados com SB e LCR do } \\
\text { FL } \\
\text {-sintomas positivos: sem } \\
\text { associações com LT } \\
\text {-sem efeitos de medicação } \\
\text { sobre quaisquer ROI }\end{array}$ \\
\hline $\begin{array}{l}\text { Kasai et al. } \\
\text { (2003a) } \\
(2003 \text { b) }\end{array}$ & $\begin{array}{c}13 \text { pacientes } \\
14 \text { controles } \\
(1,5 \text { ano })\end{array}$ & $\begin{array}{c}\text { ROI(GTS } \\
\text { anterior e } \\
\text { posterior; } \\
\text { CAH anterior } \\
\text { e posterior, } \\
\text { GHePT) }\end{array}$ & sem uso $=02$ & $\begin{array}{l}\text { - esquizofrenia: } \downarrow \text { de GTS } \\
\text { (SC), GH e PT } \\
\text { - sem associação com } \\
\text { medicação ou gravidade de } \\
\text { sintomas }\end{array}$ \\
\hline $\begin{array}{l}\text { Bachmann } \\
\text { et al. (2004) }\end{array}$ & $\begin{array}{c}14 \text { pacientes } \\
(13 \text { controles }= \\
\text { avaliados } \\
\text { apenas no t0) } \\
\text { (14 meses) }\end{array}$ & \begin{tabular}{|} 
ROI \\
(hemisférios, \\
LT e LF (SC e \\
SB), espaços \\
liquóricos e \\
VVLL)
\end{tabular} & $\begin{array}{c}\text { em uso=13 } \\
\text { (11 em remissão) }\end{array}$ & $\begin{array}{l}\text { - pacientes: } \downarrow \text { bilateral de LF } \\
\text { (SB) e } \downarrow \text { LT (SC) e } \uparrow \text { espaços } \\
\text { liquóricos }\end{array}$ \\
\hline
\end{tabular}

continua 
Tabela 2 - Estudos volumétricos longitudinais por RM a partir do primeiro episódio psicótico em adultos (continuação)

\begin{tabular}{|c|c|c|c|c|}
\hline Autores & $\begin{array}{l}\text { Amostra / } \\
\text { (intervalo) }\end{array}$ & $\begin{array}{l}\text { Método } \\
\text { (regiões) }\end{array}$ & $\begin{array}{c}\text { APs no } \\
\text { seguimento }\end{array}$ & Resultados longitudinais \\
\hline $\begin{array}{l}\text { Dickey et } \\
\text { al.(2004) }\end{array}$ & $\begin{array}{c}12 \text { pacientes } \\
15 \text { controles } \\
(1,5 \text { ano })\end{array}$ & $\begin{array}{l}\text { ROI (pré- } \\
\text { frontal) }\end{array}$ & em uso $=$ todos & $\begin{array}{l}\text {-sem diferenças longitudinais } \\
\text { (ambos os grupos com } \downarrow \text { de } \\
\text { volume ao longo do tempo) } \\
\text { - não avaliaram efeito da } \\
\text { medicação }\end{array}$ \\
\hline $\begin{array}{l}\text { Zipursky } \\
\text { et al.(2004) }\end{array}$ & $\begin{array}{c}10 \text { pacientes } \\
09 \text { controles } \\
(5 \text { anos })\end{array}$ & $\begin{array}{l}\text { ROI(VVLL, } \\
\text { SC global, } \\
\text { SB global, } \\
\text { LCR, e SC e } \\
\text { SB de cada } \\
\text { lobo) }\end{array}$ & em uso $=$ todos & $\begin{array}{l}\text {-sem diferenças } \\
\text { longitudinais entre os } \\
\text { grupos para nenhuma das } \\
\text { medidas }\end{array}$ \\
\hline $\begin{array}{c}\text { Whitworth et } \\
\text { al.(2005) }\end{array}$ & $\begin{array}{l}21 \text { primeiro } \\
\text { episódio } \\
17 \text { crônicos } \\
20 \text { controles } \\
\text { (2-4 anos) }\end{array}$ & $\begin{array}{l}\text { ROI } \\
\text { (hemisférios, } \\
\text { VCT, VVLL, } \\
\text { CAH) }\end{array}$ & $\begin{array}{l}\text { medicação } \\
\text { muito variável } \\
\text { e adesão não } \\
\text { investigada }\end{array}$ & $\begin{array}{l}\text { - sem interação grupo x tempo } \\
\text { - maior variabilidade de } \\
\text { alteração de VV nos } \\
\text { pacientes } \\
\text { - Sem correlações com tempo } \\
\text { de doença, PANSS, e } \\
\text { funcionamento }\end{array}$ \\
\hline
\end{tabular}

continua 
Tabela 2 - Estudos volumétricos longitudinais por RM a partir do primeiro episódio psicótico em adultos (continuação)

\begin{tabular}{|c|c|c|c|c|}
\hline Autores & $\begin{array}{l}\text { Amostra / } \\
\text { (intervalo) }\end{array}$ & $\begin{array}{l}\text { Método } \\
\text { (regiões) }\end{array}$ & $\begin{array}{c}\text { APs no } \\
\text { seguimento }\end{array}$ & Resultados longitudinais \\
\hline $\begin{array}{l}\text { Lieberman } \\
\text { et al. (2005) }\end{array}$ & $\begin{array}{l}\text { pacientes: } 161 \\
\text { ao início, } 34 \\
\text { ao final } \\
\text { (3 meses, } 6 \\
\text { meses, } 1 \text { ano e } \\
2 \text { anos) } \\
\text { controles: } \\
58 \text { ao início, } \\
44 \text { após } 1 \text { ano } \\
\text { (3 meses e } 1 \\
\text { ano) }\end{array}$ & $\begin{array}{c}\text { ROI } \\
\text { - VCT, SC } \\
\text { total, SB } \\
\text { total, líquor } \\
\text { total, V V LL, } \\
\text { caudado, SC } \\
\text { de cada lobo } \\
\text { exames } \\
\text { adquiridos } \\
\text { em } 8 \text { centros }\end{array}$ & $\begin{array}{c}\text { estudo } \\
\text { multicêntrico, } \\
\text { controlado, } \\
\text { randomizado, } \\
\text { duplo cego } \\
\text { início: } \\
\text { haloperidol=79 } \\
\text { olanzapina=82 } \\
\text { término: } \\
\text { haloperidol=10 } \\
\text { olanzapina=24 }\end{array}$ & $\begin{array}{l}\text { - grupos diferiam em sexo, } \\
\text { diagnóstico e duração da } \\
\text { doença } \\
\text { - haloperidol vs olanzapina: } \\
\text { - } \downarrow \text { SC total e em LF aos } 3 \text { e } 6 \\
\text { meses } \\
\text { - haloperidol vs controles: } \\
\text { - } \downarrow \text { SC total e de FL aos } 3 \\
\text { meses e } 1 \text { ano e } \downarrow \text { TL e LP } \\
\text { (SC) em } 1 \text { anos } \\
\text {-haloperidol: } \uparrow \text { caudado }\end{array}$ \\
\hline $\begin{array}{l}\text { Price et al. } \\
\text { (2006) }\end{array}$ & $\begin{array}{c}16 \text { pacientes } \\
12 \text { controles } \\
(3,7 \text { anos })\end{array}$ & $\begin{array}{c}\text { VBM- } \\
\text { análise } \\
\text { transversal } \\
\text { MTI - análise } \\
\text { longitudinal }\end{array}$ & $\begin{array}{c}\text { Em uso = } 12 \\
\text { Sem uso }=4(e m \\
\text { remissão } \\
\text { completa) }\end{array}$ & $\begin{array}{l}\text { - sem diferenças; não foi } \\
\text { analisado o efeito de } \\
\text { medicação e prognóstico } \\
\text { devido ao tamanho da } \\
\text { amostra }\end{array}$ \\
\hline $\begin{array}{l}\text { Théberge } \\
\text { et al. (2007) }\end{array}$ & $\begin{array}{l}16 \text { pacientes } \\
\text { nunca } \\
\text { tratados } \\
16 \text { controles } \\
\text { (30 meses) }\end{array}$ & VBM & $\begin{array}{c}\text { sem } \\
\text { medicação }=3\end{array}$ & $\begin{array}{l}\text { - pacientes: } \downarrow \text { STG e caudado } \\
\text { esq. }\end{array}$ \\
\hline $\begin{array}{l}\text { Nakamura } \\
\text { et al. (2007) }\end{array}$ & $\begin{array}{c}17 \text { pacientes } \\
26 \text { controles } \\
(1,5 \text { anos })\end{array}$ & $\begin{array}{c}\text { ROI(SC } \\
\text { neocortical } \\
\text { total e } \\
\text { lobares) }\end{array}$ & $\begin{array}{l}\text { sem medicação } \\
=4\end{array}$ & $\begin{array}{l}\text { - pacientes: } \downarrow \text { SC (LF e LT) } \\
\text { - } \downarrow \text { SC correlação com piora } \\
\text { de sintomas } \\
\text {-sem correlação com AP }\end{array}$ \\
\hline
\end{tabular}

continua 
Tabela 2 - Estudos volumétricos longitudinais por RM a partir do primeiro episódio psicótico em adultos

\begin{tabular}{|c|c|c|c|l|}
\hline Autores & $\begin{array}{c}\text { Amostra / } \\
\text { (intervalo) }\end{array}$ & $\begin{array}{c}\text { Método } \\
\text { (regiões) }\end{array}$ & $\begin{array}{c}\text { APs no } \\
\text { seguimento }\end{array}$ & Resultados longitudinais \\
\hline $\begin{array}{c}\text { van Haren } \\
\text { et al. (2007 e } \\
\text { 2008) }\end{array}$ & $\begin{array}{c}\text { 96 pacientes } \\
\text { (primeiro } \\
\text { episódio e } \\
\text { crônicos) } \\
113 \text { controles } \\
\text { (5 anos) }\end{array}$ & VBM & $\begin{array}{c}1 \text { paciente sem } \\
\text { AP }\end{array}$ & $\begin{array}{l}\text { - pacientes: } \downarrow \text { GFS e GTS esq, } \\
\text { caudado e tálamo dir. } \\
\text { - exposição cumulativa de } \\
\text { olanzapina: menor } \downarrow \text { redução } \\
\text { de SC } \\
\text { - pacientes: maior } \downarrow \text { de SC e } \uparrow \\
\text { V V do que controles ocorre } \\
\text { nos primeiros 20 anos de } \\
\text { doença }\end{array}$ \\
\hline
\end{tabular}

LEGENDA: AP, antipsicótico; CAH, complexo amígdala-hipocampo; CC, corpo caloso; dir, direito(a); esq., esquerdo(a); GFS, giro frontal superior; GH, giro de Heschl; GTS, giro temporal superior; LCR, líquido cefalorraquidiano; LF, lobo frontal; LO, lobo occipital; LP, lobo parietal; LT, lobo temporal; MTI, magnetization transfer imaging; PANSS, Positive and negative syndrome scale; PT, "planum temporale”; ROI, região de interesse (region of interest); SB, substância branca; SC, substância cinzenta; VBM, morfometria voxel-a-voxel; VCT, volume cerebral total; VcT, volume cortical total; VIC, volume intracraniano; VV, volume ventricular; VVLL, ventrículos laterais; vs, versus; $\uparrow$ aumento ou maior; $\downarrow$ redução ou menor.

\subsubsection{Implicações dos estudos neuroanatômicos para a investigação da etiopatogenia da esquizofrenia}

Nos anos de 1980 e início dos anos de 1990, a hipótese mais aceita e prevalente para a etiopatogenia da esquizofrenia baseava-se na presença de alterações precoces do neurodesenvolvimento (revisão de DeLisi, 2008). A patologia da esquizofrenia teria origem no segundo trimestre da gestação, e não antes, uma vez que alterações em período anterior 
afetariam a neurogênese e causariam anormalidades de conteúdo celular e de estrutura cortical mais graves e explícitas. Por outro lado, a suposta ausência de gliose dá suporte à hipótese de que a patologia ocorreria antes do terceiro trimestre de gestação (Harrison, 1999).

As evidências tidas como os pontos-chave que dão suporte à noção de patologia de neurodesenvolvimento precoce em esquizofrenia são:

- alterações ventriculares e de redução cortical presentes no início da psicose, se não antes; presença e natureza de alterações de citoarquitetura, ausência de gliose e outros padrões neurodegenerativos (Harrison, 1999); aumento de prevalência de “cavum septum pellucidum” (Shiori et al.,1996, Kwon et al.,1998); evidências de fatores de risco ambientais precoces para esquizofrenia, sendo, em sua maioria, obstétricos (Geddes e Lawrie, 1995); presença de déficits neuromotores, comportamentais e intelectuais em crianças antes de desenvolverem esquizofrenia (Jones, 1997); e aumento da prevalência de dermatóglifos anormais e anomalias físicas menores (Buckley, 1998) em pacientes com esquizofrenia.

A partir dos anos 1990, a hipótese do neurodesenvolvimento como base dos processos patológicos na esquizofrenia começou a ser questionada e voltou-se a discutir a hipótese de neurodegeneração ou progressão de anormalidades em esquizofrenia, tendo início, nesse período, as pesquisas com estudos longitudinais de neuroimagem nessa área (DeLisi, 2008), conforme descrito acima. De fato, a esquizofrenia foi entendida como transtorno progressivo ou degenerativo desde a conceituação inicial de Kraepelin (1919), que considerava a deterioração clínica progressiva uma característica marcante da doença. Mais tarde, outros autores novamente enfatizaram que o declínio funcional na esquizofrenia seria uma pista importante para sua patogênese, e postularam que as anormalidades cerebrais poderiam progredir ao longo da doença, refletindo sua evolução clínica (Woods, 1998; Lieberman et al., 1999). Levando em conta esta noção, outras versões recentes da teoria do neurodesenvolvimento para a esquizofrenia sugerem a ação de processos patológicos progressivos adicionais ou alternativos envolvendo adesão celular, alterações de mielinização 
e de poda sináptica (Keshavan et al., 1994b; Lewis, 1997; Keshavan, 1999), ou mesmo processos de apoptose celular (Glantz et al., 2006).

As alterações de sinapses no hipocampo e no córtex pré-frontal dão suporte à hipótese de poda sináptica excessiva (Keshavan et al., 1994b). Além disso, o achado de ausência de gliose é um argumento a favor da teoria do neurodesenvolvimento, mas não exclui outros processos patológicos. O mesmo argumento se aplica aos achados de alterações de citoarquitetura (alteração de migração), as quais não são inequívocas na histopatologia da esquizofrenia. Ao contrário, as alterações de volume de neurônios e sinapses são compatíveis com processos patológicos de origem mais tardia e suscetíveis a fatores ambientais, envelhecimento e fatores genéticos (Harrison, 1999).

Uma vez que os achados de pesquisa podem fornecer indicações favoráveis a mais de um processo patológico, ao invés de dar suporte para uma teoria exclusiva, há, atualmente, uma tendência em direção a uma hipótese unificadora em esquizofrenia (DeLisi, 1997b; Waddington et al., 1998; Woods, 1998; Keshavan, 1999; Tsuang et al., 2001). Um modelo unificador englobaria: a) alterações de neurodesenvolvimento pré ou perinatais, b) anormalidades em processos tardios de desenvolvimento, como mielinização e poda sináptica e c) alterações possivelmente progressivas após o período inicial da doença.

Ou seja, haveria um processo patogênico ativo antes do início clínico da doença, caracterizando a esquizofrenia como um transtorno de neurodesenvolvimento precoce, mas haveria também uma progressão de alterações cerebrais de forma particularmente pronunciada nos primeiros anos da doença. Um aspecto importante desta hipótese integrativa é o potencial para intervenções terapêuticas que interromperiam o processo da doença em seus estágios iniciais. Pesquisas recentes demonstram que o primeiro episódio de esquizofrenia é uma oportunidade terapêutica crítica. Com o tratamento precoce, um melhor prognóstico pode ser atingido (McGlashan, 1999; Harrigan et al., 2003). 
Os estudos de RM revisados acima indicam fortemente a existência de alterações estruturais cerebrais no início da esquizofrenia, e que algumas destas alterações podem ser progressivas. No entanto, é importante ressaltar que estes estudos não são de base epidemiológica e a maioria empregou amostras pequenas. É importante notar, também, que a maioria dos estudos de neuroimagem de RM descritos nos itens anteriores foi baseada no método de ROI, geralmente empregando medidas globais ou de grandes volumes, diferentes áreas cerebrais (analisadas por delineação manual de bordas anatômicas relativamente arbitrárias) com variações nos critérios usados pelos diferentes estudos. 
O primeiro objetivo do estudo é o de avaliar, através de RM estrutural e método de VBM, a presença de alterações volumétricas de substância cinzenta em primeiro episódio psicótico em pacientes de uma área delimitada da cidade de São Paulo comparados a controles não psicóticos.

O segundo objetivo do estudo é investigar o padrão de evolução de volume de substância cinzenta em ambos os grupos após o período médio de 01 ano de seguimento.

\subsection{Hipóteses}

Pacientes em primeiro episódio psicótico apresentarão diferenças de volume de substância cinzenta em relação aos controles em regiões tais como: córtex pré-frontal, córtex temporal lateral, região temporal medial (hipocampo e giro parahipocampal), ínsula e tálamo. 
Com base nas características de metodologia e amostra, espera-se observar reduções longitudinais de volume de substância cinzenta em pacientes em relação aos controles em áreas descritas na literatura como prováveis regiões de progressão em esquizofrenia (córtex pré-frontal e temporal lateral), e espera-se encontrar preservação de estruturas temporais mediais (hipocampo, amígdala, giro parahipocampal).

Espera-se encontrar diferenças longitudinais de volume de substância cinzenta entre pacientes relacionadas à exposição a antipsicóticos: pacientes expostos a antipsicóticos típicos apresentarão aumento de volume de núcleos da base em comparação aos controles, aos pacientes expostos a antipsicóticos atípicos e aos pacientes não aderentes ao tratamento medicamentoso. Espera-se, também, que pacientes expostos a antipsicóticos atípicos tenham padrão de preservação de volumes corticais quando comparados aos pacientes expostos aos antipsicóticos típicos. 


\section{MÉTOdOS}

Este trabalho foi conduzido no Laboratório de Neuroimagem em Psiquiatria (Laboratório de Investigação Médica - LIM 21) do Hospital das Clínicas da Faculdade de Medicina da Universidade de São Paulo, coordenado pelo Professor Geraldo Busatto Filho. Foi aprovado pelas Comissões de Ética do Hospital das Clínicas da Faculdade de Medicina da Universidade de São Paulo e todos os pacientes ou responsáveis legais assinaram o Termo de Consentimento após terem sido amplamente informados a respeito das características do estudo.

A autora desta tese executou o recrutamento dos voluntários para os exames de RM (a partir da amostra do estudo epidemiológico no qual este módulo de neuroimagem está inserido) e conduziu a avaliação dos participantes nos dias dos exames (entrevista psiquiátrica e aplicação dos outros instrumentos, como escalas). Acompanhou os técnicos na aquisição dos dados de RM e participou do pré-processamento das imagens utilizando o programa computacional SPM. Por fim, a autora organizou o banco de dados e processou a análise estatística dos mesmos e executou as análises das imagens por VBM. 


\subsection{Amostra}

\subsubsection{Amostra do estudo epidemiológico}

A amostra desta tese foi recrutada a partir de um estudo epidemiológico do tipo casocontrole intitulado: "Estudo de Casos Incidentes (primeiro contato com serviços de saúde) de Psicoses Funcionais no Brasil”, financiado pelo Wellcome Trust, do Reino Unido e conduzido pelos Departamentos de Medicina Preventiva e de Psiquiatria da Faculdade de Medicina da Universidade de São Paulo, sob a coordenação dos professores Paulo R. Menezes, Márcia Scazufca e Geraldo Busattto Filho, em colaboração com os Profs. Robin M. Murray e Philip K. McGuire, do Instituto de Psiquiatria de Londres, Reino Unido. Esse estudo teve início em 2002 e objetivou avaliar a incidência de psicoses funcionais na cidade de São Paulo, assim como aspectos clínicos, biológicos e fatores de risco associados ao primeiro surto psicótico, além do uso de serviços de saúde e sobrecarga em cuidadores.

Esse estudo teve continuidade em uma fase de seguimento após cerca de um ano (“Seguimento de pacientes portadores de psicoses funcionais um ano após o primeiro contato com serviços de saúde: prognóstico, aspectos de neuroimagem, uso de serviços e sobrecarga em cuidadores informais”), com financiamento da FAPESP, processo 2003/13627-0, e duração de 2003 a 2006.

O procedimento de rastreamento de casos consistia na busca ativa em serviços que poderiam ser procurados por pacientes em crise psicótica aguda, como leitos de psiquiatria, emergências psiquiátricas e ambulatórios de Saúde Mental numa área pré-definida da cidade de São Paulo, com 900.000 habitantes (abrangendo os distritos de Alto de Pinheiros, Butantã, Lapa, Pinheiros, Casa Verde, Mandaqui, Santana, Bela Vista, Consolação e Santa Cecília). Sujeitos com idade entre 18 e 65 anos, que houvessem procurado serviço médico pela primeira vez por sintomas psicóticos eram incluídos no estudo. Os pacientes eram avaliados pela Entrevista Clínica Estruturada para o DSM-IV, transtornos do eixo I (Structured Clini- 
cal Interview for DSM - axis I disorders, SCID, First et al., 1995) e incluídos no estudo ao preencherem critérios diagnósticos para transtornos psicóticos de acordo com o DSM-IV, códigos de 295 a 298: esquizofrenia, transtorno esquizofreniforme, transtorno esquizoafetivo, transtorno afetivo bipolar, transtorno depressivo maior (episódio psicótico), transtorno delirante persistente, transtorno psicótico compartilhado, transtorno psicótico breve e transtorno psicótico sem outra especificação.

Nesse estudo epidemiológico, após a inclusão de cada paciente, iniciava-se também a identificação de 2 vizinhos próximos, não-psicóticos, a serem incluídos como controles, emparelhados em relação aos pacientes por sexo, faixa etária (distribuição por faixas de 5 anos) e local de moradia. Os possíveis controles eram excluídos caso apresentassem história pessoal atual ou pregressa de transtorno psicótico, investigada pelo Psychosis Screening Questionnaire (Bebbington e Nayani, 1995). Assim, cada paciente e seus respectivos controles eram moradores da mesma região da cidade, o que contribui para a semelhança do perfil sócio-demográfico e de exposição a fatores de proteção ou risco para doenças mentais.

Ao final da coleta, conforme os procedimentos descritos acima, foram incluídos no estudo epidemiológico 200 pacientes e 400 controles. O programa de pesquisa em neuroimagem associado a este estudo epidemiológico envolveu o recrutamento e exames de RM dos sujeitos de todas as categorias diagnósticas de transtornos psicóticos (Schaufelberger et al., 2007). De acordo com o tema definido para a presente tese, são descritos aqui os procedimentos relacionados especificamente ao subgrupo de pacientes com esquizofrenia e transtorno esquizofreniforme.

\subsubsection{Amostra do estudo transversal de neuroimagem}

A partir da amostra do estudo epidemiológico descrito acima, foi recrutada a amostra de pacientes (com diagnóstico de esquizofrenia ou transtorno esquizofreniforme) e controles 
para o presente estudo de neuroimagem. A seguir, os critérios de inclusão e exclusão para este estudo.

\section{Pacientes}

Critérios de inclusão:

- idade entre 18 e 50 anos.

-sexo masculino ou feminino.

Critérios de exclusão:

- psicoses induzidas por substâncias psicoativas ou psicoses secundárias a condições médicas gerais.

- contra-indicações para o exame de RM (gestação, presença de marcapasso, clipes de aneurisma cerebral, implantes cocleares, fragmentos de metal oculares, próteses ou implantes de metal recentes) ou incapacidade de tolerar o exame (história de claustrofobia).

- doença neurológica (exemplo: epilepsia) ou condição médica geral que pudesse afetar o SNC (exemplo: Síndrome da Imunodeficiência Adquirida), história de traumatismo crânioencefálico (TCE) grave (com perda de consciência ou seqüelas neurocognitivas).

- achados de lesão anatômica grosseira no exame de RM.

O convite para os sujeitos participarem da investigação de RM era feito de maneira contínua, paralelamente à inclusão dos mesmos no estudo epidemiológico acima e logo após a avaliação clínica inicial ser completada, de acordo com os critérios descritos. No caso de pacientes que ainda estivessem internados ou ainda não estivessem em condições clínicas de serem submetidos ao exame, contatos regulares eram feitos com a família e o paciente era novamente convidado para participar quando possível.

Pacientes rastreados nos mesmos serviços de saúde e que preenchessem todos os critérios de inclusão para o estudo epidemiológico, com exceção do local de moradia, eram também convidados a participar do estudo de RM. 


\section{Controles:}

A seleção dos controles seguia os mesmos critérios aplicados aos pacientes, com o acréscimo dos seguintes critérios de exclusão: história pessoal de transtorno de humor e uso atual de medicação psicotrópica.

Como houve situações em que os dois controles de um determinado paciente recusaramse a participar do estudo de imagem, preencheram critérios de exclusão ou não foram localizados, não foi possível fazer um emparelhamento caso-controle individual. Convocamos então, todos os controles que preenchessem os critérios de inclusão e aceitassem participar do estudo, de maneira contínua, e o emparelhamento ocorreu entre os grupos, mas não individualmente.

\subsubsection{Amostra do estudo longitudinal de neuroimagem}

Todos os sujeitos submetidos ao exame de RM inicial e que foram localizados após o intervalo de seguimento, foram convidados a participar de uma segunda avaliação de neuroimagem, cerca de um ano após a aquisição dos dados iniciais. Os mesmos critérios de inclusão e exclusão aplicados para o estudo transversal foram respeitados, de forma que sujeitos que apresentassem, durante o período de seguimento, contra-indicações para RM (por exemplo, gravidez) não seriam submetidos ao novo exame. Esta tese empregou os pacientes que preenchessem critérios para esquizofrenia e transtorno esquizofreniforme.

A convocação dos sujeitos do grupo controle para o exame de seguimento fez-se necessária para que pudéssemos diferenciar entre mudanças patológicas de estrutura cerebral e alterações longitudinais fisiológicas, compatíveis com processo de maturação normal. 


\subsection{Procedimentos de AVAliação CLínica}

\subsubsection{Exame inicial}

Tanto para o grupo de pacientes como para o de controles, foram aplicados os seguintes instrumentos de avaliação:

a) Entrevista Clínica Estruturada para o DSM-IV - transtornos do eixo I (SCID) (First et al., 1995). Esse instrumento foi utilizado, no caso dos pacientes, para confirmar o diagnóstico de psicose funcional de acordo com os critérios do DSM-IV e para excluir a presença de quadros psicóticos secundários ao uso de substâncias ou condições médicas gerais. No caso dos controles, foi empregado para avaliar a presença de outros diagnósticos psiquiátricos, uma vez que apenas a presença de psicose era considerada critério de exclusão inicial. Também foi utilizado para investigar o diagnóstico de abuso ou dependência de substâncias em ambos os grupos.

b) Questionário de lateralidade cerebral (Annett, 1970), a fim de se avaliar dominância hemisférica motora.

c) Questionário sócio-econômico (ABIPEME, 1989), utilizado para classificação sócioeconômica dos sujeitos, baseada em escolaridade do chefe da família e poder de compra. Classifica o nível sócio-econômico em classes A, B, C, D ou E.

d) Entrevista com os sujeitos (e sempre que possível, com familiares) para obtenção de registro de dados sócio-demográficos e clínicos (doenças médicas gerais, uso de substâncias psicoativas, história de TCE, antecedentes familiares, renda mensal).

Alguns instrumentos foram aplicados apenas para o grupo de pacientes:

e) Registro de informações sobre uso de psicofármacos, adesão ao tratamento, duração da psicose não tratada (informação colhida com os pacientes e familiares e em alguns casos, também através de prontuários médicos). 
f) Escala das síndromes positiva e negativa - Positive and negative syndrome scale (PANSS) (Kay et al., 1987), utilizada para mensurar a gravidade dos sintomas psicóticos.

\subsubsection{Exame de seguimento}

Os sujeitos foram reavaliados com os mesmos instrumentos descritos acima para obtenção de dados sócio-econômicos e clínicos ao segundo exame de RM. A entrevista clínica estruturada (SCID) foi reaplicada com a finalidade de confirmação diagnóstica do tipo de transtorno psicótico nos pacientes e para investigação do diagnóstico de abuso e dependência de substâncias psicoativas no último ano em ambos os grupos.

Dessa maneira, para as comparações do seguimento desta tese, foram incluídos todos os sujeitos que tiveram, nesta reavaliação, confirmação do diagnóstico de esquizofrenia ou transtorno esquizofreniforme.

\subsection{EXAME DE NEUROIMAGEM}

\subsubsection{Aquisição das imagens de RM}

As imagens de RM estrutural foram adquiridas na Divisão de Diagnóstico por Imagem do Instituto do Coração (InCor) do Hospital das Clínicas da Faculdade de Medicina da Universidade de São Paulo no período de agosto de 2002 a janeiro de 2004. A partir desta data, as imagens passaram a ser adquiridas no serviço de Ressonância Magnética do Instituto de Radiologia (InRad), da mesma instituição. Em ambos os centros, foi utilizado o mesmo tipo de aparelho de RM (GE Signa 1.5 Tesla, General Electric, Milwaukee, WI, EUA).

A aquisição dos exames de RM iniciais compreendeu o período de agosto de 2002 a setembro de 2005 e a aquisição das imagens de seguimento ocorreu de agosto de 2003 a setembro de 2006. 
O mesmo protocolo de aquisição das imagens foi utilizado em todos os exames. A imagem a ser utilizada no estudo de VBM consistia numa seqüência volumétrica Spoiled Gradient Recalled Acquisition (SPGR) ponderada em T1, com os seguintes parâmetros: aquisição no plano axial, tempo de eco=5,2 ms, tempo de repetição=21,7 ms, ângulo de inclinação $($ flip angle $)=20^{\circ}$, campo de visão (field of view, FOV) $=22 \mathrm{~cm}$, espessura de corte $=1,5 \mathrm{~mm}$ sem intervalos, número de medidas (number of excitations, NEX) $=01$, tamanho da matriz=256 x 192, com 124 imagens englobando todo o encéfalo. O protocolo incluía também uma seqüência axial ponderada em T2 (fast spin echo, FSE) com 88 imagens. Essa seqüência foi avaliada pelos neurorradiologistas da equipe dos serviços de RM (cegos para o diagnóstico psiquiátrico), com o objetivo de identificar a presença de lesões anatômicas indicativas de patologias neurológicas.

\subsubsection{Processamento das imagens de $\mathrm{RM}$}

\subsubsection{Etapa de pré-processamento das imagens de $\mathrm{RM}$ e criação de template}

Realizamos a análise das imagens utilizando a seqüência T1 (SPGR), que apresenta contraste superior entre substância branca e cinzenta, com imagens englobando todo o encéfalo.

O processamento e análise das imagens foram conduzidas num computador Pentium IV, utilizando o método automático de VBM para imagens cerebrais através do programa SPM na versão 2 (SPM2) (Wellcome Department of Imaging Neuroscience, Reino Unido, www.fil.ion.ucl.ac.uk/spm), que funciona sobre a base do programa MATLAB (Mathworks Inc, Sherborn, MA, EUA).

Inicialmente, as imagens de todos os sujeitos foram submetidas às etapas iniciais de pré-processamento, envolvendo os seguintes passos:

a) conversão das imagens SPGR originais do formato DICOM para o formato Analyze. 
b) avaliação qualitativa individual de todas as imagens, com o propósito de checagem de qualidade e investigação da presença de artefatos de aquisição ou de movimento.

c) posicionamento das imagens, incluindo reorientação, realinhamento e mudança para convenção neurológica (lado esquerdo da imagem = lado esquerdo do encéfalo).

d) localização da comissura anterior, ponto de referência para que as imagens sejam posicionadas em um espaço anatômico padronizado. Assim, o ponto da comissura anterior é considerado como 0,0,0 no sistema de coordenadas x, y, z (em milímetros) do Atlas anatômico de Talairach e Tournoux (1988).

Após as etapas de pré-processamento descritas acima, realizou-se a construção de templates (termo utilizado com sentido de fôrma ou molde) específicas para cada uma das duas etapas deste estudo (análise transversal e longitudinal). A criação de templates específicas para o estudo, com o uso das imagens dos próprios sujeitos da amostra, é necessária para que as imagens do estudo não precisem sofrer grandes deformações espaciais durante a normalização espacial das mesmas (Good et al., 2001).

A template construída para análise do estudo transversal foi baseada nas imagens de todos os sujeitos que foram submetidos à RM inicial com diagnóstico de psicoses funcionais ( $\mathrm{n}=122)$ e de todos os controles (n=94). A inclusão do máximo de indivíduos estudados com o mesmo protocolo de aquisição de imagens teve como objetivos tornar a template o mais próxima possível da imagem média da população a partir da qual foram selecionados os sujeitos para esta tese, bem como minimizar diferenças entre os dados adquiridos nos dois equipamentos.

Para o estudo de seguimento, uma nova template foi criada usando as imagens inicias e finais de todos os sujeitos pertencentes ao estudo longitudinal.

Para a criação de cada template, as imagens originais dos sujeitos das respectivas amostras foram, inicialmente, normalizadas espacialmente sobre a template padrão ponderada em T1 presente no SPM (a qual é baseada em imagens de 152 sujeitos saudáveis e 
disponibilizada no SPM pelo Montreal Neurological Institute, MNI). Esta normalização espacial foi restrita a transformações lineares (12 parâmetros) a fim de minimizar as deformações nas imagens originais. As imagens normalizadas foram, em seguida, segmentadas em substâncias cinzenta, branca e líquor e, posteriormente, suavizadas com um filtro isotrópico (8 mm FWHM), a fim gerar templates específicas de cada compartimento.

A template final de substância cinzenta, obtida a partir das imagens originais normalizadas, segmentadas e suavizadas, foi utilizada como fôrma nos passos seguintes do processamento propriamente dito.

\subsubsection{Etapa de processamento das imagens originais utilizando a tem- plate criada para o estudo (VBM otimizado)}

Após a construção da template, o processamento final das imagens originais de cada sujeito foi realizado usando o método VBM de acordo com os parâmetros otimizados descritos por Good e colaboradores (2001), que inclui os seguintes passos (Figura 1):

a) segmentação e normalização espacial da substância cinzenta sobre a respectiva template customizada, através de transformações lineares (12 parâmetros) e não lineares (7x9x7 basis functions). Os parâmetros resultantes da normalização foram, então, reaplicados às imagens originais, durante um novo processo de normalização espacial.

b) segunda segmentação das imagens: as imagens normalizadas na etapa anterior passaram a ter voxels de tamanho padrão de 2x2x2 mm $\mathrm{mm}^{3}$ foram segmentadas em substâncias cinzenta, branca e líquor. Os voxels foram modulados pelos determinantes Jacobianos extraídos do processo de normalização espacial. Esse processo de modulação permite que se corrija proporcionalmente o grau de alteração de volume que as estruturas encefálicas sofreram durante o processo de normalização espacial (Good et al., 2001). Conseqüentemente, a análise estatística feita sobre as imagens moduladas avalia diferenças regionais de volume absoluto, em vez de diferenças na concentração de substância cinzenta. 
c) suavização: as imagens de substância cinzenta, já normalizadas e moduladas, foram suavizadas com um filtro Gaussiano de $12 \mathrm{~mm}$. Este processo remove variações anatômicas inter-individuais sutis de giros e sulcos, diminuindo a resolução espacial da imagem e “espalhando” a intensidade do sinal de forma uniforme, fazendo com que a distribuição da intensidade dos voxels seja mais próxima da distribuição normal.

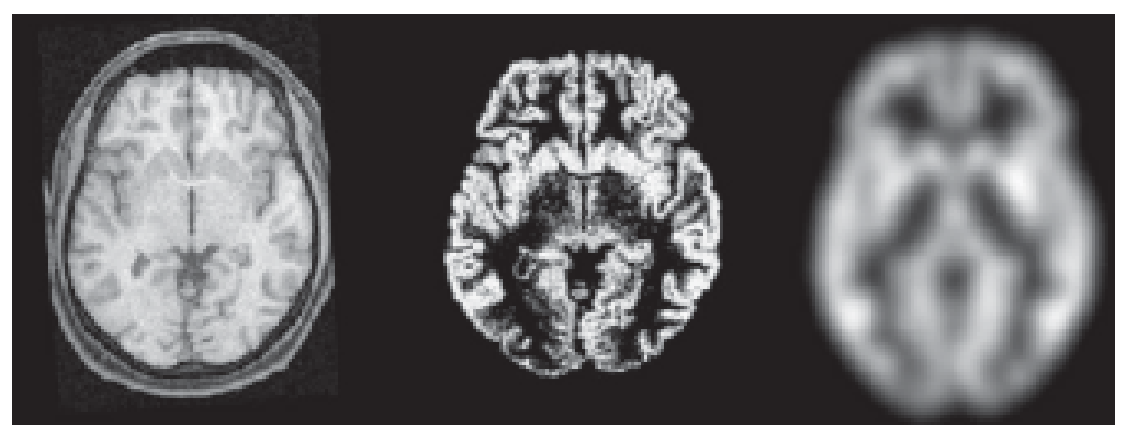

Figura 1 - Seqüência de processamento das imagens por VBM

Exemplo de algumas das etapas do processamento das imagens de RM estrutural através do programa SPM. Corte axial. Da esquerda para a direita: imagem original, imagem segmentada (substância cinzenta) e imagem de substância cinzenta já normalizada, segmentada e suavizada.

\subsubsection{Confiabilidade entre as imagens adquiridas nos dois aparelhos de $\mathbf{R M}$}

Uma vez que as imagens foram adquiridas em dois aparelhos de RM, ainda que similares, conduzimos um estudo de confiabilidade, usando o mesmo procedimento de VBM no SPM2. Seis voluntários saudáveis, não participantes da amostra do estudo, foram examinados num mesmo dia, nos dois aparelhos. Essas 12 imagens foram normalizadas espacialmente e segmentadas usando o mesmo protocolo de VBM descrito acima, e os segmentos de substância cinzenta dos dois grupos (aparelho 1 versus aparelho 2) foram comparados entre si.

Os coeficientes de correlação intraclasse (CCIs), baseados na estimativa regional de cada imagem individual, foram obtidos para as regiões neocorticais (frontal, temporal, parietal 
e occipital), estruturas temporais mediais (hipocampo, amígdala e giro parahipocampal) e núcleos subcorticais (caudado, putâmen e tálamo). Essas regiões foram circunscritas, em cada imagem, com o uso dos volumes de interesse normalizados espacialmente que estão disponíveis na ferramenta Automatic Anatomic Label (AAL) do SPM. Estimativas de substância cinzenta foram obtidas através da média de valores de intensidade dos voxels presentes em cada volume de interesse e calculadas com o auxílio do programa MRIcro (www.sph.sc.edu/comd/rorden/mricro/html). Os valores de CCI foram maiores que 0,90 para todas as regiões neocorticais e para a região temporal medial. No caso dos núcleos subcorticais, os valores de CCI foram 0,79 e 0,83 para o tálamo, 0,65 e 0,78 para o caudado e 0,23 e 0,35 para o putâmen (valores à esquerda e à direita, respectivamente).

Com base nesse padrão de resultados de confiabilidade, nós restringimos nossa análise de VBM para a investigação de diferenças entre grupos localizadas nas regiões corticais e nas estruturas temporais mediais.

Ao término destas etapas de processamento, conduzimos a análise estatística.

\subsection{ANÁLISE DOS DAdos}

\subsubsection{Análise dos dados clínicos}

A análise estatística dos dados demográficos e clínicos foi processada pelo Statistical Package for the Social Sciences, SPSS, versão 10 (SPSS Inc., Chicago, IL). Para as análises dos dados da avaliação inicial dos sujeitos, foram usados o teste t para amostras independentes no caso de comparações de variáveis contínuas com distribuição normal e o teste de Mann-Whitney para comparações de variáveis contínuas sem distribuição normal. Para as variáveis categóricas foi utilizado o qui-quadrado ou o teste exato de Fisher. Na avaliação longitudinal dos dados demográficos e clínicos, foram utilizados o teste t pareado (para variáveis contínuas com distribuição normal) e o teste de análise de variância (ANOVA) 
não paramétrica para dados ordinais repetidos quando a mesma não seguia a distribuição normal. O nível de significância adotado para a análise dos dados demográficos e clínicos foi de $5 \%(\mathrm{p}<0,05)$.

\subsubsection{Análise das imagens de RM - morfometria voxel-a-voxel (VBM)}

\section{- Estudo transversal}

Comparamos as imagens de RM inicial entre grupos (análise de covariância, ANCOVA, com o valor total de voxels de substância cinzenta introduzido no modelo como covariável). Foram comparados pacientes versus controles e pacientes em uso de medicação versus pacientes sem uso de medicação.

Também foram conduzidas análises de correlações entre variáveis clínicas medidas ao exame inicial (tais como gravidade de sintomas psicóticos, tempo de exposição a antipsicóticos, tempo de doença, duração da psicose não tratada) e os volumes regionais de substância cinzenta dos pacientes.

\section{- Estudo longitudinal}

Esta segunda análise testou a hipótese de diferença no grau de alteração longitudinal de volume de substância cinzenta entre grupos. Foram comparados pacientes versus controles, pacientes aderentes ao tratamento com antipsicóticos (APs) durante o seguimento versus pacientes não aderentes e finalmente, comparamos pacientes expostos a APs típicos versus pacientes expostos a atípicos.

Inicialmente, conduzimos uma ANCOVA para medidas repetidas (2x2) com o grupo e o tempo como fatores. Nesta ANCOVA, a comparação entre os grupos em relação à progressão do volume de substância cinzenta foi investigada em mapas mostrando os valores para a interação entre o grupo e o tempo. Além disso, a fim de investigarmos as diferenças entre as imagens obtidas em cada momento para cada grupo separadamente, foram calculados testes t pareados para o grupo de pacientes e para o grupo controle. 
O valor total de voxels de substância cinzenta foi introduzido como covariável em todas as análises, e o fator gênero foi incluído como covariável quando essa característica mostrava-se significativamente diferente entre os grupos examinados.

Em ambas as análises (estudo transversal e longitudinal), as diferenças regionais de substância cinzenta foram investigadas voxel-a-voxel em todo o encéfalo, com o uso do General Linear Model. Os valores estatísticos resultantes para cada voxel foram transformados em escores Z e apresentados como mapas paramétricos estatísticos (os chamados statistical parametric maps ou SPMs) dispostos num espaço anatômico padrão (sistema de coordenadas anatômicas de Talairach), a um nível de significância estatística de $\mathrm{p}<0,001$ (correspondente a um limiar de Z $>3,09$ ). Apenas voxels com valores acima de um limiar absoluto de 0,05 para substância cinzenta foram incluídos na análise.

Inicialmente, os mapas estatísticos gerados para cada análise foram inspecionados de modo exploratório, em todo o segmento de substância cinzenta. Apenas resultados com significância estatística de $\mathrm{p}<0,05$ que sobreviveram à correção para comparações múltiplas (family wise error estimate correction, FWE) para todo o encéfalo foram considerados estatisticamente significativos.

Em seguida, com o propósito de restringirmos as comparações para voxels presentes em regiões específicas, utilizamos a ferramenta SVC do SPM2. As regiões foram escolhidas com base em hipóteses “a priori” por serem comumente implicadas na patologia da esquizofrenia (córtex frontal, córtex temporal superior, região hipocampal e ínsula, todos bilaterais). Essas regiões foram circunscritas aplicando-se volumes espacialmente normalizados sobre o SPM, baseados nos volumes anatômicos de interesse disponíveis através da ferramenta AAL do SPM2.

No estudo transversal, os volumes do AAL predefinidos para as regiões pré-frontal dorsolateral, órbito-frontal e cíngulo anterior foram combinados em um único volume de interesse, já que em esquizofrenia, as várias sub-regiões frontais, de ambos os hemisférios 
são descritas como afetadas em diferentes estudos. Por outro lado, como no estudo de seguimento a investigação dos volumes regionais pôde ser feita com base nos achados da avaliação inicial, pudemos reduzir os volumes de interesse da região frontal. Dessa maneira, no estudo de seguimento utilizamos volumes de interesse separados para córtex frontal esquerdo e córtex frontal direito e excluímos o volume do cíngulo anterior. De forma semelhante, à análise transversal a região temporal medial de cada hemisfério foi avaliada como um volume de interesse englobando o hipocampo e o giro parahipocampal e à análise longitudinal essas estruturas foram avaliadas separadamente.

O nível de significância estatística estabelecido para essa análise com uso de SVC foi de $\mathrm{p}<0,05$, corrigido para comparações múltiplas (FWE) referentes à região analisada. A ferramenta do SVC permite que sejam testadas hipóteses “a priori”, com correção para as regiões de interesse pré-determinadas, em vez do uso de uma correção para o encéfalo todo. Uma vez que o SPM é baseado em templates do MNI, que diferem ligeiramente do Atlas de Talairach e Tournoux (1988), as coordenadas dos voxels com significância estatística máxima obtidos nas análises (geradas em padrão MNI) foram convertidas para o sistema Talairach, através do uso do programa mni2tal (Matthew Brett, www.imaging.mrccbu.cam.ac.uk). 


\subsection{Estudo TransVersal}

\subsubsection{Dados demográficos e clínicos}

Dentre os casos de psicoses funcionais da amostra do estudo epidemiológico (200 casos), 99 pacientes foram diagnosticados como portadores de esquizofrenia ou transtorno esquizofreniforme. Dezesseis desses pacientes preenchiam critérios de exclusão para o estudo de imagem, 15 recusaram o exame e 09 não foram localizados. Foram submetidos ao exame de RM 59 pacientes, porém, 02 apresentaram artefatos durante a aquisição, resultando em 57 pacientes no estudo de imagem, com esquizofrenia ou transtorno esquizofreniforme, a partir da amostra epidemiológica.

Dentre os pacientes acessados pela equipe, mas não pertencentes à área de captação do estudo (conforme descrito na seção de Métodos, item 3.1.2), 05 foram incluídos no 
estudo de imagem. Portanto, a amostra final do estudo transversal de RM foi constituída por 62 pacientes.

A aquisição das imagens do grupo controle ocorreu simultaneamente à dos pacientes. Cento e quatorze controles foram submetidos ao exame de RM, mas 11 foram excluídos por lesões anatômicas e 09 por ocorrência de artefatos de imagem, resultando numa amostra final de 94 controles.

As amostras totais de pacientes $(\mathrm{n}=62)$ e controles $(\mathrm{n}=94)$ não apresentaram diferenças quanto à idade, gênero, renda mensal individual e escolaridade dos pais. A freqüência de aquisição dos exames em cada aparelho de RM também não diferiu entre os grupos, sendo que 40 pacientes e 54 controles foram examinados no aparelho do InCor e 22 pacientes e 40 controles foram examinados no aparelho do $\operatorname{In} \operatorname{Rad}\left(x^{2}=0,7 ; \mathrm{p}=0,38\right)$. Foram observadas diferenças significativas entre os grupos em relação à média de anos de escolaridade, situação conjugal e emprego atual, classe sócio-econômica (critério ABIPEME) e freqüência de abuso ou dependência de substâncias psicoativas (englobando álcool, maconha, cocaína e “crack”). As características sócio-demográficas dos grupos estão dispostas na Tabela 3. 
Tabela 3 - Características sócio-demográficas da amostra à RM inicial

\begin{tabular}{|c|c|c|c|}
\hline Dados sócio-demográficos & Pacientes (n=62) & Controles(n=94) & $\begin{array}{l}\text { Significância } \\
\text { estatística } \\
\text { (valor de p) }\end{array}$ \\
\hline $\begin{array}{c}\text { Gênero, } \mathrm{n}(\%) \\
\text { masculino } \\
\text { feminino }\end{array}$ & $\begin{array}{l}44(71) \\
18(29)\end{array}$ & $\begin{array}{l}53(56) \\
41(44)\end{array}$ & 0,07 \\
\hline Idade, média (DP) & $27,6(8)$ & $30,2(8,4)$ & 0,06 \\
\hline $\begin{array}{l}\text { Idade em categoria, n (\%) } \\
\begin{array}{c}18-24 \\
25-30 \\
31-40 \\
41-50\end{array}\end{array}$ & $\begin{array}{l}28(45) \\
15(24) \\
14(23) \\
5(8)\end{array}$ & $\begin{array}{l}27(28,7) \\
30(31,9) \\
23(24,5) \\
14(14,9)\end{array}$ & 0,16 \\
\hline Escolaridade, média (DP) & $8,6(3,8)$ & $10(4,1)$ & 0,04 \\
\hline $\begin{array}{l}\text { Escolaridade dos pais, } \\
\text { média (DP) }\end{array}$ & $5,6(5)$ & $7,3(5,7)$ & 0,12 \\
\hline $\begin{array}{l}\text { Lateralidade, } \mathrm{n} \\
\text { direita/ esquerda ou mista }\end{array}$ & $55 / 07$ & $91 / 03$ & 0,12 \\
\hline $\begin{array}{l}\text { Abuso ou dependência de } \\
\text { substâncias, } \mathrm{n}(\%) \text {. } \\
\text { na vida / } \\
\text { no último ano }\end{array}$ & $\begin{array}{l}22(35,5) \\
18(29)\end{array}$ & $\begin{array}{l}5(5,3) \\
3(3)\end{array}$ & $\begin{array}{l}\mathrm{p}<0,001 \\
\mathrm{p}<0,001\end{array}$ \\
\hline $\begin{array}{l}\text { Classe social, } \mathrm{n}(\%) \\
\begin{array}{l}\text { A-B } \\
\text { C } \\
\text { D-E }\end{array}\end{array}$ & $\begin{array}{l}11(18,3) \\
21(25) \\
28(46,7)\end{array}$ & $\begin{array}{l}25(27,8) \\
42(46,7) \\
23(25,6)\end{array}$ & 0,03 \\
\hline $\begin{array}{l}\text { Emprego atual, n (\%) } \\
\quad \text { sim }\end{array}$ & $20(32)$ & $66(70)$ & $<0,001$ \\
\hline $\begin{array}{l}\text { Renda mensal individual } \\
\text { (em reais), mediana }\end{array}$ & 300 & 475 & 0,06 \\
\hline $\begin{array}{l}\text { Renda mensal individual } \\
\text { (em reais) em categorias, } \\
\text { n (\%) }\end{array}$ & & & 0,47 \\
\hline $\begin{array}{l}\text { até } 100 \\
101-300 \\
301-750 \\
751-10.000\end{array}$ & $\begin{array}{l}10(17,5) \\
19(33,3) \\
14(24,6) \\
14(24,6)\end{array}$ & $\begin{array}{l}10(10,9) \\
26(28,3) \\
31(33,7) \\
25(27,2)\end{array}$ & \\
\hline $\begin{array}{l}\text { Estado civil, } \mathrm{n}(\%) \\
\text { com parceiro atual }\end{array}$ & $20(32,3)$ & $46(49)$ & 0,04 \\
\hline
\end{tabular}


Em seguida, são apresentadas as características clínicas dos pacientes à avaliação inicial (Tabela 4).

Tabela 4 -Características clínicas dos pacientes à RM inicial

\begin{tabular}{|c|c|}
\hline Características clínicas & Pacientes $(\mathrm{n}=62)$ \\
\hline \multicolumn{2}{|l|}{ Diagnóstico, n } \\
\hline esquizofrenia & 47 \\
\hline transtorno esquizofreniforme & 15 \\
\hline $\begin{array}{l}\text { Idade de início dos sintomas psicóticos, } \\
\text { média (DP) }\end{array}$ & $26,7(8,1)$ \\
\hline $\begin{array}{l}\text { Duração da doença (em dias), mediana } \\
\text { (intervalo) }\end{array}$ & $178(36-2.788)$ \\
\hline DUP (em dias), mediana (intervalo) & $68,5(1-2.601)$ \\
\hline \multicolumn{2}{|l|}{ PANSS, média (DP) } \\
\hline positiva & $10,8(5)$ \\
\hline negativa & $13,6(6)$ \\
\hline geral & $23(5,7)$ \\
\hline total & $47,8(12)$ \\
\hline $\begin{array}{l}\text { Intervalo entre o } 1^{\circ} \text {. contato e a } \mathrm{RM} \text { (di } \\
\text { média (DP) }\end{array}$ & $139(107)$ \\
\hline $\begin{array}{l}\text { Intervalo entre avaliação do estudo } \\
\text { epidemiológico e a RM (dias), mediana, } \\
\text { intervalo. }\end{array}$ & $19,5(0-374)$ \\
\hline
\end{tabular}

Em relação ao tratamento medicamentoso, os pacientes foram subdivididos em 3 grupos, conforme a exposição a antipsicóticos (APs):

- pacientes medicados (n=41): pacientes com exposição a APs por pelo menos 4 semanas. Dentre eles, 35 sujeitos estavam em uso ao exame e 06 sujeitos estavam sem medicação há um período menor do que 3 semanas. 
- pacientes não medicados (n=18): pacientes nunca expostos a APs (n=2) e pacientes com exposição prévia, mas sem medicação há mais de 3 semanas (n=14). Além disso, foram incluídos nesse grupo um paciente que estava em uso de medicação há apenas 3 dias e um paciente que havia feito uso de medicação por 4 dias e havia suspendido o uso 14 dias antes da RM.

- outros (n=3): pacientes que estavam em uso de APs ao exame, mas com exposição intermediária entre os medicados e não medicados (09, 16 e 22 dias de exposição, respectivamente).

A fim de investigarmos diferenças de volume de substância cinzenta em relação ao grau de exposição aos APs, comparamos os dois primeiros grupos entre si (intitulados medicados e não medicados).

A comparação dos dados sócio-demográficos e clínicos entre esses dois grupos está exposta na Tabela 5. Essa análise revelou que os grupos não diferiam significativamente em termos de gênero, idade, escolaridade, escolaridade dos pais, renda, estado civil, emprego atual, idade de início da doença, sintomas negativos e gerais e tipo de antipsicótico a que foram expostos. No entanto, foram observadas, além da esperada diferença entre tempo de exposição a antipsicóticos, diferenças em gravidade de sintomas positivos e duração da psicose não tratada (DUP, duration of untreated psychosis) (com os pacientes não medicados apresentando maior média de escore de sintomas psicóticos e DUP mais longa). Os grupos não diferiram em relação ao aparelho de RM em que o exame foi adquirido; os pacientes medicados foram examinados no InCor=27 e no InRad=14 e os pacientes não medicados foram examinados no InCor $=12$ e no $\operatorname{InRad}=6\left(x^{2}=0,004, p=0,95\right)$. 
Tabela 5 - Características sócio-demográficas e clínicas dos pacientes medicados e não medicados ao exame de RM inicial

\begin{tabular}{|c|c|c|c|}
\hline $\begin{array}{l}\text { Dados sócio-demográficos } \\
\text { e clínicos }\end{array}$ & Medicados(n=41) & $\begin{array}{l}\text { Não medicados } \\
(\mathrm{n}=18)\end{array}$ & $\begin{array}{l}\text { Significância } \\
\text { estatística } \\
\text { (valor de p) }\end{array}$ \\
\hline $\begin{array}{l}\text { Gênero, } \mathrm{n}(\%) \\
\text { masculino } \\
\text { feminino }\end{array}$ & $\begin{array}{l}27(66) \\
14(34)\end{array}$ & $\begin{array}{l}14(78) \\
04(22)\end{array}$ & 0,36 \\
\hline Idade, média (DP) & $27,3(7,5)$ & $27,9(9,7)$ & 0,8 \\
\hline Escolaridade, média (DP) & $8,9(3,7)$ & $7,6(3,9)$ & 0,24 \\
\hline $\begin{array}{l}\text { Escolaridade dos pais, } \\
\text { média (DP) }\end{array}$ & $5,6(5)$ & $6,2(5)$ & 0,76 \\
\hline $\begin{array}{l}\text { Lateralidade, } \mathrm{n}(\%) \\
\text { direita / esquerda ou mista }\end{array}$ & $38(93) / 3(7)$ & $15(83) / 3(17)$ & 0,36 \\
\hline $\begin{array}{l}\text { Estado civil, } \mathrm{n}(\%) \\
\text { com parceiro atual }\end{array}$ & $11(27)$ & $6(33)$ & 0,6 \\
\hline Emprego atual, n(\%) & $13(32)$ & $4(22)$ & 0,46 \\
\hline $\begin{array}{l}\text { Renda mensal individual } \\
\text { (em reais), mediana }\end{array}$ & 325 & 282 & 0,37 \\
\hline $\begin{array}{l}\text { Tipo de AP (uso atual ou } \\
\text { prévio), } \mathrm{n}(\%)^{1} \\
\text { túpicos } \\
\text { atípicos }\end{array}$ & $\begin{array}{l}27(66) \\
14(34)\end{array}$ & $\begin{array}{l}13(81) \\
3(19)\end{array}$ & 0,34 \\
\hline $\begin{array}{l}\text { Tempo de exposição a APs, } \\
\text { em dias, média (DP) }\end{array}$ & $100(73)$ & $25(29)$ & $<0,001$ \\
\hline $\begin{array}{l}\text { Abuso ou dependência de } \\
\text { substâncias, } n(\%)\end{array}$ & $12(29)$ & $9(50)$ & 0,12 \\
\hline $\begin{array}{l}\text { Idade de início da doença, } \\
\text { média (DP) }\end{array}$ & $26(7,6)$ & $27(9,7)$ & 0,76 \\
\hline DUP, mediana (intervalo) & $27(1-2601)$ & $170(22-1642)$ & 0,03 \\
\hline $\begin{array}{l}\text { Tempo de doença, mediana } \\
\text { (intervalo) }\end{array}$ & $177(46-2788)$ & $187(36-1642)$ & 0,75 \\
\hline \multicolumn{4}{|l|}{ PANSS, média (DP) } \\
\hline positiva & $9,5,(3,7)$ & $13,4,(6,3)$ & 0,02 \\
\hline negativa & $14,5(6,3)$ & $12,5,3$ & 0,15 \\
\hline geral & $22,5(5,6)$ & $24,6(5,8)$ & 0,2 \\
\hline total & $46,6(11,4)$ & $51(13)$ & 0,2 \\
\hline
\end{tabular}

${ }^{1}$ Excluídos os 2 pacientes nunca expostos a antipsicóticos

AP, antipsicótico; DUP, duração da psicose não tratada (duration of untreated psychosis); DP, desvio-padrão; PANSS, Positive and Negative Syndrome Scale. 


\subsubsection{Morfometria voxel-a-voxel}

\subsubsection{Comparação entre pacientes e controles}

Os pacientes ( $\mathrm{n=62}$ ) apresentaram áreas de redução de substância cinzenta em relação aos controles ( $\mathrm{n}=94)$ quando utilizado o método de $\mathrm{SVC}(\mathrm{p}<0,05$, corrigido para comparações múltiplas) em córtex pré-frontal esquerdo (BA 47/45) e direito (BA 9/10), ínsula bilateral (BA 13), córtex temporal superior esquerdo (BA 22/41), hipocampo e giro hipocampal direitos (BA 28/35) (Tabela 6, Figura 2). Não foram encontradas áreas de significância estatística à análise exploratória.

Tabela 6 - Áreas de redução de substância cinzenta em pacientes (n=62) comparados a controles $(n=94)$

\begin{tabular}{llll}
\hline Região cerebral $^{1}$ & Voxels $^{2}$ & Escore Z & \\
& & $\begin{array}{l}\text { Significância } \\
\text { estatística } \\
\left(\text { valor de p) }{ }^{4}\right.\end{array}$ & Coordenadasx y z $^{5}$ \\
\hline
\end{tabular}

\begin{tabular}{|c|c|c|c|c|}
\hline $\begin{array}{l}\text { Córtex pré-frontal } \\
\text { esquerdo (BA 47/ } \\
\text { 45) }\end{array}$ & 156 & 4,39 & 0,021 & -38231 \\
\hline $\begin{array}{l}\text { Córtex pré-frontal } \\
\text { direito (BA 9/ 46) }\end{array}$ & 250 & 4,20 & 0,044 & 463419 \\
\hline $\begin{array}{l}\text { Córtex temporal } \\
\text { superior esquerdo (BA } \\
41 / 22 \text { ) }\end{array}$ & 215 & 3,89 & 0,009 & $-59-2312$ \\
\hline $\begin{array}{l}\text { Ínsula esquerda (BA } \\
\text { 13) }\end{array}$ & 382 & 4,53 & 0,001 & -36231 \\
\hline Ínsula direita (BA 13) & 222 & 4,17 & 0,003 & 40123 \\
\hline $\begin{array}{l}\text { Hipocampo direito/ } \\
\text { Giro parahipocampal } \\
\text { direito (BA 28/35) }\end{array}$ & 34 & 3,68 & 0,009 & $22-20-11$ \\
\hline
\end{tabular}

${ }^{1}$ números referem-se a áreas de Brodmann (BA)

${ }^{2}$ número total de voxels contíguos em cada região, que ultrapassaram o limiar original de $\mathrm{z}>3,09$

${ }^{3}$ escore Z para o voxel de significância estatística máxima em cada região

${ }^{4}$ significância estatística após correção para comparações múltiplas (voxel level)

${ }^{5}$ coordenadas de Talairach e Tournoux (1988) para o voxel de significância estatística máxima em cada região 
Não foram encontradas áreas de aumento de substância cinzenta nos pacientes quando comparados aos controles à análise exploratória ou com o uso de SVC que sobrevivessem à significância estatística estabelecida ( $\mathrm{p}<0,05$ corrigido).

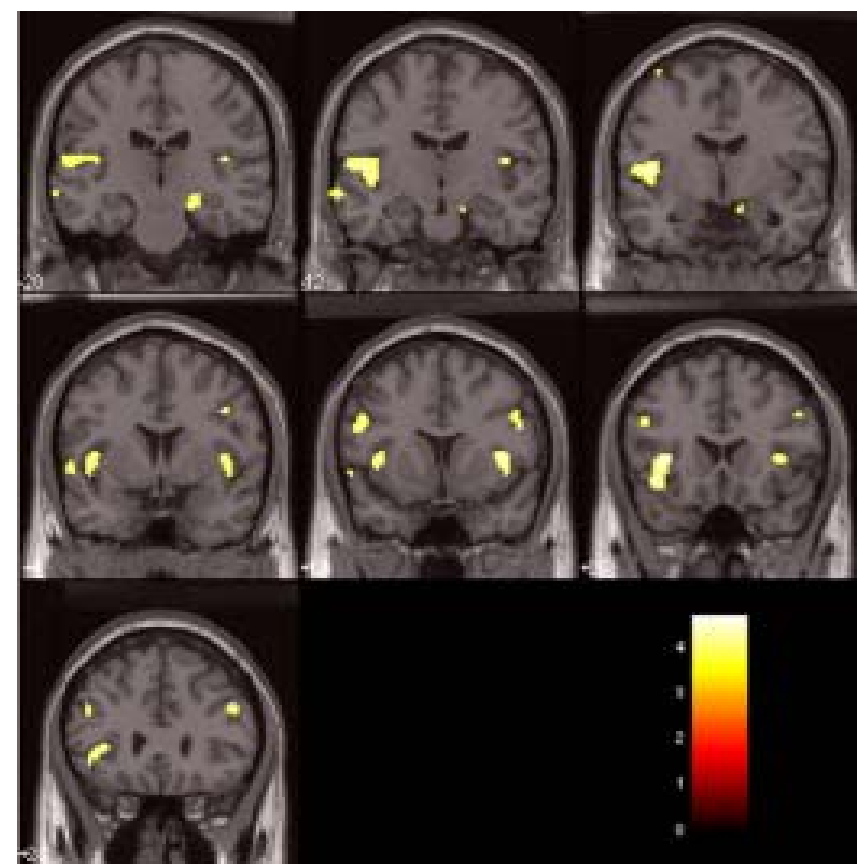

Figura 2 - Comparação entre pacientes e controles - análise transversal por VBM

Áreas de redução de substância cinzenta em pacientes com esquizofrenia e transtorno esquizofreniforme ao primeiro episódio psicótico ( $n=62)$ comparados a controles assintomáticos $(n=94)$, sobrepostas em cortes coronais de imagem T1 padrão do SPM. Os números em cada corte referem-se à coordenadas y do sistema de Talairach e Tournoux. Para fins de visualização, $\mathrm{p}<0,001$, não corrigido para comparações múltiplas.

\subsubsection{Comparação entre pacientes e controles sem abuso ou dependên-} cia de substâncias

Como uma parcela considerável da amostra (35,5\% dos pacientes e 5,3\% dos controles) apresentava diagnóstico de abuso ou dependência de substâncias ao longo da vida, conduzimos uma análise similar à descrita acima, excluindo os sujeitos com esses diagnósticos. 
A comparação de pacientes ( $n=40)$ e controles ( $n=89)$ sem abuso ou dependência de substância mostrou redução de substância cinzenta em áreas semelhantes às identificadas na comparação entre todos os pacientes ( $n=62)$ versus todos os controles ( $n=94)$. Em resumo, a região do giro parahipocampal direito passou a ser identificada já à análise exploratória, enquanto na comparação anterior a redução dessa área foi encontrada apenas com o uso da SVC. As outras áreas descritas como reduzidas nos pacientes da amostra toda (ínsula bilateral, hipocampo direito e GTS esquerdo), novamente foram identificadas como reduzidas nessa nova análise, com o uso da SVC. Os agrupamentos de redução em áreas frontais esquerda e direita foram observados nessa nova comparação, mas não resistiram à correção para comparações múltiplas ( $\mathrm{p}=0,062)$.

Novamente, não foram encontradas áreas de aumento de substância cinzenta nos pacientes quando comparados aos controles à análise exploratória ou com o uso de SVC, que sobrevivessem à significância estatística estabelecida ( $\mathrm{p}<0,05$ corrigido).

\subsubsection{Correlações entre morfometria e variáveis clínicas no grupo de pacientes}

\subsection{Tempo de doença e duração da doença não tratada (DUP)}

Não foram encontradas áreas de correlação entre o volume de substância cinzenta e o tempo de doença na amostra total de pacientes ( $n=62)$, nem tampouco entre o volume de substância cinzenta e a duração da psicose não tratada à análise exploratória ou à análise com SVC (com significância estatística de p<0,05, corrigido para comparações múltiplas). 


\subsection{Sintomas psicóticos}

Os escores de sintomas psicóticos positivos (obtidos pela PANSS da amostra total de 62 pacientes) correlacionaram-se inversamente com o volume da ínsula direita (BA 13), com o uso de SVC; ou seja, um maior grau de sintomas positivos refletiu-se em menor volume dessa região. Foram, também, observados dois agrupamentos em GTS direito, mas não resistiram à correção para comparações múltiplas (Figura 3).
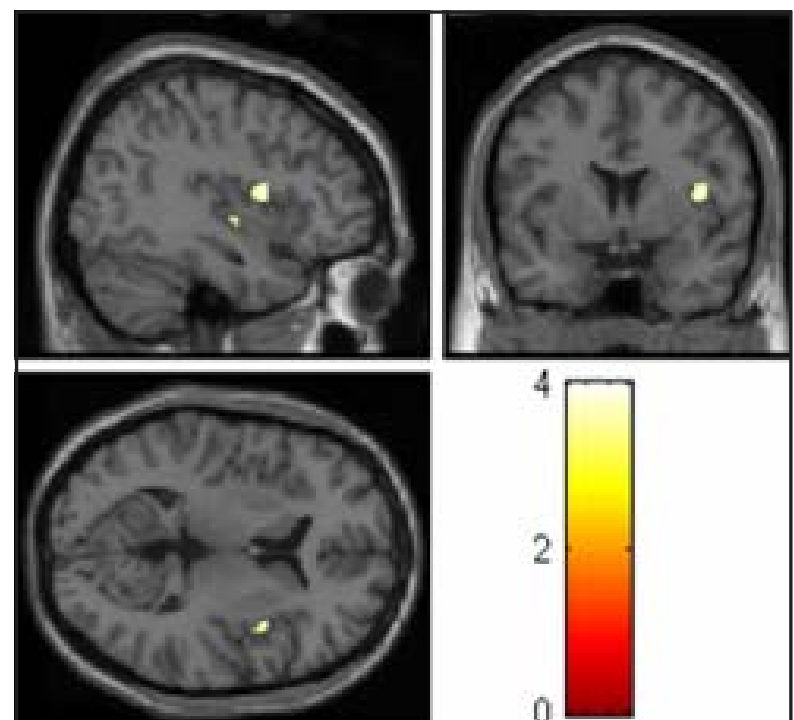

Figura 3 - Correlação negativa entre sintomas positivos (PANSS) e volume de substância cinzenta à RM inicial

Área de significância estatística (ínsula direita) sobreposta em imagem T1 padrão do SPM. Observa-se um agrupamento de voxels em giro temporal superior direito, que não sobrevive à correção para comparações múltiplas. Em sentido horário, corte sagital, coronal e axial. Para fins de visualização, $\mathrm{p}<0,001$ não corrigido para comparações múltiplas.

Em relação aos sintomas negativos, com o uso da SVC foi encontrada correlação inversa entre esse subescore da PANSS e a ínsula esquerda e o GTS esquerdo.

Os achados relacionados a essas correlações com sintomas positivos e negativos encontram-se na Tabela 7. 
Tabela 7 - Áreas de correlação entre escores da PANSS e volume de substância cinzenta em pacientes $(\mathrm{n}=62)$

\begin{tabular}{|c|c|c|c|c|}
\hline Região cerebral $^{1}$ & Voxels $^{2}$ & Escore $\mathrm{Z}^{3}$ & $\begin{array}{l}\text { Significância } \\
\text { estatística }^{4}\end{array}$ & Coordenadas ${ }^{5}$ \\
\hline
\end{tabular}

\section{Sintomas positivos}

Correlação negativa SVC

Ínsula direita

$\begin{array}{llll}33 & 3,62 & 0,019 & 40611 \\ 46 & 3,33 & 0,047 & 44-6-1\end{array}$

\section{Sintomas negativos}

Correlação negativa SVC

Ínsula esquerda

$4 \quad 3,39 \quad 0,041$

$-41 \quad 7-12$

Giro temporal superior esquerdo

$18 \quad 3,52$

0,032

$-61116$

${ }^{1}$ números referem-se a áreas de Brodmann (BA)

${ }^{2}$ número total de voxels contíguos em cada região, que ultrapassaram o limiar original de $\mathrm{z}>3,09$

${ }^{3}$ escore Z para o voxel de significância estatística máxima em cada região

${ }^{4}$ significância estatística após correção para comparações múltiplas (voxel level)

${ }^{5}$ coordenadas Talairach e Tournoux (1988) para o voxel de significância estatística máxima em cada região

\subsubsection{Investigação dos efeitos do tratamento com antipsicóticos sobre o volume de substância cinzenta}

\subsection{Comparação entre pacientes medicados e não medicados}

Foi encontrado um agrupamento de aumento de substância cinzenta em pacientes medicados ( $n=41$ ) quando comparados aos não medicados ( $n=18)$ em putâmen e em globo pálido esquerdos, sobrevivendo à correção para comparações múltiplas com o uso de SVC. Porém, conforme descrito na seção de Métodos, item 3.4.3, achados em núcleos da base 
não podem ser considerados válidos neste estudo, uma vez que apresentaram baixos CCI em medidas de comparação entre os dois aparelhos de ressonância magnética.

A inspeção exploratória identificou agrupamentos de redução de substância cinzenta em pacientes medicados quando comparados aos não medicados em regiões de pré-cúneo direito, giro frontal inferior direito e giro temporal superior direito; porém, nenhum dos achados nessas áreas sobreviveu à correção para comparações múltiplas, à análise exploratória ou ao uso de SVC.

\subsection{Correlação entre tempo de exposição a antipsicóticos e volu- me de substância cinzenta}

Quando investigamos a correlação entre os dias de exposição a APs típicos (n=30 pacientes) e substância cinzenta, encontramos, com o uso de SVC, uma correlação negativa em um agrupamento em região temporal medial esquerda, com picos de significância estatística em hipocampo (número de voxels=68, $\mathrm{p}=0,003, \mathrm{Z}=4,21$, coordenadas $\mathrm{x}, \mathrm{y}, \mathrm{z}=-34,-22,-7$ ) e giro parahipocampal (número de voxels $=30, p=0,027, z=3,59$, coordenadas $x, y, z=-24$, -30, -14 (valores de p corrigido para comparações múltiplas) (Figura 4)

Por outro lado, a correlação entre dias de exposição aos APs atípicos (n=15 pacientes) e substância cinzenta não atingiu significância estatística em nenhum voxel. 

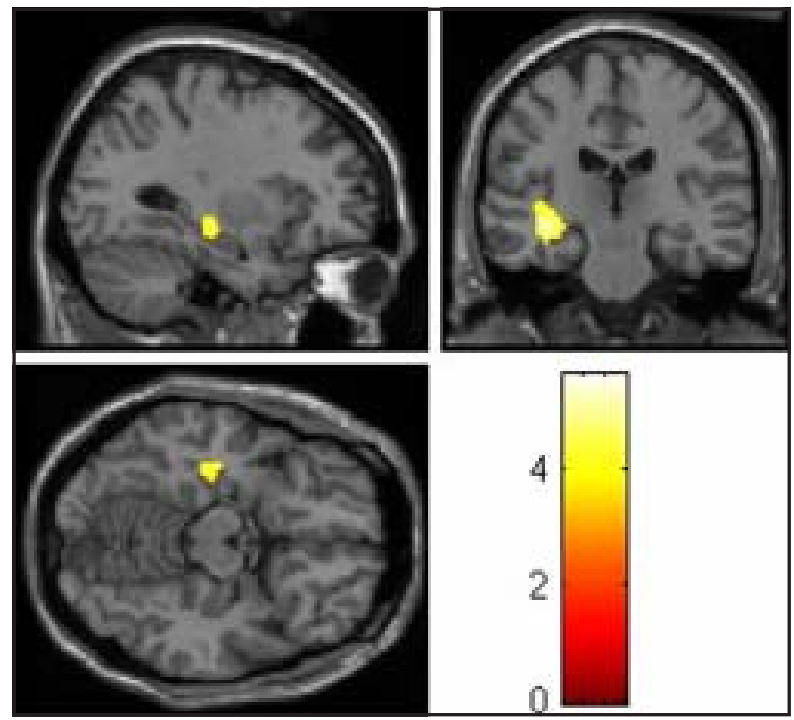

Figura 4 - Correlação negativa entre exposição a antipsicóticos típicos e substância cinzenta à RM inicial Área de significância estatística (hipocampo e giro parahipocampal esquerdos) sobreposta em imagem T1 padrão do SPM. Em sentido horário, corte sagital, coronal e axial. Para fins de visualização, $\mathrm{p}<0,001$ não corrigido para comparações múltiplas.

\subsection{Estudo Longitudinal}

\subsubsection{Dados demográficos e clínicos}

\subsubsection{Composição da amostra}

A partir da amostra inicial de 62 pacientes convocados para o exame de seguimento, 14 (22,5\%) recusaram novo exame, 7 (11,3\%) não foram localizados, 01 apresentou contra-indicação ao exame de RM e 01 apresentou artefato durante a aquisição das imagens. 
Através da reavaliação diagnóstica pela SCID ao segundo exame, observamos que um paciente que havia recebido inicialmente o diagnóstico de transtorno psicótico sem outra especificação foi rediagnosticado como portador de esquizofrenia e incluído nesta amostra de seguimento. Por outro lado, uma paciente que originalmente apresentara um quadro esquizofreniforme evoluiu para o diagnóstico de transtorno afetivo bipolar, sendo excluída da análise de seguimento.

Em relação ao grupo controle inicial (n=94), 24 (25\%) recusaram novo exame, 09 (9,5\%) não foram localizados e 06 apresentaram contra-indicação para novo exame de RM.

Portanto, a amostra final de seguimento foi composta por 39 pacientes (dentre os quais 31 com diagnóstico de esquizofrenia e 08 com diagnóstico de transtorno esquizofreniforme à reavaliação) e 52 controles.

\subsubsection{Comparação dos dados demográficos e clínicos entre sujeitos incluídos e não incluídos no exame de seguimento}

A comparação entre os pacientes com esquizofrenia ou transtorno esquizofreniforme que completaram o exame de seguimento (n=39) e os que não completaram ( $n=23)$, não mostrou diferenças significativas em características sócio-demográficas ou clínicas, investigadas ao exame inicial de RM, como mostrado na Tabela 8. 
Tabela 8-Características sócio-demográficas e clínicas (ao exame inicial) dos pacientes com e sem exame de seguimento

\begin{tabular}{|c|c|c|c|}
\hline $\begin{array}{l}\text { Paci } \\
\text { exai } \\
\text { segi }\end{array}$ & $\begin{array}{l}\text { ientes com } \\
\text { me de } \\
\text { limento }(n=39)\end{array}$ & $\begin{array}{l}\text { Pacientes sem } \\
\text { exame de } \\
\text { seguimento }(n=23)\end{array}$ & $\begin{array}{l}\text { Significância } \\
\text { estatística } \\
\text { (valor de p) }\end{array}$ \\
\hline $\begin{array}{c}\text { Gênero, } \mathrm{n}(\%) \\
\text { masculino } \\
\text { feminino }\end{array}$ & $\begin{array}{l}30(77) \\
09(23)\end{array}$ & $\begin{array}{l}15(65) \\
08(35)\end{array}$ & 0,32 \\
\hline Idade, média (DP) & $28(9)$ & $27,2(5,8)$ & 0,71 \\
\hline Escolaridade, média (DP) & $9(3,36)$ & $7,83(4,6)$ & 0,45 \\
\hline Escolaridade do pai & $6,2(5)$ & $5(5)$ & 0,36 \\
\hline $\begin{array}{l}\text { Abuso ou dependência de } \\
\text { substâncias, } \mathrm{n}(\%)\end{array}$ & $16(41)$ & $6(26)$ & 0,23 \\
\hline $\begin{array}{l}\text { Estado civil (com parceiro), } \\
\mathrm{n}(\%)\end{array}$ & $12(31)$ & $8(35)$ & 0,74 \\
\hline Emprego, n (\%) & $14(36)$ & $7(30,4)$ & 0,66 \\
\hline Renda, em reais, média (DP) & $497(476)$ & $528(704)$ & 0,85 \\
\hline $\begin{array}{l}\text { Idade de início dos sintomas } \\
\text { psicóticos, média (DP) }\end{array}$ & $27(9)$ & $26(6)$ & 0,87 \\
\hline $\begin{array}{l}\text { Tempo de doença em dias, } \\
\text { média (DP) }\end{array}$ & $324(354)$ & $429(598)$ & 0,89 \\
\hline $\begin{array}{l}\text { Duração da psicose não } \\
\text { tratada, em dias, média (DP) }\end{array}$ & $229(354)$ & $332(580)$ & 0,66 \\
\hline \multicolumn{3}{|l|}{$\begin{array}{l}\text { Medicação ao exame inicial, } \\
\text { n (\%) }\end{array}$} & 0,73 \\
\hline $\begin{array}{l}\text { medicados } \\
\text { não-medicados }\end{array}$ & $\begin{array}{l}29(74,4) \\
10(25,6)\end{array}$ & $\begin{array}{l}18(78) \\
5(22)\end{array}$ & \\
\hline $\begin{array}{l}\text { Tempo de exposição a APs } \\
\text { (em dias), média (DP) }\end{array}$ & $70(78)$ & $80(58)$ & 0,21 \\
\hline \multicolumn{4}{|l|}{ PANSS, média (DP) } \\
\hline positiva & $11,3(5)$ & $10,2(5)$ & 0,13 \\
\hline negativa & $14(5,8)$ & $128(6,3)$ & 0,22 \\
\hline geral & $22,8(5,3)$ & $23,8(6,2)$ & 0,47 \\
\hline total & $48,7(11,5)$ & $46,9(12,6)$ & 0,36 \\
\hline
\end{tabular}

A comparação entre os controles que completaram o exame de seguimento ( $n=52)$ e os que não completaram ( $\mathrm{n}=42$ ) não mostrou diferença significativa em características sóciodemográficas, conforme descrito na Tabela 9. 
Tabela 9-Características sócio-demográficas (ao exame inicial) dos controles com e sem exame de seguimento

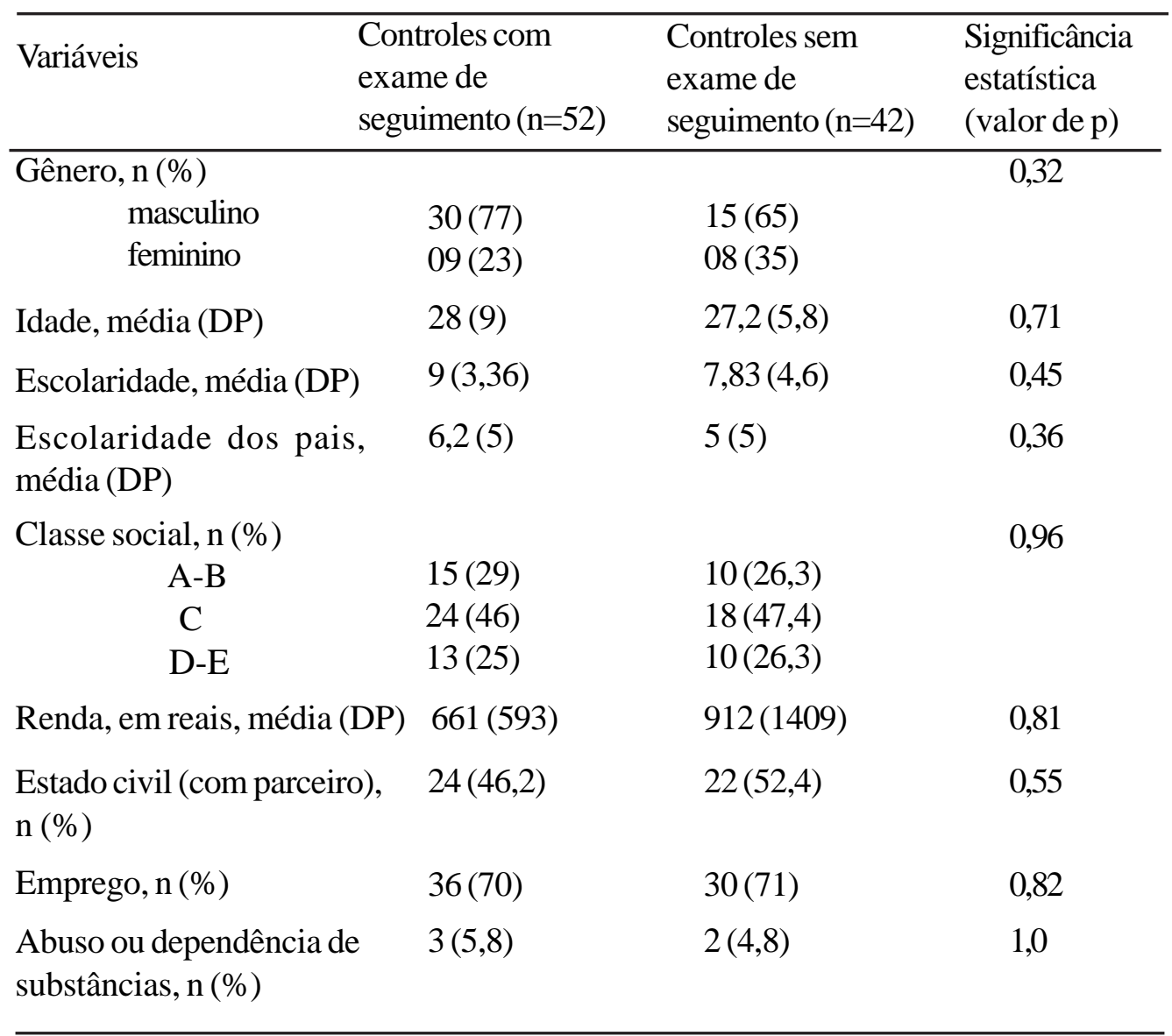

\subsubsection{Comparação de dados demográficos entre pacientes e controles ao exame de seguimento}

A comparação das características sócio-demográficas entre os grupos presentes no estudo longitudinal de RM mostrou que os grupos não diferem em idade e escolaridade iniciais, mas apresentam diferença em proporção de gênero, sendo que houve maior freqüência de sexo masculino no grupo de pacientes em relação ao grupo de controles, como descrito na Tabela 10. 
O intervalo de aquisição entre os exames para a amostra toda foi de 480 (179) dias (média e DP), mediana=415 e intervalo de 251 a 1.193 dias. Em meses, o intervalo foi de 16 (6) meses (média e DP), mediana=13,8 e intervalo de 8 a 40 meses. Não houve diferença significativa de intervalo de exames entre os grupos, conforme descrito na Tabela 10.

Tabela 10 - Comparação de variáveis demográficas entre pacientes e controles submetidos ao exame de seguimento

\begin{tabular}{|c|c|c|c|}
\hline Variáveis & $\begin{array}{l}\text { entes } \\
\text { 9) }\end{array}$ & $\begin{array}{l}\text { Controles } \\
(\mathrm{n}=52)\end{array}$ & $\begin{array}{l}\text { Significância } \\
\text { estatística } \\
\text { (valor de p) }\end{array}$ \\
\hline $\begin{array}{l}\text { Gênero, } \mathrm{n}(\%) \\
\text { masculino } \\
\text { feminino }\end{array}$ & $\begin{array}{l}30(77) \\
09(23)\end{array}$ & $\begin{array}{l}27(52) \\
25(48)\end{array}$ & 0,015 \\
\hline $\begin{array}{l}\text { Idade ao exame inicial, } \\
\text { média (DP) }\end{array}$ & $28(9)$ & $30,5(8,8)$ & 0,2 \\
\hline $\begin{array}{l}\text { Escolaridade ao exame } \\
\text { inicial, média (DP) }\end{array}$ & $9,0(3,4)$ & $10,3(4)$ & 0,11 \\
\hline $\begin{array}{l}\text { Intervalo entre os exames } \\
\text { dias, média (DP) } \\
\text { meses, média (DP) }\end{array}$ & $\begin{array}{l}499(202) \\
16,64(6,7)\end{array}$ & $\begin{array}{l}466(160) \\
15,56(5,3)\end{array}$ & 0,6 \\
\hline \multicolumn{4}{|l|}{ Aquisição dos exames } \\
\hline $\begin{array}{l}\text { ambos os exames no } \\
\text { aparelho } 1 .\end{array}$ & $07(18)$ & $15(29)$ & 0,090 \\
\hline $\begin{array}{l}1^{\circ} \text {. exame no aparelho } 1 \mathrm{e} \\
2^{\circ} \text {. exame no aparelho } 2\end{array}$ & $19(49)$ & $4(27)$ & \\
\hline $\begin{array}{l}\text { ambos os exames no } \\
\text { aparelho } 2\end{array}$ & $13(33)$ & $23(44)$ & \\
\hline
\end{tabular}

\subsubsection{Características sócio-demográficas e clínicas dos pacientes $(n=39)$ ao exame inicial e de seguimento}

Em relação à renda média individual mensal no grupo de portadores de esquizofrenia, esta passou de 497 reais (476) para 516 reais $(551)(p=0,89)$. Dezoito pacientes permaneciam 
sem atividade remunerada, 08 permaneciam empregados, enquanto 06 pararam de trabalhar e 07 que estavam sem trabalhar ao exame inicial estavam trabalhando ao seguimento.

Quanto ao uso de substâncias, 16 pacientes preenchiam critérios para abuso e dependência ao longo da vida ao exame inicial. Seis destes pacientes não preencheram esses diagnósticos durante o seguimento, enquanto 1 paciente previamente sem diagnóstico, passou a preenchê-lo.

Não houve mudança longitudinal significativa na gravidade dos sintomas psicóticos medida pelos escores da PANSS ao exame inicial e ao exame de seguimento: PANSS positiva inicial $=11,28$ (5), final=10,3 (4) $(p=0,31)$; PANSS negativa inicial $=14(5,8)$, final $=14,5(6,3)$ $(p=0,86)$ e PANSS total inicial $=48,7(11,5)$, final $=46,5(12)(p=0,3)$.

A comparação longitudinal das características sócio-demográficas dos controles (n=52) (avaliação inicial versus avaliação final) não mostrou diferenças na distribuição de freqüências de classe social, estado civil, emprego e abuso ou dependência de substâncias.

\subsubsection{Tratamento medicamentoso durante o seguimento}

A descrição do uso de APs dos pacientes que completaram o estudo longitudinal, assim como o uso de outros psicotrópicos durante o intervalo entre os exames, encontra-se na Tabela 11. 
Tabela 11 - Características relacionadas ao tratamento dos pacientes durante o seguimento

\begin{tabular}{ll}
\hline \multicolumn{1}{c}{ Variáveis } & Pacientes (n=39) \\
\hline $\begin{array}{l}\text { Em uso de antipsicóticos } \\
\text { no dia do exame de }\end{array}$ & $25(64)$ \\
seguimento, n (\%) & \\
Adesão ao tratamento, n (\%) & \\
$\quad$ sem qualquer tratamento & $05(12,8)$ \\
tratamento irregular & $19(48,7)$ \\
$\quad$ tratamento contínuo (uso por & $15(38,4)$ \\
pelo menos 80\% do tempo) & \\
Uso de outras medicações, n (\%) & \\
antidepressivos & $8(21,6)$ \\
benzodiazepínicos & $5(13,5)$ \\
estabilizadores de humor & $7(16,2)$ \\
anticolinérgicos & $11(30)$ \\
\hline
\end{tabular}

Para a análise de VBM, os pacientes foram agrupados em relação à adesão ao tratamento antipsicótico durante o período de seguimento da seguinte forma:

- aderentes: exposição por $80 \%$ do tempo de seguimento ou mais (n=15; típicos=6, atípicos=9). O tempo médio de exposição desses pacientes durante o seguimento foi de 437 (101) dias para os típicos e 434 (180) dias para os atípicos.

- não-aderentes: exposição por menos de 50\% do tempo de seguimento (n=19), sendo que 5 não tiveram exposição a APs durante o seguimento, 8 haviam feito uso durante o intervalo, mas não estavam mais em uso à RM (típicos=6, atípicos=2) e 06 estavam em uso de antipsicóticos à RM (típicos=4, atípicos=2).

- outros: pacientes que fizeram tratamento por período entre 50 e $80 \%$ do tempo de seguimento.

A comparação entre os grupos de pacientes aderentes e não aderentes mostrou que eles não apresentavam diferenças sócio-demográficas e clínicas, com exceção de maior renda, 
escolaridade (dos sujeitos e dos pais) e maior tempo de exposição a antipsicóticos (inclusive antes do exame inicial) no grupo dos aderentes. As características sócio-demográficas e clínicas desses grupos encontram-se na Tabela 12. 
Tabela 12 - Comparação de variáveis sócio-demográficas e clínicas entre pacientes aderentes e não aderentes ao tratamento com antipsicóticos durante o seguimento

\begin{tabular}{|c|c|c|c|}
\hline Variáveis & $\begin{array}{l}\text { Pacientes } \\
\text { aderentes }(n=15)\end{array}$ & $\begin{array}{l}\text { Pacientes não } \\
\text { aderentes (n=19) }\end{array}$ & $\begin{array}{l}\text { Significância } \\
\text { estatística } \\
\text { (valor de p) }\end{array}$ \\
\hline $\begin{array}{l}\text { Gênero, } \mathrm{n}(\%) \\
\text { masculino } \\
\text { feminino }\end{array}$ & $\begin{array}{l}11(73,3) \\
4(26,7)\end{array}$ & $\begin{array}{l}16(84,2) \\
3(15,8)\end{array}$ & 0,67 \\
\hline Idade ao exame inicial, média (DP) & $29,3(9,6)$ & $25,6(6,7)$ & 0,2 \\
\hline $\begin{array}{l}\text { Escolaridade ao exame } \\
\text { inicial, média(DP) }\end{array}$ & $11(3,4)$ & $7,6(2,4)$ & 0,002 \\
\hline Escolaridade dos pais, média (DP) & $9(5,7)$ & $4(3,2)$ & 0,012 \\
\hline $\begin{array}{l}\text { Renda, em reais, média (DP) } \\
\text { ao exame inicial } \\
\text { ao seguimento }\end{array}$ & $\begin{array}{l}713(500) \\
942(662)\end{array}$ & $\begin{array}{l}247(195) \\
211(142)\end{array}$ & $\begin{array}{l}0,002 \\
<0,001\end{array}$ \\
\hline $\begin{array}{l}\text { Emprego, } \mathrm{n}(\%) \\
\text { ao exame inicial } \\
\text { ao seguimento }\end{array}$ & $\begin{array}{l}5(33,3) \\
7(46,7)\end{array}$ & $\begin{array}{l}7(36,8) \\
8(42,1)\end{array}$ & $\begin{array}{l}0,8 \\
0,8\end{array}$ \\
\hline $\begin{array}{l}\text { Estado civil (com parceiro), n (\%) } \\
\text { ao exame inicial } \\
\text { ao seguimento }\end{array}$ & $\begin{array}{l}5(33,3) \\
4(26,7)\end{array}$ & $\begin{array}{l}6(31,6) \\
8(42,1)\end{array}$ & $\begin{array}{l}1,0 \\
0,35\end{array}$ \\
\hline $\begin{array}{l}\text { Abuso ou dependência de } \\
\text { substâncias } \\
\text { prévio } \\
\text { durante o seguimento }\end{array}$ & $\begin{array}{l}6(40) \\
5(33,3)\end{array}$ & $\begin{array}{l}11(58) \\
6(31,6)\end{array}$ & $\begin{array}{l}0,3 \\
1,0\end{array}$ \\
\hline $\begin{array}{l}\text { Idade de início da doença, } \\
\text { média (DP) }\end{array}$ & $28,2(9,7)$ & $25(6,6)$ & 0,25 \\
\hline $\begin{array}{l}\text { Tempo de exposição a } \\
\text { antipsicóticos, em dias, até o } \\
\text { primeiro exame, média (DP) }\end{array}$ & $116(105)$ & $41,21(33)$ & 0,006 \\
\hline $\begin{array}{l}\text { Tempo de exposição a } \\
\text { antipsicóticos, durante o } \\
\text { seguimento, em dias, média (DP) }\end{array}$ & $435(149)$ & $93(68)$ & $<0,001$ \\
\hline $\begin{array}{l}\text { PANSS, ao exame inicial, } \\
\text { média (DP) }\end{array}$ & & & \\
\hline $\begin{array}{l}\text { positiva } \\
\text { negativa }\end{array}$ & $\begin{array}{l}11(4,3) \\
15,8(5,4)\end{array}$ & $\begin{array}{l}12(6) \\
13,9(6,2)\end{array}$ & $\begin{array}{l}0,58 \\
0,34\end{array}$ \\
\hline $\begin{array}{l}\text { PANSS, ao seguimento, } \\
\text { média (DP) } \\
\text { positiva } \\
\text { negativa }\end{array}$ & $\begin{array}{l}11(3) \\
16,7(6,6)\end{array}$ & $\begin{array}{l}10,5(5) \\
12,8(5,4)\end{array}$ & $\begin{array}{l}0,78 \\
0,065\end{array}$ \\
\hline
\end{tabular}




\subsubsection{Morfometria voxel-a-voxel}

\subsubsection{Comparação longitudinal entre pacientes e controles}

A análise de covariância (ANCOVA) entre pacientes ( $n=39)$ e controles ( $n=52)$ com 2 fatores (grupo x tempo) e com o número total de voxels e gênero incluídos como covariáveis mostrou uma interação significativa ( $\mathrm{p}<0,05$, corrigido para comparações múltiplas) ao SVC para um agrupamento de voxels em giro temporal superior esquerdo (GTS), BA 22 (número de voxels=74, valor de $\mathrm{Z}=3,83$, valor de $\mathrm{p}=0,015$, coordenadas $\mathrm{x}, \mathrm{y}, \mathrm{z}=-51,-15,1$ ) e em hipocampo direito (número de voxels $=5$, valor de $Z=3,41$, valor de $p=0,028$, coordenadas x,y,z= 26, -14, -9), indicando um maior grau de preservação de substância cinzenta nessas áreas em pacientes em relação aos controles (Figura 5).

Não foram encontradas áreas de maior grau de redução de substância cinzenta em pacientes em relação aos controles que sobrevivessem à correção para comparações múltiplas.

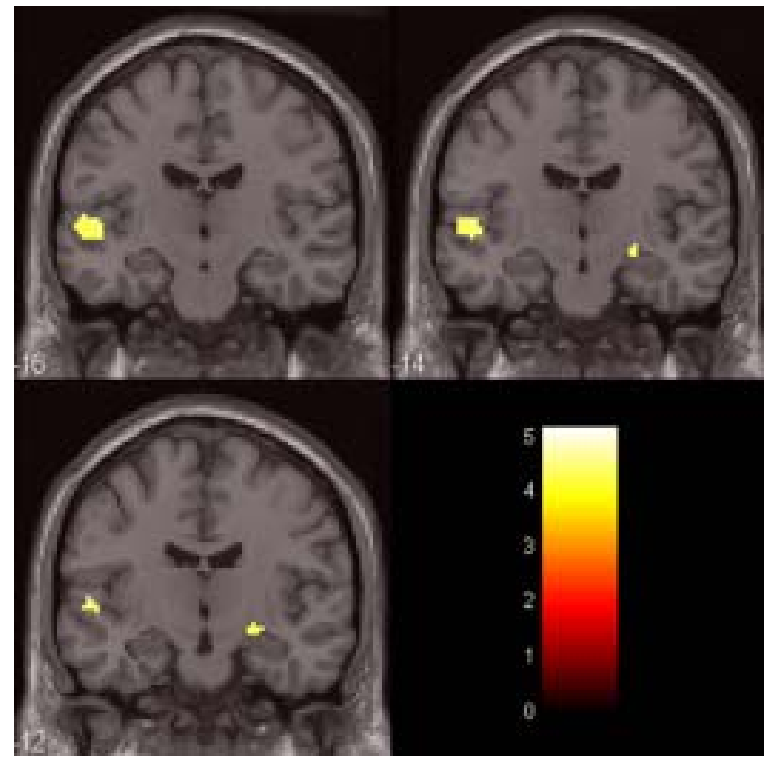

Figura 5- Comparação entre pacientes e controles análise longitudinal por VBM

Àreas de maior preservação de substância cinzenta em pacientes $(n=39)$ em relação aos controles $(n=52)$ em giro temporal superior esquerdo e hipocampo direito, sobrepostas à imagem T1 padrão do SPM (cortes coronais). Os números nos cortes referem-se à coordenada y do sistema Talairach e Tournoux. Para fins de visualização, $\mathrm{p}<0,001$, não corrigido para comparações múltiplas. 


\subsubsection{Comparação longitudinal entre pacientes (teste t pareado)}

A comparação longitudinal direta entre os pacientes $(n=39)$ (teste t pareado com as imagens do exame inicial versus exame final) não mostrou áreas de aumento ou redução de volume de substância cinzenta com significância estatística $(\mathrm{p}<0,05$, corrigido) à análise exploratória ou ao o uso de SVC.

\subsubsection{Comparação longitudinal entre controles (teste t pareado)}

A comparação longitudinal direta entre os controles (n=52) (teste t pareado com as imagens do exame inicial versus exame final) não mostrou áreas de aumento ou redução de volume de substância cinzenta com significância estatística ( $<<0,05$, corrigido) à análise exploratória ou ao uso de SVC.

\subsubsection{Comparação longitudinal entre pacientes e controles sem} diagnóstico de abuso e dependência de substâncias

Assim como na análise transversal das imagens, comparamos os grupos excluindo os casos que preenchessem critérios para abuso e dependência de substâncias ao longo da vida (pacientes=17 e controles=3).

A análise de covariância (ANCOVA) com 2 fatores (grupo x tempo), com o número total de voxels incluídos como covariáveis (gênero não foi incluído como covariável porque esses subgrupos não apresentaram diferença em relação à freqüência dessa variável) mostrou novamente uma interação significativa ( $<<0,05$, corrigido para comparações múltiplas) com o uso de SVC, com maior grau de preservação de substância cinzenta em pacientes (n=22) em relação aos controles ( $n=49$ ) em GTS esquerdo (BA 22 e 21, tanto o agrupamento 
encontrado na comparação anterior quanto um novo agrupamento situado superior e posteriormente àquele, coordenadas $\mathrm{x}, \mathrm{y}, \mathrm{z}=-55,-40,20)$ e em ínsula esquerda (BA 13; 9 voxels, picos em coordenadas $\mathrm{x}, \mathrm{y}, \mathrm{z}=-31,19,-11$, valor de $\mathrm{Z}=3,65$, valor de $\mathrm{p}=0,025$ ).

\subsubsection{5- Comparação longitudinal entre pacientes com tempo de doença ao exame inicial menor que 1 ano e controles}

Esses dois grupos diferiam em gênero (pacientes, masculino=23 e controles, masculino=26, $\mathrm{p}=0,027)$.

Novamente, foi observada interação significativa entre grupo e tempo (ANCOVAcom número total de voxels de substância cinzenta e gênero como cováriáveis), indicando maior grau de preservação de substância cinzenta em pacientes (n=30) em relação aos controles ( $\mathrm{n}=52),(\mathrm{p}<0,05$, corrigido) na áreas já descrita nas comparações anteriores (GTS ao SVC, 50 voxels, coordenadas $\mathrm{x}, \mathrm{y}, \mathrm{z}=-51,-15,1$, valor de $\mathrm{Z}=3,55$, valor de $\mathrm{p}=0,04)$, assim como em hipocampo direito (45 voxels, pico em coordenada $x, y, z=24,-12$, -9 , valor de $Z=3,98$, valor de $\mathrm{p}=0,005)$.

\subsubsection{Comparação longitudinal entre pacientes aderentes e não aderentes ao tratamento com antipsicóticos}

Com o objetivo de avaliar, de maneira exploratória, se o uso de medicamentos antipsicóticos teve influência sobre os padrões de resultados das comparações entre pacientes e controles descritas acima, as comparações do volume de substância cinzenta entre aderentes e não aderentes foram realizadas usando um limiar estatístico flexível de $\mathrm{p}<0,001$ não corrigido para comparações múltiplas. A interação grupo x tempo (ANCOVA) com número total de voxels como covariável mostrou que os pacientes aderentes ( $\mathrm{n}=15)$, comparados aos não 
aderentes (n=19) apresentam uma tendência a maior preservação de volume de substância cinzenta em região frontal (giro frontal médio direito, BA 8, cíngulo anterior direito e em giro frontal inferior esquerdo, BA 11), à análise exploratória $(\mathrm{p}<0,001$, não corrigido para comparações múltiplas).

Por outro lado, houve uma tendência a menor preservação de volume em outras áreas frontais (giro frontal inferior, BA9 e pré-central, BA 6 esquerdos) e em giro lingual (BA17) direito à análise exploratória ( $\mathrm{p}<0,001$, não corrigido para comparações múltiplas). No entanto, nenhum desses achados sobreviveu à correção para comparações múltiplas.

\subsubsection{Comparação longitudinal entre pacientes aderentes expostos a antipsicóticos típicos e expostos a antipsicóticos atípicos}

O grupo de pacientes aderentes à medicação $(n=15)$ foi subdividido de acordo com 0 tipo de AP utilizado durante o seguimento (típicos, $n=6$ versus atípicos, $n=9$ ). AANCOVA, com o número total de voxels incluído como covariável, mostrou interação grupo x tempo indicando maior preservação de substância cinzenta no grupo de pacientes aderentes a APs típicos em região temporal bilateralmente (giro temporal médio e inferior à esquerda e giro temporal médio e superior à direita) e em região occipital esquerda (cúneus, BA 18), (à análise exploratória, p<0,001, não corrigido para comparações múltiplas).

Uma tendência à maior preservação de volume em pacientes aderentes à APs atípicos quando comparados aos expostos aos APs típicos pôde ser observada em região frontal (giro frontal superior esquerdo e giro frontal médio direito) e em região parietal (giro parietal inferior esquerdo e giro parietal superior direito) à análise exploratória ( $<<0,001$, não corrigido para comparações múltiplas). Novamente, nenhum desses achados sobreviveu à correção para comparações múltiplas. 


\section{Discussão}

Nesta tese, foram avaliadas, com o uso da morfometria voxel-a-voxel (VBM), as diferenças volumétricas regionais de substância cinzenta entre pacientes com esquizofrenia e transtorno esquizofreniforme examinados à época do primeiro contato com serviços de saúde e um grupo de voluntários não psicóticos procedente da mesma comunidade. Foram, também, investigadas as diferenças volumétricas longitudinais entre os dois grupos após o período de 16 meses.

Estudos investigando aspectos neuroanatômicos da esquizofrenia empregando amostras de pacientes crônicos apresentam fatores de confusão, como efeitos do prolongado de medicação psicotrópica, hospitalizações e interações entre doença e envelhecimento cerebral. Este trabalho está inserido no contexto de que os estudos mais recentes de neuroimagem em esquizofrenia têm investigado seus aspectos biológicos durante os períodos iniciais da doença, assim como seu comportamento longitudinal (Copolov et al., 2000; Pantelis et al., 2005). Até o momento, apenas um grupo de pesquisa (britânico) empregou amostra de 
origem epidemiológica em seus estudos de neuroimagem em primeiro episódio psicótico (Dazzan et al., 2005; Morgan et al., 2007) e nenhum estudo longitudinal de RM em psicose foi conduzido com este tipo de amostra.

\subsection{INTERPRETAÇÃo DOS RESULTADOS DO ESTUDO TRANSVERSAL À ÉPOCA DO PRIMEIRO EPISÓDIO PSICÓTICO}

\subsubsection{Características sócio-demográficas e clínicas da amostra}

O recrutamento dos sujeitos a partir de um estudo epidemiológico permitiu que obtivéssemos uma amostra relativamente grande de pacientes em estágios inicias de psicose e de controles não psicóticos (62 pacientes com esquizofrenia e transtorno esquizofreniforme e 94 controles em nosso estudo, em comparação com 44 pacientes e 58 controles no estudo de Morgan et al. (2007), citado acima). Segundo metanálise de Steen et al. (2006), a média de sujeitos avaliados em estudos de RM em primeiro episódio psicótico é de 30 pacientes e 28 controles. Esse autor sugere que, dada a complexidade da esquizofrenia, o número de estudos de RM em primeiro episódio e a média de sujeitos avaliados por estudo ainda são relativamente pequenos.

A média de idade dos pacientes em nosso estudo foi de 27,6 (8) anos, compatível com a média de idade dos pacientes em estudos de primeiro episódio psicótico (26 anos), assim como a proporção entre gênero masculino e feminino: 70\% de homens no nosso estudo; 2/3 na literatura, segundo Steen et al. (2006).

Os critérios de inclusão utilizados pelos autores dos chamados estudos de primeiro episódio psicótico costumam ser a primeira hospitalização psiquiátrica, o primeiro contato com serviços de saúde por sintomas psicóticos (como no caso do presente estudo) ou o início do tratamento (Vita et al., 2006). Embora alguns estudos incluam em suas amostras pacientes com diagnóstico de transtorno esquizoafetivo e psicoses afetivas, a maioria dos 
estudos de RM em primeiro episódio psicótico avalia pacientes com diagnóstico de esquizofrenia e transtorno esquizofreniforme(Vita et al., 2006). Ainclusão de pacientes com transtorno esquizofreniforme justifica-se porque em grande parcela desses pacientes esse diagnóstico é provisório, ou seja, os pacientes evoluirão com diagnóstico de esquizofrenia (após o período necessário de observação de 6 meses).

O recrutamento da amostra a partir de um desenho epidemiológico reduziu o viés de seleção presente na maioria dos estudos de esquizofrenia, nos quais, em geral, os pacientes são procedentes de unidades de tratamento especializadas e os controles não são, necessariamente, procedentes da mesma comunidade que aqueles. Dessa forma, o método de recrutamento dos sujeitos deste trabalho possibilitou a coleta de uma amostra mais representativa da população geral. Embora os sujeitos de cada grupo não tenham sido emparelhados individualmente, ambos os grupos foram extraídos da comunidade geral e das mesmas regiões da cidade de São Paulo. Além disso, pacientes e controles foram recrutados, avaliados e submetidos ao exame de RM ao longo do mesmo período.

Quanto ao tempo de contato (intervalo entre o surgimento dos sintomas psicóticos e o contato com atendimento médico) e à duração da doença (tempo decorrido entre o surgimento dos sintomas psicóticos e o primeiro exame de RM), estes se mostraram bastante variáveis. Embora essa variedade seja também encontrada em estudos de RM em psicose (Steen et al., 2006), alguns estudos de primeiro episódio incluem pacientes cuja duração de doença não seja superior a 1 ano e meio (Vita et al., 2006). Optamos por incluir todos os pacientes que preenchessem o critério de primeiro contato com serviço de saúde por psicose, independente do tempo de duração de doença prévia.

Houve diferenças sócio-demográficas entre os pacientes e controles, compatíveis com descrições na literatura. Apesar de ambos os grupos terem sido extraídos da comunidade geral, o grupo de pacientes (mesmo em início de doença) apresentava características relacionadas a um pior funcionamento social, como menor escolaridade, classe social mais 
baixa, menor freqüência de sujeitos exercendo atividade remunerada e vivendo com parceiro(a) regular. Esses achados podem refletir um pior funcionamento pré-mórbido ou a conseqüência dos efeitos da psicose (Larsen et al., 1996; Addington et al., 2008).

Outra diferença entre pacientes e controles foi observada em relação ao uso de substâncias psicoativas (sendo que não foram incluídas neste trabalho as freqüências de uso de nicotina e cafeína). Os pacientes apresentaram maior freqüência de abuso ou dependência de substâncias psicoativas do que os controles e do que o esperado para a população geral, e esse achado é compatível com a literatura a respeito do primeiro episódio psicótico, sugerindo que o uso de substâncias não seja secundário ao surgimento da psicose (Addington e Addington, 2007).

Em relação aos sintomas, observamos que os valores médios obtidos na escala PANSS na data do exame inicial indicaram baixa gravidade de sintomas positivos e negativos. Os pacientes foram submetidos ao exame inicial de RM 4 meses (em média) após o primeiro contato com serviço de saúde, sendo tal avaliação realizada apenas quando os sujeitos estivessem em condições clínicas para tal. Não foram coletadas medidas de gravidade de sintomas no momento do primeiro contato em si. Portanto, em geral, as medidas da PANSS não se referem ao momento mais agudo do quadro clínico desses pacientes. Além disso, ao contrário da maioria dos estudos em esquizofrenia, que não são de base epidemiológica, este estudo não empregou amostra de pacientes acompanhados em serviços de atendimento psiquiátrico especializado ou pacientes em unidades de internação, os quais costumam apresentar maior gravidade de sintomas psicóticos à época das investigações.

Uma vez havendo esse intervalo de tempo entre o primeiro contato com serviço de saúde e a realização do exame de RM, apenas um número pequeno de pacientes ( $\mathrm{n}=02$ ) nunca havia sido exposto a APs antes do exame de RM inicial (haviam sido medicados apenas com benzodiazepínicos nas unidades de urgência). Por outro lado, uma parcela substancial dos sujeitos (34\%), apesar de ter feito uso inicial de APs, não aderiu ao tratamento e estava sem medicação no momento do exame. 
Observa-se que o restante (63\%) dos pacientes estava em uso de APs ao primeiro exame de RM, o que não é incomum nos estudos de primeiro episódio; os pacientes são tipicamente tratados com APs assim que possível quando o diagnóstico é feito, de modo que raríssimos estudos de imagem conseguiram avaliar amostras inteiras de pacientes sem qualquer exposição prévia a esse tipo de medicação (Steen et al., 2006). Além da heterogeneidade em relação à adesão ao tratamento inicial, a classe (típicos ou atípicos) e dose de APs utilizadas pelos pacientes também foram variáveis e não controlados no presente estudo, uma vez que os pacientes foram tratados nos diversos serviços disponíveis na comunidade e o tratamento seguiu as necessidades clínicas e opções dos médicos responsáveis.

\subsubsection{Achados de neuroimagem}

\subsubsection{Redução do volume de substância cinzenta em pacientes comparados aos controles}

O achado principal da análise por VBM comparando pacientes com esquizofrenia e transtorno esquizofreniforme com os controles assintomáticos foi a identificação de áreas de redução de substância cinzenta no grupo de pacientes. Essa redução foi observada em áreas neocorticais frontais e temporais (córtex pré-frontal dorsolateral bilateralmente e córtex do giro temporal superior esquerdo), em áreas límbicas (hipocampo direito) e paralímbicas (giro parahipocampal direito e ínsula bilateral) (Schaufelberger et al., 2007).

Essas regiões estão incluídas entre as mais freqüentemente identificadas como reduzidas em estudos de neuroimagem por RM em primeiro episódio psicótico e são comumente implicadas na fisiopatologia da esquizofrenia (Honea et al., 2005, Vita et al., 2006; Steen et al., 2006).

Até o momento, apenas um estudo investigou a presença de anormalidades cerebrais estruturais em primeiro episódio psicótico em países em desenvolvimento, com uma amostra 
menor e um desenho não epidemiológico. Jayakumar e colaboradores (2005) utilizaram o método de VBM para examinar volumes de substância cinzenta numa amostra de 18 pacientes em primeiro episódio psicótico na Índia. Comparados aos controles, os pacientes mostraram menor volume de substância cinzenta global e alterações regionais em córtex frontal, temporal e insular e região parahipocampal.

Nossos achados implicam a mesma rede de regiões, usando uma amostra de primeiro episódio de tamanho comparável aos utilizados nos maiores estudos de RM em psicose conduzidos em países desenvolvidos (Steen et al., 2006) e corroboram a hipótese de que a redução volumétrica de substância cinzenta em pacientes com esquizofrenia acomete diversas áreas cerebrais e encontra-se presente já no início da doença, não sendo conseqüência dos efeitos crônicos da patologia ou da exposição prolongada dos APs sobre o tecido cerebral (Honea et al., 2005; Vita et al., 2006, Steen et al., 2006).

A redução de volume em córtex pré-frontal tem sido relatada em estudos de esquizofrenia crônica e em primeiro episódio psicótico (Honea et al., 2005; Shenton et al., 2001), sendo também compatível com a literatura de neuropatologia em esquizofrenia discutida na seção de Introdução desta tese (item 1.2.1.2) (Harrison, 1999). O córtex pré-frontal apresenta conexões com todas as outras áreas corticais, com estruturas límbicas e núcleos da base, tendo um importante papel modulatório em todos os aspectos do funcionamento humano. A importância dessa região no estudo da esquizofrenia deve-se à presença de sintomas cognitivos e comportamentais compatíveis com alterações de funcionamento frontal, além de sintomas positivos que podem estar relacionados à uma disfunção na conexão fronto-temporal (Shenton et al., 2001).

É importante discutir as possíveis implicações dos métodos usados no presente estudo sobre o padrão de resultados obtidos. A escolha de um grande volume de interesse para a investigação com SVC (região pré-frontal inteira, incluindo o giro do cíngulo) deveu-se ao fato de que os estudos prévios identificaram alterações em diferentes áreas do córtex frontal. 
Especula-se que a razão pela qual alguns estudos falharam em encontrar redução de volume em lobo frontal em pacientes com esquizofrenia comparados a controles tenha sido a utilização de medidas do lobo como um todo (ao invés de sub-regiões separadas) e a não segmentação entre substância cinzenta e branca. É possível, também, que as alterações volumétricas em áreas frontais na esquizofrenia sejam sutis, não sendo detectáveis em estudos com amostras pequenas (Shenton et al., 2001). O uso do método de VBM com a análise voxel-a-voxel da substância cinzenta e o emprego de uma amostra grande permitiu a identificação de diferença cortical frontal entre pacientes e controles em nosso estudo. No entanto, embora tenhamos identificado redução de volume em uma área implicada na fisiopatologia da esquizofrenia (córtex pré-frontal dorsolateral), reconhecemos que usar um volume de interesse grande tem a desvantagem de reduzir nossa capacidade de detectar alterações de volume mais sutis e em outras sub-regiões do córtex frontal.

Outra região neocortical que apresentou redução de volume em nossa amostra de pacientes em relação aos controles foi o giro temporal superior esquerdo (GTS). Esta região tem sido constantemente descrita como reduzida em estudos de RM em esquizofrenia crônica e em primeiro episódio psicótico (Shenton et al., 2001; Honea et al., 2005). Já foram relatadas reduções no GTS total e em sub-regiões anterior e posterior, sendo que as anormalidades geralmente referem-se ao lado esquerdo (Kim et al., 2003).

O GTS faz parte de uma rede neural de processamento de linguagem e geração da fala e estaria implicado na fisiopatologia dos sintomas positivos. Vários estudos encontraram relação entre redução de volume do lobo temporal esquerdo (principalmente do GTS) e gravidade de sintomas positivos, particularmente alucinações auditivas e alteração de pensamento (Barta et al., 1990; Flaum et al., 1995; Levitan et al., 1999; Milev et al., 2003, Kim et al., 2003), embora esse padrão de resultados nem sempre tenha sido replicado (Fannon et al., 2000; Sanfilipo et al., 2000; Gur et al., 2000). A inconsistência de resultados na literatura relacionando o volume dessa região aos sintomas psicóticos pode refletir diferentes metodologias de volumetria empregadas nas investigações (Kim et al., 2003). 
Em nosso estudo, a correlação entre a gravidade de sintomas positivos e uma redução de volume de substância cinzenta em GTS (à direita) não sobreviveu à correção para comparações múltiplas. Por outro lado, encontramos uma correlação inversa com os escores dos sintomas negativos em GTS esquerdo. A região do GTS onde essa associação foi encontrada situa-se anteriormente àquela descrita com reduzida na comparação geral entre pacientes e controles.

Embora na literatura os sintomas negativos sejam principalmente associados a alterações em córtex pré-frontal (O’Donnell e Grace, 1998) redução de volume de lobo temporal esquerdo foi correlacionada a sintomas negativos nos estudos de Turetsky et al. (1995) e de Becker et al. (1996). Por outro lado, Kim et al. (2003) encontraram aumento, ao invés de redução, de GTS posterior direito relacionado a sintomas negativos. Os autores deste último estudo declararam que, por este achado não ter sobrevivido à correção para comparações múltiplas e por ser contra-intuitivo, deve ser interpretado com cautela. A fisiopatologia da relação entre sintomas negativos e a morfologia do córtex temporal superior ainda não foi esclarecida. Segundo Kim et al. (2003), uma explicação para essa associação seria a relação com a presença de alogia, dado o papel do GTS na linguagem.

Deve-se ressaltar que a associação entre sintomas negativos e redução de GTS em nosso estudo foi encontrada em uma região diferente daquela identificada como reduzida na comparação entre pacientes e controles, ou seja, alterações em GTS parecem expressar tanto os efeitos dos sintomas negativos, quanto o efeito direto e independente do processo da doença em si.

Em relação ao sistema límbico, a redução do hipocampo em esquizofrenia é relatada em estudos de metanálise, tanto em pacientes crônicos como em primeiro episódio (Honea et al., 2005; Vita et al., 2006; Steen et al., 2006). O interesse sobre o hipocampo em esquizofrenia começou na década de 70 do século passado, com o surgimento da hipótese límbica da doença, sendo que os primeiros achados de redução de hipocampo neste transtorno 
psiquiátrico surgiram na década de 1980. Atualmente, há uma vasta literatura a respeito das alterações de estrutura e função do hipocampo em esquizofrenia, sendo a redução de volume desta região cerebral, embora sutil, um dos achados de anormalidades cerebrais mais replicados nesse transtorno (Heckers, 2004).

A disfunção do lobo temporal medial está implicada na psicose, pois contribuiria para a presença dos sintomas positivos (Copolov et al., 2000), tendo um papel na gênese dos delírios e alucinações. Segundo revisão de Heckers (2004), os sintomas positivos são considerados secundários a uma hirperatividade ou a uma redução da inibição do hipocampo, e não apenas os processos de memória, mas também outros déficits cognitivos, como déficits de funções frontais, estariam relacionados à redução do volume desta estrutura límbica. Ainda segundo Heckers (2004), estudos de neuroimagem funcional em esquizofrenia mostram que o hipocampo apresenta uma hipoativação basal e uma hiperativação em tarefas de memória, sendo que durante esta última, ocorreria, simultaneamente, um aumento da ativação em região pré-frontal.

Entre os possíveis mecanismos causais de redução de volume hipocampal encontramse: hipóxia perinatal por complicações obstétricas, estresse (tanto por ação dos glucocorticóides como por ação de aminoácidos excitatórios) e desinibição do eixo hipotálamo-hipófise-adrenal (Copolov et al., 2000). Na base da fisiopatologia do envolvimento do hipocampo na esquizofrenia, estaria uma disfunção na conexão dos interneurônios do sistema gabaérgico, como conseqüência de lesão ocorrida possivelmente em fases iniciais do desenvolvimento ou mesmo durante o período prodrômico da doença. Essa disfunção estaria presente em outras psicoses, sugerindo a presença de um fator não específico (o estresse, por exemplo), ao invés de um fator exclusivo da esquizofrenia (Benes, 1999). De fato, alteração de volume hipocampal não tem sido observada apenas em esquizofrenia, sendo descrita também em estudos de neuroimagem em transtornos do humor, no envelhecimento normal, em doença de Cushing e em pacientes com transtorno de estresse pós-traumático (Shenton et al., 2001). 
Deve-se destacar, também, que a presença de redução volumétrica em córtex préfrontal e em regiões temporais (córtex temporal superior e região temporal medial) presentes no mesmo grupo de pacientes do presente estudo é compatível com estudos prévios em esquizofrenia que demonstraram a existência de correlações volumétricas e de relações neuroanatômicas e funcionais entre essas áreas (Shenton et al., 2001).

Em nosso estudo, o grupo de pacientes também apresentou redução volumétrica de regiões paralímbicas (giro parahipocampal e ínsula) em relação aos controles. A redução de volume do giro parahipocampal foi encontrada à direita, justaposta à área de redução do hipocampo. Acometimento dessa região também vem sendo descrito nos estudos de RM em esquizofrenia (Honea et al., 2005), embora esta seja uma área cerebral menos estudada e os resultados, menos consistentes.

O giro parahipocampal encontra-se intimamente relacionado com o hipocampo, enviando-lhe informação sensorial multimodal altamente processada e integrada, dando origem ao registro e à coleta de informação da memória de longo prazo. Ambos (hipocampo e giro parahipocampal) estão em conexão com o córtex pré-frontal associativo e uma interação anormal entre essas áreas levaria aos sintomas positivos e cognitivos da esquizofrenia (Heckers, 2004).

Por fim, o acometimento da ínsula também vem sendo descrito em estudos com amostras de sujeitos em primeiro episódio psicótico comparados a controles (Crespo-Facorro et al., 2000; Pressler et al., 2005). A redução do volume dessa estrutura é quase unanimemente encontrada nos estudos de RM que avaliaram essa região em esquizofrenia (Saze et al., 2007). A ínsula faz parte do chamado córtex paralímbico (área justaposta entre o neocórtex e o sistema límbico e com arquitetura intermediária entre ambos), tendo um importante papel na integração de percepções sensoriais e afetivas responsável pela geração de um comportamento adequado, sendo, portanto, considerada como uma região de córtex de integração límbico (Chua et al., 1999). Essa estrutura tem importância na fisiopatologia da 
esquizofrenia, uma vez que anormalidades na capacidade de distinção entre percepções internas e externas e alterações na geração de comportamentos reguladores podem ser estar subjacentes aos sintomas psicóticos (Saze et al., 2007).

A redução da ínsula, em nosso estudo, correlacionou-se com a gravidade dos sintomas à RM, medida pela PANSS. Observamos que a redução de volume à direita correlacionouse com maiores escores de sintomas positivos, enquanto à esquerda associou-se com a gravidade de sintomas negativos. Podemos inferir, portanto, que a sintomatologia psicótica apresenta reflexo na anatomia cerebral em uma região previamente implicada na esquizofrenia. Correlações entre alterações em ínsula e gravidade de sintomas positivos já foram relatadas anteriormente (Barta et al., 1990; Crespo-Facorro et al., 2000; Pressler et al., 2005; Makris et al., 2006). Adicionalmente, o estudo de Shapleske et al. (2002) mostrou uma redução de ínsula em pacientes com história de alucinações quando comparados a pacientes sem esse sintoma. Achado semelhante foi encontrado no estudo de O’Daly et al. (2007), no qual a redução da ínsula bilateralmente estava presente em pacientes com alucinações persistentes comparados a controles, embora não houvesse correlação entre a gravidade dos sintomas e o volume da estrutural. Por outro lado, essa relação entre a ínsula e sintomas positivos nem sempre foi observada (Saze et al., 2007) e não há, até o momento, descrições de associação dessa região com sintomas negativos.

\subsubsection{Influência de possíveis fatores confundidores sobre o resultado da comparação entre pacientes e controles}

\subsection{Exposição a antipsicóticos}

Como a o tempo de exposição a essas medicações foi bastante variável entre os pacientes e a informação a respeito das doses diárias não eram precisas em todos o casos, optamos por avaliar a amostra de pacientes de acordo com o tempo de exposição aos APs 
antes do exame de RM inicial, para podermos comparar as diferenças anatômicas entre sujeitos com maior exposição a APs em relação ao sujeitos que pudessem ser considerados como não expostos à época do exame (medicados versus não medicados). Em seguida, subdividimos o grupo de pacientes medicados em 2 grupos de acordo com a classe de APs utilizada (típicos ou atípicos).

A ausência de diferença volumétrica à comparação entre pacientes medicados e não medicados indicou que as reduções de volume de substância cinzenta em pacientes comparados aos controles observadas em nossa análise principal também não foram secundárias aos efeitos dos APs sobre o tecido cerebral. Por outro lado, a investigação dos efeitos das duas classes de APs evidenciou uma redução de volume em hipocampo e giro parahipocampal esquerdos relacionada a uma maior exposição aos típicos, sendo que não foi observada nenhuma correlação entre volume de substância cinzenta e exposição aos APs atípicos.

A questão dos efeitos dos APs sobre a estrutura cerebral ainda não está esclarecida. Embora haja uma literatura consistente em relação aos efeitos dos APs típicos sobre os núcleos da base, os estudos de RM sobre os efeitos dos APs sobre o córtex, e particularmente sobre os efeitos dos APs atípicos, ainda são recentes e inconclusivos (Scherk e Falkai, 2006).

Nos estudos de Velakoulis et al. (1999) e de Chakos et al. (2005) não foram observadas correlações entre exposição a APs típicos e volume do hipocampo em pacientes com doença inicial ou em pacientes crônicos. Essa associação também não foi observada nos pacientes de primeiro episódio de Lieberman et al. (2001). Apesar desses achados negativos, conforme discutido na revisão de Konradi e Heckers (2001), os APs típicos, como o haloperidol, teriam a capacidade de causar alterações anatômicas e moleculares, via plasticidade sináptica (não apenas no estriado, como em áreas límbicas e frontais, gerando aumento de volume) que seriam reversíveis após cessação do uso ou troca por atípicos. Por outro lado, os APs típicos seriam responsáveis, também, por efeitos neurotóxicos e por redução de volume cerebral após o tratamento de longo prazo ou após exposição a altas dosagens. Ou seja, os 
APs típicos teriam um efeito simultâneo de induzir neurotoxicidade e neuroplasticidade, enquanto as ações dos APs atípicos seriam mais sutis e espalhadas (Konradi e Heckers, 2001). Essa hipótese é corroborada por estudos em animais que sugerem que a administração crônica de APs típicos (mas não de atípicos) reduziria a expressão da neurotrofina “brainderived neurotrophic factor” (BDNF) no hipocampo de ratos (Lipska et al., 2001; ChlanFourney et al., 2002; Bai et al., 2003; Pillai et al., 2006).

Supõe-se, então, que a ausência de diferenças volumétricas em nosso estudo entre pacientes medicados e não medicados possa ser explicada pelo fato de que em ambos os grupos havia pacientes expostos a APs típicos e a atípicos. Já quando analisamos o efeito do tempo de exposição de cada tipo de AP separadamente sobre o cérebro, encontramos um efeito dos APs típicos, mas não dos atípicos, sobre o hipocampo.

Nota-se que a exposição aos APs típicos correlacionou-se à redução de volume temporal medial à esquerda, enquanto a redução de volume observada na comparação entre pacientes e controles localizava-se à direita. Dessa forma, concluímos que as diferenças volumétricas entre pacientes e controles não foram causadas por efeito confundidor da medicação no primeiro grupo.

\subsection{Uso de substâncias psicoativas}

Como o abuso ou dependência de substâncias era mais prevalente nos pacientes do que nos controles, esse fato poderia confundir a interpretação dos resultados volumétricos. Por isso, conduzimos uma subanálise, incluindo apenas os sujeitos sem esses diagnósticos, o que tornou nossa comparação mais compatível com outras investigações, já que a maioria dos estudos prévios de RM em esquizofrenia exclui sujeitos com dependência de álcool e drogas. 
Com exceção da perda de significância estatística no caso do achado de redução préfrontal (o que pode dever-se à diminuição da amostra nessa comparação), foi observado um padrão similar àquele encontrado na análise que englobava todos os pacientes e todos os controles. Ou seja, podemos afirmar que as diferenças volumétricas entre pacientes e controles no nosso estudo não foram secundárias aos efeitos da exposição ao álcool e drogas.

\subsection{Variabilidade do tempo de história de psicose}

A duração da doença até a primeira RM foi bastante variável entre os pacientes incluídos neste estudo, com tempo de história de psicose variando entre 01 e 92 meses. Com o propósito de avaliar se as possíveis alterações volumétricas aqui discutidas seriam encontradas realmente no início do quadro psicótico e não seriam decorrentes de subcronicidade da doença, conduzimos uma análise de correlação entre o volume de substância cinzenta com o tempo de história de doença e com a duração da psicose não tratada (DUP). Essas análises não mostraram áreas de correlação significativas, ou seja, não houve efeito do tempo de psicose sobre a morfometria da substância cinzenta, o que é compatível com a maioria dos estudos transversais deste tipo (Vita et al., 2006) e sugere a presença de alterações causadas por processos de neurodesenvolvimento, e não por efeitos tóxicos da psicose. A ausência de correlação linear entre tempo de doença e volume também corrobora os achados de neuroimagem de que as alterações já são encontradas em estágios iniciais da psicose, e não apenas nos pacientes com tempo mais longo de doença.

\subsection{INTERPRETAÇÃO DOS RESULTADOS DO ESTUDO LONGITUDINAL}

\subsubsection{Características sócio-demográficas e clínicas da amostra}

A princípio, todos os sujeitos que completaram o estudo de RM inicial (e que não apresentassem contra-indicação para o novo exame de RM) seriam incluídos no estudo de 
seguimento. No entanto, pelo fato de tratar-se de sujeitos da comunidade geral e não sendo os pacientes vinculados a um mesmo serviço de psiquiatria, não foi possível localizar todos os sujeitos após o intervalo de um ano. Além disso, alguns sujeitos não estavam mais morando em São Paulo à época da reconvocação.

Apesar da perda amostral, o número final de sujeitos que completou o estudo de seguimento torna esta amostra uma das maiores entre os estudos desse tipo, como pode ser observado pela Tabela 2, da seção da Introdução. Não é possível comparar diretamente a taxa de reconvocação de nosso estudo (63\% dos pacientes e 55\% dos controles) com a de outros estudos longitudinais similares, uma vez que este é o único estudo de RM longitudinal em esquizofrenia com amostra de base epidemiológica. No entanto, pudemos demonstrar que não houve diferenças sócio-demográficas e clínicas entre os sujeitos que completaram o estudo de seguimento e aqueles que só participaram do estudo inicial.

Quanto à comparação entre pacientes e controles, a diferença na freqüência de gênero (que apresentava uma tendência a ser significativa ao exame inicial de toda a amostra), tornouse, de fato, significativa ao exame de seguimento, com uma maior proporção de sexo masculino no grupo de pacientes. Por esse motivo, salvo algumas subanálises, as análises de VBM longitudinal comparando pacientes e controles passaram a ser covariadas por gênero.

Dentre os pacientes que completaram o estudo de seguimento $(n=39)$, uma parcela significativa dos pacientes com diagnóstico de transtorno esquizofreniforme à RM inicial preencheu diagnóstico de esquizofrenia durante o seguimento (70\%), como seria esperado de acordo com a literatura (Addington et al., 2006; Schimmelmann, et al., 2005).

Quanto à evolução clínica, embora as medidas de gravidade de sintomas obtidas pelas médias da PANSS não tenham mostrado diferença entre o primeiro e o segundo exames, tendo permanecido em níveis baixos, é necessário destacar que as medidas da PANSS foram obtidas apenas nos momentos dos dois exames e que alguns pacientes apresentaram períodos de reagudização ou continuidade de sintomas psicóticos durante o intervalo de 
seguimento (o que pode ser constatado pela evolução no diagnóstico de transtorno esquizofreniforme para esquizofrenia, por exemplo). As medidas da PANSS fornecem informação relativa ao período transversal em que é aplicada, e não necessariamente fornecem informação sobre o comportamento dos sintomas continuamente ao longo do tempo (16 meses, em média, neste caso). Podemos inferir, apenas, que enquanto grupo, os pacientes apresentavam gravidade de sintomas similar às duas avaliações.

Em nosso estudo, os pacientes não foram incluídos em nenhum protocolo específico de tratamento. Eles permaneceram na comunidade geral, recebendo tratamento na rede de saúde pública ou em consultórios particulares.

O estudo foi naturalístico, não havendo um protocolo de intervenção e de acompanhamento medicamentoso. Dessa forma, durante o seguimento, os pacientes apresentaram variáveis graus de adesão ao tratamento e exposição a APs.

Enquanto 41\% dos pacientes apresentou boa adesão ao tratamento aos APs durante o intervalo de seguimento (uso, de fato, por 80\% do tempo ou mais), 13\% deles não fez uso de APs em nenhum momento e $46 \%$ seguiu o tratamento de maneira irregular (nesse grupo, os APs foram utilizados, em média, durante 33\% do tempo).

Portanto, pode-se dizer que cerca de $60 \%$ dos pacientes não apresentaram boa adesão ao tratamento durante o seguimento. Esta taxa de não-adesão é mais elevada do que o apresentado pela literatura. No estudo epidemiológico de Cooper et al., (2007), os pacientes com esquizofrenia foram categorizados em persistentes (os que compareciam às consultas médicas) e aderentes (os que realmente ingeriam a medicação prescrita, no caso APs atípicos, por $80 \%$ do tempo ou mais). Após 12 meses, 67,5\% deles persistiam e 78,6\% destes eram aderentes. Ou seja, quase um terço abandonou o tratamento e dos que seguiam em acompanhamento, quase 20\% não usavam a medicação prescrita de forma regular. Em resumo, 53\% da amostra toda eram, de fato, aderentes. A revisão de Rosa et al. (2007), que inclui um trabalho conduzido em São Paulo, também indica taxas de não-adesão ao tratamento farmacológico em esquizofrenia variando entre 41 a 48\% em um ano de seguimento. 
A investigação a respeito da adesão ao tratamento foge do objetivo deste trabalho. No entanto, pode-se supor que a maior taxa de não-adesão ao tratamento em nossa amostra esteja associada a fatores como características clínicas dos sujeitos, fatores de saúde pública, diferenças no acesso ao tratamento e ao fato de tratar-se de uma amostra da comunidade geral e não de uma amostra institucional. Essa diferença é particularmente acentuada quando observamos a adesão de pacientes aos APs nos estudos longitudinais de RM. Essas investigações não seguiram pacientes dispersos na comunidade e as amostras avaliadas, em geral, eram menores do que a compreendida no nosso estudo, de forma que a grande maioria dos pacientes desses estudos de RM continuava em uso de AP ao segundo exame (conforme descrito na Tabela 2, na seção de Introdução desta tese).

Quando o grupo de pacientes foi dicotomizado de acordo com a adesão aos APs para fins de análises dos dados de neuroimagem (aderentes=pacientes que utilizaram esse tipo de medicação por pelo menos $80 \%$ do intervalo de seguimento; não aderentes=pacientes com uso inferior a 50\% desse período), encontramos algumas diferenças sócio-demográficas e clínicas entre eles. Tanto ao exame inicial, quanto ao seguimento, os pacientes com má adesão tinham menor escolaridade (assim como seus pais) e menor renda mensal, enquanto os pacientes com melhor adesão apresentavam tendência a maior gravidade de sintomas negativos (em média). Esse último achado pode ter sido conseqüência da dificuldade de diferenciação, ao exame clínico, entre a presença de sintomas negativos verdadeiros e os efeitos colaterais dos APs.

\subsubsection{Achados de neuroimagem}

\subsubsection{Alterações longitudinais de volume de substância cinzenta em pacientes e controles}

Apesar da variabilidade de achados nos estudos longitudinais de RM que avaliaram pacientes a partir do primeiro episódio psicótico, segundo revisão sobre esses estudos feita 
por Steen et al. (2006), alterações progressivas já foram observadas em sistema ventricular, hipocampo, substância cinzenta global, giro deHeschl, “planum temporale” e substância cinzenta temporal. Por outro lado, alterações progressivas ainda não teriam sido descritas em regiões como ínsula e tálamo.

Em nosso estudo, embora as comparações intragrupo não tenham mostrado áreas de alteração volumétrica longitudinal nos pacientes ou nos controles, a interação entre grupo e tempo mostrou que os grupos evoluíram de maneira diferente. Os pacientes apresentaram, em relação aos controles, uma preservação de volume de substância cinzenta na região posterior do córtex temporal superior esquerdo e na região temporal medial direita (hipocampo). Esses agrupamentos identificados, embora constituídos por pequeno número de voxels, apresentaram significância estatística mesmo após correção para comparações múltiplas.

Ou seja, embora não tenha sido observada variação de volume do córtex temporal superior e do hipocampo nem no grupo de pacientes e tampouco no grupo de controles após 16 meses, essas regiões apresentaram um diferente grau de evolução longitudinal entre os grupos. Deve-se notar que essa diferença foi observada em áreas que mostravam redução de volume nos pacientes em relação aos controles ao exame inicial (GTS e hipocampo), ou seja, são áreas comprometidas ao primeiro episódio psicótico, mas que evoluem com preservação de volume em relação aos processos de envelhecimento cerebral normal ao longo dos 16 meses seguintes.

Em relação ao GTS, alguns estudos de RM longitudinal em amostras de sujeitos portadores de esquizofrenia evidenciaram progressão de redução volumétrica em pacientes (Kasai et al. 2003b), enquanto outros apresentaram resultados compatíveis com nosso achado de preservação longitudinal de volume nessa área cerebral em estágios iniciais da psicose (Gur et al.,1998; Keshavan et al., 1998b; DeLisi et al., 2005).

No estudo de Gur et al. (1998), os pacientes em primeiro episódio já apresentavam menor volume cerebral total e menor volume de lobos frontal e temporal do que os controles. 
Após o período médio de 30 meses, os lobos temporais apresentavam redução em maior grau nos controles do que nos pacientes (apesar destes últimos apresentarem redução longitudinal de lobos frontais). Esses autores não correlacionaram esse achado de preservação relativa de GTS em pacientes ao uso de APs durante o seguimento, e pelo contrário, correlacionaram a perda volumétrica frontal ao uso da medicação.

Outro estudo a relatar preservação de GTS em pacientes foi o de Keshavan et al. (1998b). Nesta investigação, a comparação de 17 pacientes em primeiro episódio de psicose a 17 controles saudáveis mostrou que os pacientes também apresentavam menor volume de GTS esquerdo à avaliação inicial. O seguimento de 11 pacientes e 12 controles, após um ano, mostrou um aumento de GTS (bilateralmente) nos pacientes, enquanto não houve diferença entre o volume dessa região nos controles. Este artigo, ao contrário do estudo de Gur et al. (1998), discute a possibilidade de um efeito dos APs típicos no aumento longitudinal de GTS nos pacientes. A outra hipótese levantada nesse estudo é a de que a redução inicial vista no GTS seria, ao menos em parte, um efeito de estado, podendo haver melhora após a estabilização da doença. Segundo esses autores, vários mecanismos podem estar subjacentes às alterações estruturais no início da psicose e essas alterações poderiam refletir lesão ao invés de morte neuronal. Seriam, assim, potencialmente reversíveis, como no caso de estarem vinculadas a alterações no eixo hipotálamo-hipófise-adrenal ou de serem conseqüência de lesão oxidativa (Keshavan et al., 1998b).

Quanto à questão do papel do estado sintomatológico sobre a evolução de alterações volumétricas cerebrais associadas à esquizofrenia, observa-se que, embora alterações do córtex do GTS tenham sido correlacionadas à gravidade de sintomas psicóticos (particularmente com sintomas positivos) em outros estudos (Kim et al., 2003), a redução inicial em córtex do GTS esquerdo nos pacientes, identificada em nosso estudo transversal, não se correlacionada aos sintomas positivos ou negativos. Além disso, não encontramos diferença longitudinal entre as medidas de sintomas psicóticos extraídos pela PANSS. Portanto, o comportamento 
longitudinal do GTS em nosso estudo também não parece ser secundário ao estado sintomatológico dos pacientes.

Em relação ao hipocampo, nossos achados corroboram outros estudos longitudinais que avaliaram presença de redução hipocampal ao primeiro episódio psicótico e a não progressão longitudinal após o início da doença (Lieberman et al., 2001; Wood et al., 2001).

Lieberman et al. (2001) mostraram que os pacientes apresentavam menores volumes de hipocampo anterior em relação aos controles tanto no início da doença quanto ao seguimento; no entanto, a interação entre grupo e tempo mostrou que o volume do hipocampo anterior dos controles diminuiu com o tempo, enquanto o volume hipocampal dos pacientes de mau prognóstico aumentou. Além disso, o volume cortical dos pacientes de bom prognóstico também aumentou em maior grau em relação aos controles. Lieberman et al. discutem nesse artigo sobre a possibilidade de efeito protetor do tratamento (assim como Keshavan et al. haviam discutido em relação ao achado do GTS em 1998, conforme mencionado acima) ou de adaptações neuroplásticas a ele, embora não tenham encontrado correlação entre os volumes corticais ou hipocampais e exposição a APs. Essa ausência de correlação, segundo Lieberman et al., não excluiria a possibilidade de que o efeito do tratamento resulte em diferentes graus de mudança volumétrica cerebral, já que estes autores encontraram associação entre volume ventricular menor(inicial e final)e maior tempo de tratamento no intervalo de seguimento.

\subsubsection{Influência de possíveis fatores confundidores sobre os resultados da comparação entre pacientes e controles}

\subsection{Exposição a antipsicóticos}

Conforme apontado nos estudos longitudinais discutidos no item anterior e conforme discutido no item 5.1.2.2.1 desta seção, o tratamento com APs pode exercer influência sobre o volume de estruturas cerebrais. 
Existe a possibilidade de que as reduções relatadas em estudos longitudinais sejam confundidas por efeito medicamentoso. Segundo Dorph-Petersen (2005), entre 50 estudos de neuroimagem estrutural em esquizofrenia, 11 encontraram redução de volume cerebral total; entretanto, todos esses 11 estudos foram conduzidos com amostras de pacientes com quadros crônicos de esquizofrenia e medicados, enquanto 10 dos estudos negativos eram baseados em pacientes em primeiro episódio psicótico.

Conforme observado na discussão sobre os efeitos dos APs no estudo transversal, alguns estudos (tanto em neuroimagem de pacientes psicóticos quanto estudos em animais) sugerem que os atípicos, em relação aos típicos, teriam um efeito neuroprotetor ou causariam menor redução de volume cortical (Dazzan et al., 2005; Lieberman et al., 2005; Garver et al., 2005; Pillai et al., 2006, van Haren et al., 2008). Outros estudos, por sua vez, falharam em encontrar efeito protetor associado a atípicos (Konopaske et al., 2007), ou encontraram efeitos opostos para diferentes APs atípicos (Molina et al., 2005b e 2007). A associação entre exposição a típicos e redução volumétrica também não é unânime, uma vez que a exposição cumulativa a típicos cursou com menor dilatação ventricular (DeLisi et al., 1997) e normalização de volume de GTS (Keshavan et al., 1998) nos estudos de imagem, e provocou proliferação glial em córtex pré-frontal em primatas no estudo de Selemon et al. (1999a).

No nosso estudo, de caráter naturalístico, com uma amostra da comunidade geral, a adesão ao tratamento e os tipos de medicação utilizados pelos pacientes durante o intervalo de seguimento foram variáveis e não controlados, dificultando análises precisas a respeito das ações dos APs sobre a estrutura cerebral. Além disso, a comparação dos achados dos efeitos dos APs em nosso estudo com os achados de investigações anteriores é difícil de ser feita, uma vez que a grande maioria destes últimos também não foram homogêneos em termos de tipos e dosagem de medicações e duração de tratamento.

A maneira empregada para investigarmos o efeito longitudinal dos APs sobre a morfometria cerebral foi justamente dicotomizar a amostra de pacientes de acordo com a 
adesão ao tratamento durante o intervalo de seguimento. $\mathrm{O}$ achado de aumento de volume longitudinal em núcleos da base no grupo de pacientes aderentes não pode ser valorizado, já que a análise dessa região não se mostrou adequada no presente estudo, devido às diferenças observadas entre os aparelhos de RM nas medidas dessas regiões anatômicas.

Não foram encontradas outras áreas mostrando diferença longitudinal de volume significativa entre os dois grupos (aderentes e não aderentes), sugerindo que os APs não exerceram influência direta sobre a preservação da substância cinzenta nos pacientes ao longo do tempo de seguimento. Além disso, a comparação entre pacientes aderentes expostos a APs típicos versus atípicos, apesar de limitada pelo número reduzido de sujeitos avaliados nesta comparação, também não indicou um padrão de preservação ou redução de substância cinzenta específico para determinada classe de AP.

\subsection{Uso de substâncias psicoativas}

Conforme discutido por Steen et al., (2006), fatores ambientais como a exposição ao álcool ou outras drogas de abuso podem confundir os resultados dos estudos de neuroimagem longitudinais em psicose. De fato, a maioria desses estudos exclui pacientes com critérios de abuso ou dependência de substância ou não avalia seus efeitos (Vita et al., 2005). Conforme discutido anteriormente nesta tese (itens 3.1.2 e 4.1.2.2), a presença dessa comorbidade não foi critério de exclusão de nosso estudo e os resultados das análises de neuroimagem mostraram que a exposição às substâncias psicoativas não teve efeito sobre o comportamento longitudinal do volume de substância cinzenta em nossa amostra. A diferença entre as análises feitas com e sem a presença de sujeitos com essa comorbidade refletiu-se apenas em mudanças na significância estatística dos mapas (o que pode ser reflexo da redução de número de sujeitos avaliados quando conduzimos a segunda comparação) e não em mudança de padrão de achados de alteração morfométrica propriamente ditos. 


\subsection{Variabilidade do tempo de psicose}

Os estudos a respeito da progressão das anormalidades cerebrais em esquizofrenia sugerem que essa progressão ocorre, principalmente, no início do quadro psicótico, e de fato a maioria dos estudos longitudinais objetiva investigar os pacientes nos períodos iniciais da doença (MacGlashan, 2006). No entanto, como diversos fatores influenciam o tempo entre o surgimento dos sintomas psicóticos e a procura por tratamento, é comum que nos estudos de primeiro episódio haja sujeitos cujos sintomas começaram há dias e outros que apresentam sintomas há alguns anos. Com o propósito de investigar especificamente os pacientes que, teoricamente, teriam risco maior de evoluir com progressão de reduções volumétricas, conduzimos uma análise entre pacientes e controles excluindo os pacientes que tivessem tempo de psicose maior do que um ano à época em que foram submetidos ao exame de RM pela primeira vez.

O resultado dessa análise demonstrou a presença do mesmo padrão de preservação de regiões temporais (GTS esquerdo e hipocampo direito) nos pacientes em relação aos controles, ou seja, não identificamos risco maior de redução de substância cinzenta nesses pacientes. Este padrão de resultados reforça a conclusão do nosso estudo de que não há progressão de reduções volumétricas nos períodos iniciais da esquizofrenia.

\subsubsection{Considerações a respeito do período de instalação e progressão de alterações estruturais em esquizofrenia}

\subsection{Estudos de alto risco e ultra alto risco}

A presença de reduções volumétricas cerebrais ao primeiro episódio psicótico e a não progressão longitudinal encontradas em nosso estudo são compatíveis com um modelo de patologia em que as alterações estruturais cerebrais na esquizofrenia instalam-se pouco antes 
do surgimento do quadro psicótico, evoluem durante a transição para a psicose, e não necessariamente progridem após a instalação desta. Este modelo tem recebido suporte da literatura de neuroimagem através de estudos de RM com amostras de voluntários em risco para esquizofrenia. Esses sujeitos em risco apresentariam, então, alterações anatômicas intermediárias entre controles e pacientes psicóticos.

A identificação de um estado de risco pode ser feita por razões genéticas, como no caso dos chamados sujeitos em alto risco (high-risk, HR), ou pela presença de sintomas sub-sindrômicos que atinjam critérios estabelecidos para que os sujeitos sejam considerados de ultra alto risco (ultra high-risk, UHR), ou seja, pessoas que estão em risco iminente de desenvolver um transtorno psicótico (Pantelis et al., 2005). O objetivo desses estudos é, entre outros, o de avaliar a volumetria cerebral dos sujeitos antes e depois da instalação de um quadro psicótico franco e investigar diferenças entre sujeitos em risco que desenvolvem psicose de fato e aqueles que permanecem assintomáticos, além de comparar os sujeitos em risco a amostras de pacientes já psicóticos.

Um desses estudos, do grupo de Melbourne, avaliou transversalmente uma grande amostra, comparando sujeitos UHR, pacientes em primeiro episódio psicótico e pacientes crônicos. Foi observado que, em relação aos controles, os pacientes crônicos tinham hipocampos menores bilateralmente, enquanto que os pacientes em primeiro episódio com esquizofrenia, mas não com transtorno esquizofreniforme, tinham hipocampo menor à esquerda; por fim, os sujeitos UHR tinham hipocampo e amígdala normais, independentemente do fato de tornarem-se psicóticos posteriormente ou não (Velakoulis et al., 2006).

Esses dados sugerem que algumas alterações ocorreriam mais perto da transição para a psicose do que o sugerido pelo modelo de neurodesenvolvimento tradicional. No entanto, a conclusão de que após a manifestação franca da doença ainda ocorreria maior redução hipocampal (inferida pelo achado de acometimento bilateral do hipocampo em crônicos e apenas unilateral no primeiro episódio) não está de acordo com nosso achado de não 
progressão hipocampal após o primeiro episódio psicótico. Deve-se observar, no entanto, que essa inferência a favor de redução progressiva de volume no estudo de Melbourne foi feita a partir de análise transversal entre os diferentes grupos, e não a partir de uma análise longitudinal (Velakoulis et al., 2006). Neste estudo, as diferenças entre os subgrupos não foram causadas por medicação, uma vez que a exposição a APs típicos ou a atípicos não alterou as medidas dos volumes avaliados (Velakoulis et al., 2006). Este estudo sugere que a redução de hipocampo não seja um marcador de vulnerabilidade de doença e nem preditor de evolução para psicose, e possivelmente seja o resultado de eventos não específicos, como complicações obstétricas (Wood et al., 2008).

Empregando um desenho de estudo longitudinal, Pantelis et al., (2003) avaliaram as mudanças estruturais num grupo de UHR durante a transição para a psicose. Os sujeitos que desenvolveram psicose, em relação aos que não desenvolveram, apresentavam, ao início, menor volume de hipocampo/giro parahipocampal e GTS, giro frontal e ínsula direitos e cíngulo bilateralmente. Longitudinalmente, ou seja, durante a transição para psicose, apresentaram, ainda, redução de cíngulo, giro parahipocampal e córtex pré-frontal (Pantelis et al., 2003; Sun et al., 2008). Além disso, o grau de redução pré-frontal estava associado à proximidade da transição (Sun et al., 2008). Os artigos desse grupo sugerem como possíveis causas dessas progressões durante a transição para a psicose o estresse (através da ação do cortisol) associado ao momento do início da psicose e um distúrbio do eixo hipotálamohipófise-adrenal, já que foi observado também um aumento da hipófise no grupo de UHR que evoluiu para psicose (Wood et al., 2008).

Outros estudos que avaliaram amostra de alto risco para esquizofrenia, conduzidos pelo grupo de Edimburgo, observaram que jovens em HR por motivos genéticos apresentam padrão de volumes cerebrais (mais especificamente do complexo amígdala-hipocampo) intermediário entre controles e pacientes em primeiro episódio e que reduções de volume são maiores nos jovens com tendência a ter sintomas prévios. Além disso, uma redução de giro 
temporal inferior esquerdo parece ser específica dos sujeitos que vão desenvolver esquizofrenia (Lawrie et al., 2001 e 2002; Job et al., 2003; Job et al., 2005).

Corroborando a hipótese de que alterações estruturais estão presentes e evoluem antes do início do quadro psicótico, Borgwardt et al., (2007a e 2007b) do grupo da Basiléia, identificaram que, transversalmente, sujeitos em HR apresentavam volumes maiores do que pacientes em primeiro episódio em córtex temporal e que as alterações estavam presentes mesmo quando eram excluídos os sujeitos com uso de APs. Os sujeitos de HR que evoluíram para psicose tinham redução de ínsula, GTS e região pré-frontal em relação aos que não evoluíram, resultado similar ao encontrado no estudo de Pantelis et al. (2003).

Complementando esses estudos de alto risco, Lappin et al. (2007) demonstaram que o tempo de pródromo correlacionou-se inversamente com o volume de substância cinzenta ao exame de RM ao primeiro contato em pacientes com psicoses funcionais em cíngulo e giro frontal medial bilateralmente e ínsula esquerda, estendendo-se para o giro frontal inferior esquerdo. Ou seja, ocorreria progressão de alterações cerebrais antes do primeiro episódio psicótico. É discutido nesse artigo que as alterações não são simplesmente lineares, caso contrário o volume cerebral chegaria a zero em algum momento.

\subsection{Integração entre resultados de neuroimagem ao primeiro episódio e ao seguimento}

Em revisão sobre os modelos fisiopatológicos da esquizofrenia, Keshavan (1999) discorre sobre a evolução destes e suas bases biológicas. O modelo inicial de esquizofrenia como patologia do neurodesenvolvimento (Murray e Lewis, 1987; Weinberger, 1987) postulava a presença de alterações de estrutura cerebral não progressivas, originadas durante o período pré ou perinatal, que ao interagirem com os processos normais de maturação cerebral posteriores levariam ao surgimento do fenótipo da esquizofrenia. 
Feinberg sugeriu um modelo de neurodesenvolvimento tardio, em que o a patologia cerebral na esquizofrenia teria origem no período da peri-adolescência, como conseqüência de alterações no processo fisiológico de eliminação sináptica. A eclosão do quadro psicótico franco dar-se-ia no momento em que o limiar de perda sináptica fosse ultrapassado, comumente no período da adolescência (Feinberg, 1982/1983; Keshavan et al., 1994b). Esse modelo recebe suporte de estudos que indicam que, em esquizofrenia, erros na poda sináptica em córtex pré-frontal levariam ao envio de terminais glutamatérgicos anômalos para o lobo temporal (Deakin e Simpson, 1997). O acometimento dos terminais sinápticos, e não de perda de neurônios em si, está de acordo com os achados de neuropatologia em esquizofrenia, que sugerem redução de neurópila neste transtorno (Harrison et al., 1999; Selemon et al., 1995 e 1999b), embora o modelo da poda sináptica excessiva não explique o acometimento heterogêneo observado nas diferentes camadas celulares dentro de uma mesma região cortical (Selemon, 2001). É digno de nota que a redução da neurópila ocorreria principalmente em córtex pré-frontal dorsolateral, e também em hipocampo e em córtex temporal superior (Selemon, 2001), as mesmas áreas apontadas como alteradas na amostra do nosso estudo.

A poda sináptica excessiva (assim como uma possível apoptose celular excessiva) pode ser predisposta por fatores genéticos, que tornam esses processos maturacionais alterados na esquizofrenia. Outros fatores, como alterações hormonais, fatores ambientais ou estresse também podem afetar a neuroplasticidade e a mielinização (Cannon et al.,2003).

Keshavan et al. (1999) e Lieberman et al. (1999) entre outros autores, discutem a hipótese de um modelo integrativo na fisiopatologia da esquizofrenia, que implica na presença de associação de alterações de neurodesenvolvimento precoce e tardio e alterações degenerativas que ocorreriam após a instalação do quadro psicótico.

Segundo esses autores, a presença de processos degenerativos adquiridos após o início da psicose é sugerida pela evidência de progressão clínica e reagudização dos sintomas 
e por estudos que correlacionam a piora do prognóstico à falta de tratamento (de onde advém a suposição de um efeito “tóxico” da psicose sobre o cérebro). Esse efeito seria causado por uma toxicidade glutamatérgica via estresse oxidativo, secundária a um excesso de transmissão dopaminérgica fásica (este, por sua vez, seria secundário a uma hipofunção glutamatérgica inicial).

Os estudos longitudinais de neuroimagem constituem o método mais direto pelo qual se pode investigar a característica temporal das alterações cerebrais em esquizofrenia, isto é, se há progressão dessas alterações ou se elas são fixas. Embora a literatura a respeito dos achados de neuroimagem em primeiro episódio psicótico seja consistente, os estudos de RM longitudinal nessa área apresentam resultados diversos (conforme Tabela 2, na Introdução) e ainda não há uma conclusão definitiva a respeito da presença ou não de progressão de alterações estruturais em psicose. Esses estudos também não proporcionaram, ainda, conclusões a respeito do efeito dos antipsicóticos sobre a estrutura cerebral.

De acordo com a literatura e com as hipóteses de neurodesenvolvimento em esquizofrenia, encontramos um padrão difuso de reduções volumétricas de substância cinzenta em áreas neocorticais e límbicas em pacientes em estágio inicial da doença, em relação aos controles assintomáticos (Shenton et al., 2001; Steen et al., 2006; Honea et al., 2005). Esse achado sugere que essas alterações não são efeitos da cronicidade da doença ou da exposição crônica a antipsicóticos. Tais resultados sugerem, também, que alterações volumétricas estão presentes em esquizofrenia independentemente do ambiente de origem (uma vez que a imensa maioria dos estudos foi conduzida em países desenvolvidos) e podem ser observadas mesmo quando avaliados pacientes oriundos da comunidade geral (amostra social e clinicamente heterogênea) comparados a controles também de origem epidemiológica, diferentemente dos grupos comumente empregados em estudos de neuroimagem prévios.

O outro achado principal do nosso estudo foi a não progressão dessas alterações iniciais encontradas nos pacientes e um padrão de preservação longitudinal de algumas dessas 
áreas em relação ao grupo controle (o qual serviu como modelo de envelhecimento normal durante o período avaliado).

Como o período avaliado foi curto (16 meses em média), a ausência de alterações longitudinais nos controles foi esperada. A não redução volumétrica em pacientes em relação aos controles e a ausência de correlação entre tempo de doença (e de duração da psicose não tratada) e volume de substância cinzenta vão contra o modelo de degeneração em estágios iniciais da esquizofrenia. No entanto, não podemos afirmar se as lesões serão estáticas, uma vez que nossos achados sugerem que algumas áreas de redução podem passar a ter um padrão de preservação, diferente do esperado. A natureza desse processo e os fatores causais não são explicáveis por este estudo, mas não parece ter havido um efeito direto das medicações antipsicóticas ou do estado sintomatológico.

Não é possível descartar a hipótese de que esse grupo de pacientes evolua com redução volumétrica em períodos posteriores, e que seja necessário um seguimento mais longo e seriado para detectarmos a presença de diferenças entre os grupos.

Nosso estudo não permite identificar qual foi o período exato em que as alterações volumétricas instalaram-se e se houve ou não períodos de progressão dessas mudanças antes do primeiro episódio psicótico. Conforme discutido num artigo de revisão recente (Pantelis et al, 2005), talvez a maior parte da progressão já tenha ocorrido no período imediatamente anterior ao início da psicose, ou seja, pode ter havido alterações dinâmicas antes da eclosão da psicose propriamente dita, mas este período prodrômico não foi avaliado em nosso estudo.

Deve-se ressaltar que os achados deste estudo fornecem informação sobre o volume do compartimento de substância cinzenta, mas não é possível, através da técnica de RM morfométrica, obter informação sobre a natureza das alterações em níveis mais específicos. Portanto, os resultados não nos informam sobre a etiologia ou a natureza da lesão ou quais estruturas são responsáveis pela perda do volume (neurônios, glia, sinapses, mielina), nem tampouco fornecem informação sobre o funcionamento das regiões afetadas. 


\subsection{CONSIDERAÇõES METODOLÓGICAS}

Entre as limitações do presente estudo, deve-se citar o fato de que algumas regiões cerebrais, como o tálamo e os núcleos da base, tiveram que ser excluídas das análises estatísticas devido a CCIs não satisfatórios entre os dois aparelhos de RM utilizados. Além disso, é importante mencionar o fato que o estudo não permitiu a investigação adequada dos efeitos dos tipos de antipsicóticos sobre a morfometria cerebral dos pacientes com esquizofrenia.

Por outro lado, é importante também destacar algumas características vantajosas do desenho experimental aqui utilizado, em comparação com estudos anteriores nesta área de investigação. O emprego de uma amostra recrutada a partir de um estudo epidemiológico permitiu avaliar pacientes e controles mais representativos da comunidade geral e com menor risco de viés de seleção. Nosso estudo de RM longitudinal em esquizofrenia foi o primeiro a empregar este tipo de amostra, e o primeiro conduzido em um país em desenvolvimento. O tamanho da amostra foi compatível com as utilizadas nos principais estudos de RM em primeiro episódio psicótico e de seguimento conduzidos até hoje. Outra vantagem foi o emprego do método de VBM, que permitiu a investigação da substância cinzenta regional em todo o cérebro, ao invés de se investigar poucas regiões de volumes grandes e pré-definidos com bordas arbitrárias. 
1- Pacientes em primeiro episódio psicótico, portadores de esquizofrenia e transtorno esquizofreniforme, apresentam reduções regionais de substância cinzenta, quando comparados a controles não psicóticos. As áreas implicadas são compatíveis com as regiões cerebrais descritas na literatura de neuroimagem estrutural como afetadas pelo processo patológico da esquizofrenia. As alterações descritas em primeiro episódio psicótico não são provocadas pelos efeitos da exposição a antipsicóticos ou a álcool e drogas e são independentes do período de psicose não tratada. Tais achados dão suporte à hipótese de que os déficits morfométricos na esquizofrenia sejam provocados por alterações de neurodesenvolvimento. No entanto, os achados de nosso estudo não permitem identificar se houve alterações de neurodesenvolvimento precoce, tardio ou uma associação de ambos, uma vez que não foi possível avaliar os sujeitos em períodos prodrômicos. 
2- Durante o período posterior ao primeiro episódio psicótico (16 meses em média), não há progressão das reduções volumétricas observadas ao primeiro episódio psicótico, ocorrendo, ao contrário, maior grau de preservação de volume de substância cinzenta nos pacientes do que controles não psicóticos em algumas das regiões inicialmente afetadas (córtex temporal superior esquerdo e hipocampo direito). Esse achado contraria a hipótese de ação de processos neurodegenerativos nos estágios iniciais da esquizofrenia. A exposição aos antipsicóticos não exerce efeito sobre os padrões volumétricos longitudinais da substância cinzenta. 
ABIPEME (Associação Brasileira do Instituto de Pesquisa de Mercado). Questionário sócioeconômico dos XXXI Estudos Marplan. Brasil.1989.

Addington J, Chaves A, Addington D. Diagnostic stability over one year in first-episode psychosis. Schizophr Res. 2006; 86(1-3): 71-5.

Addington J, Addington D. Patterns, predictors and impact of substance use in early psychosis: a longitudinal study. Acta Psychiatr Scand. 2007; 105(4): 304-9.

Addington J, Penn D, Woods SW, Addington D, Perkins DO. Social functioning in individuals at clinical high risk for psychosis. Schizophr Res. 2008; 99(1-3): 119-24.

American Psychiatry Association. Diagnostic and Statistical Manual of Mental Disorders, 4th ed (DSM-IV). Washington DC: APA. 1994.

American Psychiatry Association. Diagnostic and Statistical Manual of Mental Disorders, $4^{\text {th }}$ ed, Text Revision (DSM-IV-TR). Washington DC: APA. 2000.

Andreasen NC, Carpenter WT Jr. Diagnosis and classification of schizophrenia. Schizophr Bull. 1993; 19(2): 199-214.

Andreasen NC, O’Leary DS, Cizadlo T, Arndt S, Rezai K, Ponto LL, Watkins GL, Hichwa RD. Schizophrenia and cognitive dysmetria: a positron-emission tomography study of dysfunctional prefrontal-thalamic-cerebellar circuitry. Proc Natl Acad Sci USA. 1996; 93(18): 9985-90. 
Annett M. A classification of hand preference by association analysis. Br J Psychol. 1970; 61(3):303-21.

Ashburner J, Friston KJ. Voxel-based morphometry - the methods. Neuroimage. 2000; 11(6 Pt 1): 805-21.

Bachmann S, Bottmer C, Pantel J, Schroder J, Amann M, Essig M, Schad LR. MRImorphometric changes in first-episode schizophrenic patients at 14 months follow-up. Schizophr Res. 2004; 67(2-3): 301-3.

Bai O, Chlan-Fourney J, Bowen R, Keegan D, Li XM. Expression of brain-derived neurotrophic factor mRNA in rat hippocampus after treatment with antipsychotic drugs. $J$ Neurosci Res. 2003; 71(1): 127-31.

Barta PE, Pearlson GD, Powers RE, Richards SS, Tune LE. Auditory hallucinations and smaller superior temporal gyral volume in schizophrenia. Am J Psychiatry. 1990; 147(11); 1457-62.

Bebbington, P.E., Nayani, T. The Psychosis Screening Questionnaire. Int J Methods Psychiatr Res. 1995; 5: 11-9.

Becker T, Elmer K, Schneider F, Schneider M, Grodd W, Bartels M, Heckers S, Beckmann $\mathrm{H}$. Confirmation of reduced temporolimbic structure volume on magnetic resonance imaging in male patients with schizophrenia. Psychiatry Res. 1996; 67(2): 135-43.

Benes F. Evidence for altered trisynaptic circuitry in schizophrenic hippocampus. Biol Psychiatry. 1999; 46(5): 589-99.

Bleuler E. Dementia praecox or the group of schizophrenias. New York: International Universities Press; 1950.

Bogerts B. The neuropathology of schizophrenic diseases: historical aspects and present knowledge. Eur Arch Psychiatry Clin Neurosci. 1999; 249 (suppl 4): 2-13.

Borgwardt SJ, McGuire PK, Aston J, Berger G, Dazzan P, Gschwandtner U, Pflüger M, D'Souza M, Radue E, Riecher-Rössler A. Structural brain abnormalities in individuals with an at-risk mental state who later develop psychosis. Br J Psychiatry. 2007a; 191 (51): s69-75.

Borgwardt SJ, Riecher-Rösler A, Dazzan P. Regional gray matter volume abnormalities in the at risk mental state. Biol Psychiatry. 2007b; 61(10): 1148-56.

Bucley PF. The clinical stigmata of aberrant neurodevelopment in schizophrenia. J Nerv Ment Dis. 1998; 186(2): 79-86.

Bullmore ET, Woodruff PW, Wright IC, Rabe-Hesketh S, Howard RJ, Shuriquie N, Murray RM. Does dysplasia cause anatomical dysconnectivity in schizophrenia? Schizophr Res. 1998; 30(2):127-35. 
Cahn W, Hulshoff Pol HE, Bongers M, Schnack HG, Mandl RC, Van Haren NE, Durston S, Koning H, Van Der Linden JA, Kahn RS. Brain morphology in antipsychotic-naive schizophrenia: a study of multiple brain structures. Br J Psychiatry Suppl. 2002; 43:s66-72.

Cannon TD, van Erp TG, Bearden CE, Lowey R, Thompson P, Toga AW, Huttunen MO, Keshavan MS, Seidman LJ, Tsuang MT. Early and late neurodevelopmental influences in the prodrome to schizophrenia: contributions of genes, environment, and their interactions. Schizophr Bull. 2003; 29(4): 653-69.

Chakos MH, Lieberman JA, Bilder RM, Borestein M, Lerner G, Bogerts B, Wu H, Kinon B, Ashtari M. Increased in caudate nuclei of first-episode schizophrenic patients taking antipsychotic drugs. Am J Psychiatry. 1994; 151(10): 1430-36.

Chakos MH, Lieberman JA, Alvir J, Bilder R, Ashtari M. Caudate nuclei volumes in schizophrenic patients treated with typical antipsychotics or clozapine. Lancet. 1995; 345(8947): 456-7.

Chakos MH, Schobel SA, Gu H, Gerig G, Bradford D, Charles C, Lieberman JA. Duration of illness and treatment effects on hippocampal volume in males patients with schizophrenia. Brit J Psychiatry. 2005; 186: 26-31.

Chlan-Fourney J, Ashe P, Nylen K, Juorio AV, Li XM. Differetnial regulation of hipocampal BDNF mRNA by typical and atypical antipsychotic administration. Brain Res. 2002; 954(1): 11-20.

Chua P, Krams M, Toni I, Passingham R, Dolan R. A functional anatomy of anticipatory anxiety. NeuroImage. 1999; 9(6): 563-71.

Cooper D, Moisan J, Grégoire J. Adherence to atypical antipsychotic treatment among newly treated patients : a population-based study in schizophrenia. J Clin Psychiatry. 2007; 68(6): 818-25.

Copolov D, Velakoulis D, McGorry P, Mallard C, Yung A, Rees S, Jackson G, Rehn A, Brewer W, Pantelis C. Neurobiological findings in early phase schizophrenia. Brain Res Rev. 2000; 31(2-3): 157-65.

Corson PW, Nopoulos P, Miller DD, Arndt S, Andreasen NC. Change in basal ganglia volume over 2 years in patients with schizophrenia: typical versus atypical neuroleptics. Am J Psychiatry. 1999; 156(8): 1200-4.

Crespo-Facorro B, Kim J, Andreasen NC, O’Leary DS, Bockholt HJ, Magnotta V. Insular cortex abnormalities in schizophrenia: a structural magnetic resonance imaging study of firstepisode patients. Schizophr Res. 2000; 46(1):35-43. 
Dazzan P, Morgan KD, Orr K, Hutchinson G, Chitnis X, Suckling J, Fearon P, McGuire PK, Mallett RM, Jones PB, Leff J, Murray RM. Different effects of typical and atypical antipsychotics on grey matter in first episode psychosis: the AESOP Study. Neuropsychopharmacology. 2005; 30(4): 765-74.

Deakin JF, Simpson MD. A two-process theory of schizophrenia: evidence from studies in post-mortem brain. J Psychiat Res. 1997; 31(2): 277-95.

Degreef G, Bogerts B, Falkai P, Greve B, Lantos G, Ashtari M, Lieberman J. Increased prevalence of the cavum septum pellucidum in magnetic resonance scans and post-mortem brains of schizophrenic patients. Psychiatry Res. 1992. 45(1): 1-13.

DeLisi LE, Hoff AL, Schwartz JE, Shields GW, Halthore SN, Gupta SM, Henn FA, Anand AK. Brain morphology in first-episode schizophrenic-like psychotic patients: a quantitative magnetic resonance imaging study. Biol Psychiatry. 1991; 29(2): 159-75.

DeLisi LE, Sakuma M, Tew W, Kushner M, Hoff AL, Grimson R. Schizophrenia as a chronic active brain process: a study of progressive brain structural change subsequent to the onset of schizophrenia. Psychiatry Res. 1997a; 74(3): 129-40.

DeLisi LE. Is schizophrenia a lifetime disorder of brain plasticity, growth and aging? Schizophr Res. 1997b; 23(2): 119-29.

DeLisi LE, Sakuma M, Maurizio AM, Relja M, Hoff AL. Cerebral ventricular change over the first 10 years after the onset of schizophrenia. Psychiatry Res. 2004; 130(1): 57-70.

DeLisi LE, Hoff AL. Failure to find progressive temporal lobe volume decreases 10 years subsequent to a first episode of schizophrenia. Psychiatry Res. 2005; 138(3):265-8.

DeLisi LE. The concept of progressive brain change in schizophrenia: implications for understanding schizophrenia. Schizophr Bull. 2008; 34(2): 312-21.

Dickey CC, Salisbury DF, Nagy AI, Hirayasu Y, Lee CU, McCarley RW, Shenton ME. Follow-up MRI study of prefrontal volumes in first-episode psychotic patients. Schizophr Res. 2004; 71(2-3): 349-51.

Diwadkar VA, Keshavan MS. Newer techniques in magnetic resonance imaging and their potential for neuropsychiatry research. J Psychosom Res. 2002; 53(2): 677-85.

Dorph-Petersen KA, Pierri JN, Perel J, Sun Z, Sampson AR, Lewis DA. The influence of chronic exposure to antipsychotic medications on brain size before and after tissue fixation: a comparison of haloperidol and olanzapine in macaque monkeys. Neuropsychopharmacology. 2005; 30(9): 1649-61.

Elkis H, Friedman L, Wise A, Meltzer HY. Meta-analyses of studies of ventricular enlargement and cortical sulcal prominence in mood disorders. Comparisons with controls or patients with schizophrenia. Arch Gen Psychiatry. 1995; 52(9):735-46. 
Fannon D, Chitnis X, Doku V, Tennakoon L, O’Ceallaigh S, Soni W, Sumich A, Lowe J, Santamaria M, Sharma T. Features of structural brain abnormality detected in firs-episode psychosis. Am J Psychiatry. 2000; 157(11): 1829-34.

Feinberg I. Schizophrenia: caused by a fault in programmed synaptic elimination during adolescence? J Psychiatry Res. 1982-1983; 17(4): 319-34.

First MB, Spitzer RL, Gibbon M, Williams JBW. Structured Clinical Interview for DSMIVAxis I Disorders - Patient Edition (SCID-I/P). 1995. New York State Psychiatry Institute, New York.

Flaum M, O’Leary DS, Swayze VW 2 ${ }^{\text {nd }}$, Miller DD, Arndt S, Andreasen NC. Symptom dimension and brain morphology in schizophrenia and related psychotic disorders. J Psychiatr Res. 1995; 29(4): 261-76.

Friston KJ, Liddle PF, Frith CD, Hirsch SR, Frackowiak RS. The left medial temporal region and schizophrenia. A PET study. Brain. 1992; 115 (Pt 2): 367-82.

Friston KJ, Frith CD. Schizophrenia: a disconnection syndrome? Clin Neurosci. 1995; 3(2): 89-97.

Garver DL, Holcomb JA, Christensen JD. Cerebral cortical gray expansion associated with two-second generation antipsychotic. Biol Psychiatry. 2005; 58 (1): 62-6.

Geddes JR, Lawrie SM. Obstetric complications and schizophrenia: a meta-analysis. Br J Psychiatry. 1995; 167(6): 786-93.

Glantz LA, Gilmore JH, Lieberman JA, Jarskoq LF. Apoptotic mechanisms and the synaptic pathology of schizophrenia. Schizophr Res. 2006; 81(1): 47-63.

Good CD, Johnsrude IS, Ashburner J, Henson RN, Friston KJ, Frackowiak RS. A voxelbased morphometric study of ageing in 465 normal adult human brains. Neuroimage. 2001; 14(1 Pt 1):21-36.

Greenstein D, Lerch J, Shaw P, Clasen L, Giedd J, Gochman P, Rapoport J, Gogtay N. Childhood onset schizophrenia: cortical brain abnormalities as young adults. JChild Psychol Psychiatry. 2006; 47(10): 1003-12.

Gur RE, Cowell P, Turetsky BI, Gallacher F, Cannon T, Bilker W, Gur RC. A follow-up magnetic resonance imaging study of schizophrenia. Relationship of neuroanatomical changes to clinical and neurobehavioral measures. Arch Gen Psychiatry. 1998; 55(2):145-52.

Gur RE, Turetsky BI, Bilker WB, Gur RC. Reduced gray matter volume in schizophrenia. Arch Gen Psychiatry. 1999; 56(10):905-11.

Gur RE, Turestsky BI, Cowell PE, Finkelman C, Grossman RI, Arnold SE, Bilker WB, Gur, RC. Temporolimbic volume reductions in schizophrenia. Arch Gen Psychiatry. 2000; 57(8): 769-75. 
Gur RE, Keshavan MS, Lawrie SM. Deconstructing psychosis with human brain imaging. Schizophr Bull. 2007; 33(4): 921-31.

Harrigan SM, McGorry PD, Krstev H. Does treatment delay in first-episode psychosis really matter? Psychol Med. 2003; 33(1): 97-110.

Harrison PJ. The neuropathology of schizophrenia. A critical review of the data and their interpretation. Brain 1999; 122 (Pt 4): 593-624.

Harrison PJ, Weinberger DR. Schizophrenia genes, gene expression and neuropathology: on the matter of their convergence. Mol Psychiatry. 2005; 10(1): 40-68.

Heckers S. The hippocampus and schizophrenia. Search for the causes of schizophrenia, vol V. WF Gattaz e H Hafner (Editores). Steinkopff Verlag Darmstadt, Alemanha; 2004.

Hegarty JD, Baldessarini RJ, Tohen M, Waternaux C, Oepen G. One hundred years of schizophrenia: a meta-analysis of the outcome literature. Am J Psychiatry. 1994; 151(10):1409-16.

Hietala J, Cannon TD, Syvälahti E, Vilkman H, Laakso A, Vahlberg T, Alakare B, Räkköläinen V, Salokangas RK. Regional brain morphology and duration of illness in never-medicated first-episode patients with schizophrenia. Schizophr Res. 2003; 64(1): 79-81.

Hirayasu Y, Shenton ME, Salisbury DF, Dickey CC, Fischer IA, Mazzoni P, Kisler T, Arakaki H, Kwon JS, Anderson JE, Yurgelun-Todd D, Tohen M, McCarley RW. Lower left temporal lobe MRI volumes in patients with first-episode schizophrenia compared with psychotic patients with first-episode affective disorder and normal subjects. Am J Psychiatry. 1998; 155(10):1384-91.

Ho BC, Andreasen NC, Nopoulos P, Arndt S, Magnotta V, Flaum M. Progressive structural brain abnormalities and their relationship to clinical outcome: a longitudinal magnetic resonance imaging study early in schizophrenia. Arch Gen Psychiatry. 2003; 60(6):585-94.

Honea R, Crow TJ, Passingham D, Mackay CE. Regional deficits in brain volume in schizophrenia: a meta-analysis of voxel-based morphometry studies. Am J Psychiatry. 2005; 162(12):2233-45.

Hulshoff $\mathrm{PH}$, Kahn RS. What happens after the first episode? A review of progressive brain changes in chronically ill patients with schizophrenia. Schizophr Bull. 2008; 34(2): 354-66.

Ichimiya T, Okubo Y, Suhara T, Sudo Y. Reduced volume of the cerebellar vermis in neurolepticnaive schizophrenia. Biol Psychiatry. 2001; 49(1):20-7.

Illowsky BP, Juliano DM, Bigelow LB, Weinberger DR. Stability of CT scan findings in schizophrenia: results of an 8 year follow-up study. J Neurol Neurosurg Psychiatry. 1988; 51(2): 209-13. 
Jacobsen LK, Giedd JN, Castellanos FX, Vaituzis AC, Hamburger SD, Kumra S, Lenane MC, Rapoport JL. Progressive reduction of temporal lobe structures in childhood-onset schizophrenia. Am J Psychiatry. 1998; 155(5): 678-85.

Jaskiw GE, Juliano DM, Goldberg TE, Hertzman M, Urol-Hamell E, Weinberger DR. Cerebral ventricular enlargement in schizophreniform disorder does not progress. A seven year followup study. Schizophr Res.1994; 14(1): 23-8.

Jayakumar PN, Venkatasubramanian G, Gangadhar BN, Janakiramaiah N, Keshavan MS. Optimized voxel-based morphometry of gray matter volume in first-episode, antipsychoticnaive schizophrenia. Prog Neuropsychopharmacol Biol Psychiatry. 2005; 29(4): 587-91.

Job DE, Whalley HC, McConnell S, Glabus M, Johnstone EC, Lawrie SM. Structural gray matter differences between first-episode schizophrenics and normal controls using voxelbased morphometry. Neuroimage. 2002; 17(2):880-9.

Job DE, Whalley HC, McConnell S, Glabus M, Johnstone EC, Lawrie SM. Voxel-based morphometry of grey matter densities in subjects at high risk of schizophrenia. Schizophr Res. 2003; 64 (1): 1-13.

Johnstone EC, Crow TJ, Frith CD, Husband J, Kreel L. Cerebral ventricular size and cognitive impairment in chronic schizophrenia. Lancet. 1976; 2(7992):924-6.

Jones P. The early origins of schizophrenia. Br Med Bull. 1987; 53(1): 135-55.

Kasai K, Iwanami A, Yamasue H, Kuroki N, Nakagome K, Fukuda M. Neuroanatomy and neurophysiology in schizophrenia. Neurosci Res. 2002; 43(2): 93-110.

Kasai K, Shenton ME, Salisbury DF, Hirayasu Y, Onitsuka T, Spencer MH, Yurgelun-Todd DA, Kikinis R, Jolesz FA, McCarley RW. Progressive decrease of left Heschl gyrus and planum temporale gray matter volume in first-episode schizophrenia: a longitudinal magnetic resonance imaging study. Arch Gen Psychiatry. 2003a; 60(8):766-75.

Kasai K, Shenton ME, Salisbury DF, Hirayasu Y, Lee CU, Ciszewski AA, Yurgelun-Todd D, Kikinis R, Jolesz FA, McCarley RW. Progressive decrease of left superior temporal gyrus gray matter volume in patients with first-episode schizophrenia. Am J Psychiatry. 2003b; 160(1):156-64.

Kasai K, McCarley RW, Salisbury DF, Onitsuka T, Demeo S, Yurgelun-Todd D, Kikinis R, Jolesz FA, Shenton ME. Cavum septi pellucidi in first-episode schizophrenia and first-episode affective psychosis: an MRI study. Schizophr Res. 2004; 71(1): 65-76.

Kay SR, Fiszbein A, Opler LA. The positive and negative syndrome scale (PANSS) for schizophrenia. Schizophr Bull. 1987; 13(2): 261-76.

Keshavan MS, Schooler NR. First-episode studies in schizophrenia: criteria and characterization. Schizophr Bull. 1992; 18(3):491-513. 
Keshavan MS, Bagwell WW, Haas GL, Sweeney JA, Schooler NR, Pettegrew JW. Changes in caudate volume with neuroleptic treatment. Lancet. 1994a; 344(8934):1434.

Keshavan MS, Anderson S, Pettegrew JW. Is schizophrenia due to excessive synaptic pruning in the prefrontal cortex? The Feinberg hypothesis revisited. J Psychiatr Res. 1994b; 28(3): 239-65.

Keshavan MS, Rosenberg D, Sweeney JA, Pettegrew JW. Decreased caudate volume in neuroleptic-naive psychotic patients. Am J Psychiatry. 1998a; 155(6):774-8

Keshavan MS, Haas GL, Kahn CE, Aguilar E, Dick EL, Schooler NR, Sweeney JA, Pettegrew JW. Superior temporal gyrus and the course of early schizophrenia: progressive, static, or reversible? J Psychiatr Res. 1998b; 32(3-4):161-7.

Keshavan MS. Development, disease and degeneration in schizophrenia: a unitary pathophysiological model. J Psychiatr Res. 1999; 33(6): 513-21.

Kim JJ, Crespo-Facorro B, Andreasen NC, O’Leary DS, Magnotta V, Nopoulos P. Morphology of the lateral superior temporal gyrus in neuroleptic naïve patients with schizophrenia: relationship to symptoms. Schizophr Res. 2003; 60(2-3): 173-81.

Konopaske GT, Dorph-Petersen KA, Pierri J, Wu Q, Sampson AR, Lewis DA. Effect of chronic exposure to antipsychotic medication on cell numbers in the parietal cortex of macaque monkeys. Neuropsychopharmacology. 2007; 32(6): 1216-23.

Konradi C, Heckers S. Antipsychotic drugs and neuroplasticity: insights into the treatment and neurobiology of schizophrenia. Biol Psychiatry. 2001; 50(10): 729-42.

Kraepelin E. Dementia praecox and paraphrenia. Textbook of Psychiatry. $8^{\text {th }}$ edition. George M. Robertson (Editor). Edimburgo: E \& S Livingstone; 1919.

Kubicki M, Shenton ME, Salisbury DF, Hirayasu Y, Kasai K, Kikinis R, Jolesz FA, McCarley RW. Voxel-based morphometric analysis of gray matter in first episode schizophrenia. Neuroimage. 2002; 17(4):1711-9.

Kwon JS, Shenton ME, Hirayasu Y, Salisbury DF, Fischer IA, Dickey CC, Yurgelun-Todd D, Tohen M, Kikinis R, Jolesz FA, McCarley RW. MRI study of cavum septi pellucidi in schizophrenia, affective disorder, and schizotypal personality disorder. Am J Psychiatry. 1998; 155(4): 509-15.

Lang DJ, Kopala LC, Vardorpe RA, Rui Q, Smith GN, Goghari VM, Lapointe JS, Honer WG. Reduced basal ganglia after switching to olanzapine in chronically treated patients with schizophrenia. Am J Psychiatry. 2004; 161(10): 1829-36.

Lappin JM, Dazzan P, Morgan K, Morgan C, Chitnis X, Suckling J, Fearon P, Jones PB, Leff J, Murray RM, McGuire PK. Duration of prodromal phase and severity of volumetric abnormalities in first-episode psychosis. Br J Psychiatry Suppl. 2007; 191(51): s123-27. 
Larsen TK, McGlashan TH, Johannessen JO, Vibe-Hansen L. First-episode schizophrenia: II. Premorbid patterns by gender. Schizophr Bull. 1996; 22(2): 257-69.

Lawrie SM, Abukmeil SS. Brain abnormality in schizophrenia. A systematic and quantitative review of volumetric magnetic resonance imaging studies. Br J Psychiatry. 1998; 172:110-20.

Lawrie SM, Whalley HC, Abukmeil SS, Kestelman JN, Donnelly L, Miller P, Best JJ, Owens DG, Johnstone EC. Brain structure, genetic liability, and psychotic symptoms in subjects at high risk of developing schizophrenia. Biol Psychiatry. 2001; 49(10):811-23.

Lawrie SM, Whalley HC, Abukmeil SS, Kestelman JN, Miller P, Best JJ, Owens DG Johnstone EC. Temporal lobe volume changes in people at high risk of schizophrenia with psychotic symptoms. Br J Psychiatry. 2002; 181: 138-43.

Levitan C, Ward PB, Catts SV. Superior temporal gyral volumes and laterality correlates of auditory hallucinations in schizophrenia. Biol Psychiatry. 1999; 46(7): 955-62.

Levitt JJ, McCarley RW, Nestor PG, Petrescu C, Donnino R, Hirayasu Y, Kikinis R, Jolesz FA, Shenton ME. Quantitative volumetric MRI study of the cerebellum and vermis in schizophrenia: clinical and cognitive correlates. Am J Psychiatry. 1999; 156(7):1105-7.

Lewis DA, Lieberman JA. Catching up on schizophrenia: natural history and neurobiology. Neuron. 2000; 28 (2): 325-34.

Lewis SW. Computerised tomography in schizophrenia 15 years on. Br J Psychiatry Suppl. 1990; (9): 16-24.

Lieberman JA. Is schizophrenia a neurodegenerative disorder? A clinical and neurobiological perspective. Biol Psychiatry. 1999; 46(6):729-39.

Lieberman JA, Chakos M, Wu H, Alvir J, Hoffman E, Robinson D, Bilder R. Longitudinal study of brain morphology in first episode schizophrenia. Biol Psychiatry. 2001; 49(6):487-99.

Lieberman JA, Tollefson GD, Charles C, Zipursky R, Sharma T, Kahn RS, Keefe RS, Green AI, Gur RE, McEvoy J, Perkins D, Hamer RM, Gu H, Tohen M, HGDH Study Group. Antipsychotic drug effects on brain morphology in firs-episode psychosis. Arch Gen Psychiatry. 2005; 62(4): 361-70.

Lim KO, Tew W, Kushner M, Chow K, Matsumoto B, DeLisi LE. Cortical gray matter volume deficit in patients with first-episode schizophrenia. Am J Psychiatry. 1996; 153(12):1548-53.

Lipska BK, Khaing ZZ, Weickert CS, Weinberger DR. BDNF mRNA expression in rat hippocampus and prefrontal cortex: effects of neonatal ventral hippocampal damage and antipsychotic drugs. Eur J Neurosci. 2001; 14(1): 135-44. 
Madsen AL, Karle A, Rubin P, Cortsen M, Andersen HS, Hemmingsen R. Progressive atrophy of the frontal lobes in first-episode schizophrenia: interaction with clinical course and neuroleptic treatment. Acta Psychiatr Scand. 1999; 100(5):367-74.

Makris N, Goldstein JM, Kennedy D, Hodge S, Caviness VS, Faraone SV, Tsuang MT, Seidman LJ. Decreased volume of left and total anterior insular lobule in schizophrenia. Schizophr Res. 2006; 83 (2-3): 155-71.

Marsh L, Suddath RL, Higgins N, Weinberger DR. Medial temporal lobe structures in schizophrenia: relationship of size to duration of illness. Schizophr Res. 1994; 11(3): 225-38.

Mathalon DH, Sullivan EV, Lim KO, Pfefferbaum A. Progressive brain volume changes and the clinical course of schizophrenia in men: a longitudinal magnetic resonance imaging study. Arch Gen Psychiatry. 2001; 58(2): 148-57.

McGlashan TH. Duration of untreated psychosis in first-episode schizophrenia: marker or determinant of course? Biol Psychiatry. 1999; 46(7):899-907.

McGlashan TH. Is active psychosis neurotoxic? Schizophr Bull. 2006; 32 (4): 609-13.

McGuire PK, Frith CD. Disordered functional connectivity in schizophrenia. Psychol Med. 1996.26(4): 663-7.

Milev P, Ho BC, Arndt S, Nopoulos P, Andreasen NC. Initial magnetic resonance imaging volumetric brain measurements and outcome in schizophrenia: a prospective longitudinal study with 5-year follow-up. Biol Psychiatry. 2003; 54(6): 608-15.

Molina V, Sanz J, Sarramea F, Benito C, Palomo T. Lower prefrontal gray matter volume in schizophrenia in chronic but not in first-episode schizophrenia patients. Psychiatry Res. 2004; 131(1): 45-56.

Molina V, Sanz J, Sarramea F, Benito C, Palomo T. Prefrontal atrophy in first episodes of schizophrenia associated with limbic metabolic hyperactivity. J Psychiatry Res. 2005a; 39(2): 117-27.

Molina V, Reige S, Sanz J, Palomo T, Benito C, Sanchez J, Sarramea F, Pascau J, Descu M. Increase in gray matter and decrease in white matter volumes in the cortex during treatment with atypical neuroleptics in schizophrenia. Schizophr Res. 2005b; 80(1): 61-70.

Molina V, Reig S, sanz J, Palomo T, Benito C, Sanchez J, Pascau J, Desco M. Changes in cortical volume with olanzapine in chronic schizophrenia. Pharmacopsychiatry. 2007; 40(4): 135-9.

Morgan KD, Dazzan P, Orr KG Hutchinson G, Chitnis X, Suckling J, Lythgoe D, Pollock SJ, Rossel S, Shapleske J, Fearon P, Morgan C, David A, McGuire PK, Jones PB, Leff J, Murray RM. Grey matter abnormalities in first-episode schizophrenia and affective psychosis. Brit J Psychiatry Suppl. 2007; 51: s111-6. 
Mueser KT e McGurk SR. Schizophrenia. Lancet. 2004; 363 (9426): 2063-72.

Murray RM, Lewis SW. Is schizophrenia a neurodevelopmental disorder? Br Med J (Clin Res Ed). 1987; 295(6600): 681-2.

Nair TR, Christensen JD, Kingsbury SJ, Kumar NG, Terry WM, Garver DL. Progression of cerebroventricular enlargement and the subtyping of schizophrenia. Psychiatry Res. 1997; 74(3): 141-50.

Nakamura M, Salisbury DF, Hirayasu Y, Bouis S, Pohl KM, Yoshida T, Koo MS, Shenton ME, McCarley RW. Neocortical gray matter volume in firs-episode schizophrenia and firsepisode affective psychosis: a cross-sectional and longitudinal MRI study. Biol Psychiatry. 2007; 62(7): 773-83.

Nasrallah HA, Olson SC, McCalley-Whitters M, Chapman S, Jacoby CG. Cerebral ventricular enlargement in schizophrenia. A preliminary follow-up study. Arch Gen Psychiatry. 1986; 43(2): 157-9.

Nelson MD, Saykin AJ, Flashman NL, Riordan HJ. Hippocampal volume reduction in schizophrenia as assessed by magnetic resonance imaging: a meta-analytic study. Arch Gen Psychiatry. 1998; 55(5): 433-40.

O’Daly OG, Frangou S, Chitnis X, Shergill. Brain structural changes in schizophrenia patients with persistent hallucinations. Psychiatry Res. 2007; 156 (1): 15-21.

O’Donnell P, Grace AA. Dysfunctions in multiple interrelated systems as the neurobiological bases of the schizophrenic symptom clusters. Schizophr Bull. 1998; 24(2): 267-83.

Okugawa G, Sedvall GC, Agartz I. Smaller cerebellar vermis but not hemisphere volumes in patients with chronic schizophrenia. Am J Psychiatry. 2003; 160(9):1614-7.

Pantelis C, Velakoulis D, McGorry PD, Wood SJ, Suckling J, Philips LJ, Yung AR, Bullmore ET, Brewer W, Soulsby B, Desmond P, McGuire PK. Neuroanatomical abnormalities before and after onset of psychosis: a cross-sectional and longitudinal MRI comparison. Lancet. 2003; 361: 281-8.

Pantelis C, Yucel M, Wood SJ, Velakoulis D, Sun D, Berger G, Stuart GW, Yung A, Phillips L, McGorry PD. Structural brain imaging evidence for multiple pathological processes at different stages of brain development in schizophrenia. Schizophr Bull. 2005; 31(3):672-96.

Pearlson GD, Marsh L. Structural brain imaging in schizophrenia: a selective review. Biol Psychiatry. 1999; 46(5):627-49.

Pillai A, Terry AV Jr., Mahadik SP. Differential effects of long-term treatment with typical and atypical antipsychotics on NGF and BDNF levels in rat striatum and hippocampus. Schizophr Res. 2006; 82(1): 95-106. 
Premkumar P, Kumari V, Corr PJJ, Sharma T. Frontal lobe volumes in schizophrenia: effects of stage and duration of illness. J Psychiatr Res. 2006; 40(7): 627-37.

Pressler M, Nopoulos P, Ho BC, Andreasen NC. Insular cortex abnormalities in schizophrenia: Relationship to symptoms and typical neuroleptic exposure. Biol Psychiatry. 2005; 57(4):394-8.

Price G, Cercignani M, Bagary MS, Barnes TR, Barker GJ, Joyce EM, Ron MA. A volumetric MRI and magnetization transfer imaging follow-up study of patients with first-episode schizophrenia. Schizophr Res. 2006; 87(1-3):100-8.

Puri BK, Hutton SB, Seed N, Oatridge A, Hajnal JV, Duncan L, Chapman MJ, Barnes TR, Bydder GM, Joyce EM. A serial longitudinal quantitative MRI study of cerebral changes in first-episode schizophrenia using image segmentation and subvoxel registration. Psychiatry Res. 2001; 106(2): 141-50.

Raz S, Raz N. Structural brain abnormalities in the major psychoses: a quantitative review of the evidence from computerized imaging. Psychol Bull .1990; 108(1):93-108.

Raz S. Structural cerebral pathology in schizophrenia: regional or diffuse? J Abnorm Psychol.1993; 102(3): 445-52.

Razi K, Greene KP, Sakuma M, Ge S, Kushner M, DeLisi LE. Reduction of the parahipocampal gyrus and the hippocampus in patients with chronic schizophrenia. $\mathrm{Br} J$ Psychiatry. 1999; 174: 512-9.

Sanfilipo M, Lafargue T, Rusinek H, Arena L, Loneragan C, Lautin A, Feiner D, Rotrosen J, Wolkin A. Volumetric measure of the frontal and temporal lobe regions in schizophrenia: relationship to negative symptoms. Arch Gen Psychiatry. 2000; 57(5): 471-80.

Saze T, Hirao K, Namiki C, Fukuyama H, Hayashi T, Murai T. Insular volume reduction in schizophrenia. Eur Arch Psychiatry Clin Neurosci. 2007; 257(8): 473-9.

Schaufelberger MS, Duran FL, Lappin JM, Scazufca M, Amaro E Jr., Leite CC, de Castro CC, Murray RM, McGuire PK, Menezes PR, Busatto GF. Grey matter abnormalities in Brazilians with first-episode psychosis. Br J Psychiatry Suppl. 2007; 51: s117-22.

Scherk H, Falkai P. Effects of antipsychotics on brain structure. Curr Opin Psychiatry. 2006; 19(2):145-50.

Schimmelmann BG, Conus P, Edwards J, McGorry PD, Lambert M. Diagnostic stability 18 months after treatment initiation for first-episode psychosis. J Clin Psychiatry. 2005; 66(10): 1239-46.

Schneider K. Clinical Psychopathology; traduzido por MW Hamilton, New York: Grune and Stratton; 1959. 
Selemon LD, Lidow MS, Goldman-Rackik PS. Increased volume and glial density in primate prefrontal cortex associated with chronic antipsychotic drug exposure. Biol Psychiatry. 1999a; 46(2): 161-72.

Selemon LD, Goldman-Rackik PS. The reduced neuropil hypothesis: a circuit based model of schizophrenia. Biol Psychiatry. 1999b; 45(1): 17-25.

Selemon LD. Regionally diverse cortical pathology in schizophrenia: clues to the etiology of the disease. Schizophr Bull. 2001; 27(3): 349-77.

Shapleske J, Rossell SL, Chitnis XA, Suckling J, Simmons A, Bullmore ET, Woodruff PW, David AS. A computational morphometric MRI study of schizophrenia: effects of hallucinations. Cereb Cortex. 2002; 12(12): 1331-41.

Shenton ME, Dickey CC, Frumin M, McCarley RW. A review of MRI findings in schizophrenia. Schizophr Res. 2001; 49(1-2):1-52.

Shiori T, Oshitani Y, Kato T, Murashita J, Hamakawa H, Inubushi T, Nagata T, Takahashi S. Prevalence of cavum septum pellucidum detected by MRI in patients with bipolar disorder, major depression and schizophrenia. Psychol Med. 1996; 26(2): 431-4.

Sponheim SR, Iacono WG, Beiser M. Stability of ventricular size after the onset of psychosis in schizophrenia. Psychiatry Res. 1991; 40(1): 21-9.

Sporn AL, Greenstein DK, Gogtay N, Jeffreis NO, Lenane M, Gochman P, Clasen LS, Blumenthal J, Giedd JN, Rapoport JL. Progressive brain volume loss during adolescence in childhood-onset schizophrenia. Am J Psychiatry. 2003; 160(12): 2181-9.

Steen RG, Mull C, McClure R, Hamer RM, Lieberman JA. Brain volume in first-episode schizophrenia: systematic review and meta-analysis of magnetic resonance imaging studies. Br J Psychiatry. 2006; 188: 510-8.

Suddath RL, Christison GW, Torrey EF, Casanova MF, Weinberger DR. Anatomical abnormalities in the brains of monozygotic twins discordant for schizophrenia. $N$ Engl J Med. 1990; 322(12):789-94.

Sun D, Phillips L, Velakoulis D, Yung A, McGorry PD, Wood SJ, van Erp TG, Thompson PM, Toga AW, Cannon TD, Pantelis C. Progressive brain structural changes mapped as psychosis develops in “at risk” individuals. Schizophr Res. 2008; IN PRESS.

Talairach J, Tournoux P. Co-planar stereotaxic atlas of the human brain. Thieme, New York. 1988.

Théberge J, Williamson KE, Aoyama N, Drost DJ, Manchanda R, Mala AK, Northcott S, Menon RS, Neufeld RW, Rajakumar N, Pavlosky W, Densmore M, Schaefer B, Williamson PC. Longitudinal grey matter and glutamatergic losses in firs-episode schizophrenia. $\mathrm{Br} J$ Psychiatry. 2007; 191: 325: 34. 
Tsuang MT, Stone WS, Faraone SV. Genes, environment and schizophrenia. Br J Psychiatry Suppl. 2001; 40:s18-24.

Turetsky B, Cowell PE, Gur RC, Grosman RI, Shtasel DL, Gur RE. Frontal and temporal lobe brain volumen in schizophrenia. Relationship to symptoms and clinical subtype. Arch Gen Psychiatry. 1995; 52(12): 1061-70.

van Haren NE, Hulshoff Pol HE, Schnack HG, Cahn W, Mandl RC, Collins DL, Evans AC, Kahn RS. Focal gray matter changes in schizophrenia across the course of the illness: a 5year follow-up study. Neuropsychopharmacology. 2007; 32(10):2057-66.

van Haren NE, Pol HE, Schnack HG, Cahn W, Brans R, Carati I, Rais M, Kahn RS. Progressive brain volume loss in schizophrenia over the course of the iones: evidence of maturational abnormalities in early adulthood. Biol Psychiatry. 2008; 63(1): 106-13.

Van Horn JD, McManus IC. Ventricular enlargement in schizophrenia. A meta-analysis of studies or the ventricular: brain ratio (VBR). Br J Psychiatry. 1992; 160: 687-97.

Velakoulis D, Pantelis C, McGorry PD, Dudgeon P, Brewer W, Cook M, Desmond P, Bridle N, Tierney P, Murrie V, Singh B, Copolov D. Hippocampal volume in first-episode psychoses and chronic schizophrenia: a high-resolution magnetic resonance imaging study. Arch Gen Psychiatry. 1999; 56(2):133-41.

Velakoulis D, Wood SJ, Smith DJ, Soulsby B, Brewer W, Leeton L, Desmond P, Suckling J, Bullmore ET, McGuire PK, Pantelis C. Increased duration of illness is associated with reduced volume in right medial temporal/anterior cingulated grey matter in patients with chronic schizophrenia. Schizophr Res. 2002; 57(1): 43-9.

Velakoulis D, Wood SJ, Wong MT, McGorry PD, Yung A, Philips L, Smith D, Brewer W, Proffitt T, Desmond P, Pantelis C. Hippocampal and amygdala volumes according to psychosis stage and diagnosis: a magnetic resonance imaging study of chronic schizophrenia, first-episode psychosis and ultra-high-risk individuals. Arch Gen Psychiatry. 2006; 63(2): 139-49.

Vita A, Sacchetti E, Valvassori G, Cazzulo CL. Brain morphology in schizophrenia: a 2 to 5 year CT scan follow-up study. Acta Psychiatry Scand. 1988; 78(5): 618-21.

Vita A, Giobbio GM, Dieci M, Garbarini M, Morganti C, Comazzi M, Invernizzi G. Stability of cerebral ventricular size from the appearance of the first psychotic symptoms to the later diagnosis of schizophrenia. Biol Psychiatry. 1994; 35(12): 960-2.

Vita A, De Peri L, Silenzi C, Dieci M. Brain morphology in first-episode schizophrenia: a meta-analysis of quantitative magnetic resonance imaging studies. Schizophr Res. 2006; 82(1):75-88.

Waddington JL, Lane A, Scully PJ, Larkin C, O’Callaghan E. Neurodevelopmental and neuroprogressive processes in schizophrenia. Antithetical or complementary, over a lifetime trajectory of disease? Psychiatr Clin North Am. 1998; 21(1):123-49. 
Weinberger DR. Implications of normal brain development for the pathogenesis of schizophrenia. Arch Gen Psychiatry. 1987; 44(7):660-9.

Whitworth AB, Kemmler G, Honeder M, Kremser C, Felber S, Hausmann A, Walch T, Wanko C, Weiss EM, Stuppaeck CH, Fleischhacker WW. Longitudinal volumetric MRI study in first- and multiple-episode male schizophrenia patients. Psychiatry Res. 2005; 140(3):225-37.

WHO - The ICD-10 Classification of Mental and Behavioural Disorders. World Health Organization. 1992.

Wood SJ, Velakoulis D, Smith DJ, Bond D, Stuart GW, McGorry PD, Brewer WJ, Bridle N, Eritaia J, Desmond P, Singh B, Copolov D, Pantelis C. A longitudinal study of hippocampal volume in first episode psychosis and chronic schizophrenia. Schizophr Res. 2001; 52(12):37-46.

Wood SJ, Pantelis C, Velakoulis D, Yücel M, Fornito A, McGorry P. Progressive changes in the development toward schizophrenia : studies in subjects at increased symptomatic risk. Schizophr Bull. 2008; 34(2): 322-9.

Woods BT. Is schizophrenia a progressive neurodevelopmental disorder? Toward a unitary pathogenetic mechanism. Am J Psychiatry. 1998; 155(12):1661-70.

Wright IC, Rabe-Hesketh S, Woodruff PW, David AS, Murray RM, Bullmore ET. Metaanalysis of regional brain volumes in schizophrenia. Am J Psychiatry. 2000; 157(1):16-25.

Zipursky RB, Christenses BK, Mikulis DJ. Stable deficits in grey matter volumes following a first episode of schizophrenia. Schizophr Res. 2004; 71(2-3): 515-6. 